John Frederick Henderson, B.Sc.

\begin{abstract}
A thesis submitted to the Faculty of Graduate Studies and Research of McGill University in partial fulfilment of the requirements for the Degree of Doctor of Philosophy
\end{abstract}

From the Physical Chemistry Laboratory under the supervision of Dr. C.A. Winkler.

McGill University,

Montreal, Canada.

April, 1958. 


\section{ACKNOWLEDGMENT}

The author wishes to express his appreciation to McGill University for the award of a Kodak Fellowship during the tenure of which part of this work was carried out. 
TABLE OF CONTENTS

\section{INTRODUCTION}

General Introduction $\ldots \ldots \ldots \ldots \ldots \ldots \ldots \ldots \ldots$ I

Reactions of Persulphate Ion .............. 2

Reactions of Mercaptans and Disulphides ...... 15

EXPERIMENTAL METHODS AND RESULTS

Materials .......................... 28

Experimental Methods and Techniques ........ 29

Determination of Thioglycolic Acid in the Presence of Persulphate .............. 30

Comparative Rate of Disappearance of Thioglycolic Acid and Rate of Appearance

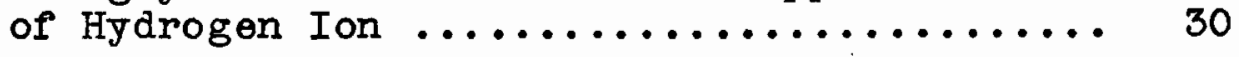

Determination of Persulphate in the Presence

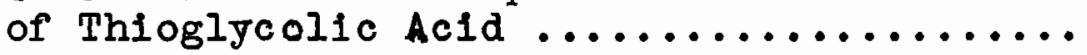

Comparative Rate of Disappearance of Thioglycollc Acid and Persulphate ....... 38

Effect of Different Concentrations of Thioglycolic Acid and Persulphate on the Rate of Disappearance of Thioglycolic Acid . 42

Rate of Disappearance of Thioglycolic Acid in Reaction Mixtures Prepared Using Different

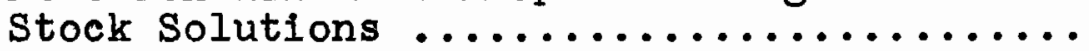

Rate of Disappearance of Thioglycolic Acid in Vessels Coated with Paraffin and Silicone .. 50

Effect of Initial Cupric Ion Concentration on the Rate of Disappearance of Thioglycolic Acid

Effect of Initial Ferric Ion Concentration on the Rate of Disappearance of Thioglycolic Acid $\ldots \ldots \ldots \ldots \ldots \ldots \ldots \ldots \ldots \ldots \ldots \ldots$

Fffect of Different Initial Concentrations of Ferric Ion, Persulphate and Thioglycolic Acid on the Rate of Disappearance of Thioglycolic Acid 
EXPERIMENTAL METHODS AND RESULTS (continued)

Effect of Ionic Strength on the Calculated

Second Order Rate Constant, $k_{1} \ldots \ldots \ldots \ldots$.

Effect of Low Concentrations of Sulphuric

Acid on the Rate of Disappearance of

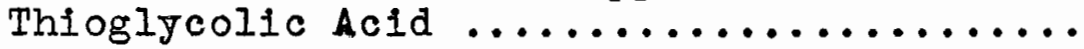

Effect of Different Concentrations of

Thioglycolic Acid and Persulphate on the

Rate of Disappearance of Thioglycolic

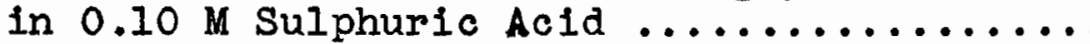

Ef fect of Different Concentrations of Ferric Ion, Thioglycolic Acld and Sulphuric Acid on the Rate of Reaction between Ferric Ion

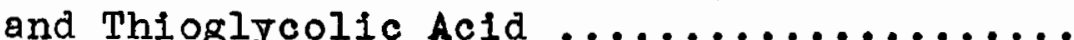

Effect of Sulphuric Acid Concentration on the Rate of Reaction between Ferrous Ion and

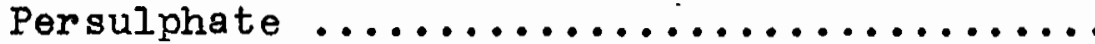

The Absorption of Ultraviolet Light by Solutions of Persulphate in $0.15 \mathrm{M}$ Sulphuric Acid ....

The Absorption of Ultraviolet Light by Solutions of Thioglycolic Acid in $0.15 \mathrm{M}$

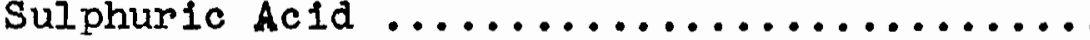

The Absorption of Ultraviolet Light by Solutions of Dithiodiglycolic Acid in

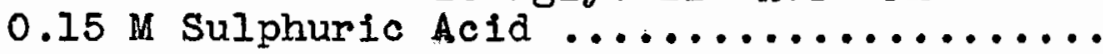

The Absorption of Ultraviolet Light by Solutions of Ferric Ion in $0.15 \mathrm{M}$ Sulphuric Acid .....

The Absorption of UItraviolet Light by Various Mixtures of Persulphate, Thioglycolic Acid, Dithlodiglycolic Acid, Ferric Ion and

Ferrous Ion in $0.15 \mathrm{M}$ Sulphuric Ac1d ...... 98

Rate of Disappearance of Persulphate in $0.15 \mathrm{M}$ Sulphuric Acid Measured both Iodimetrically

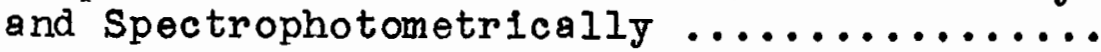

Rate of Disappearance of Persulphate in $0.15 \mathrm{M}$ Sulphuric Acid when the Dissolved Iron was Initially in the Ferric state ............

Effect of Different Concentrations of Thioglycolic Acid and Persulphate on the Stationary State Concentration of Ferric Ion and the Rate of Disappearance of Persulphate in $0.15 \mathrm{M}$ Sulphuric Acld. 
EXPERIMEAMTAL METHODS AND RESULTS (continued)

Effect of Initial Ferrous Ion Concentration on the Stationary State Concentration of Ferric Ion and the Rate of Disappearance of Persulphate in $0.15 \mathrm{M}$ Sulphuric Acid ....

Effect of Thioglycolic Acid Concentration on the Stationary State Concentration of Ferric Ion and the Rate of Disappearance of Persulphate in $0.15 \mathrm{M}$ Sulphuric Acid when the Iron was Initially in the Ferric State.

Effect of Different Concentrations of Ferric Ion, Thioglycolic Acid and Perchloric Acid on the Rate of Reaction between Ferric Ion and Thioglycolic Acid at an Ionic Strength of $1.00 \ldots \ldots \ldots \ldots \ldots \ldots \ldots \ldots \ldots \ldots$

Effect of Sulphate Ion Concentration on the Rate of Reaction between Ferric Ion and Thioglycolic Acid at an Ionic Strength of 1.00

\section{DISCUSSION}

Development of Mechanism for the Iron Catalyzed Reaction at Low Concentrations of Sulphuric

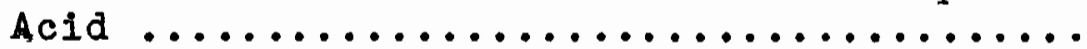

Development of Mechanism for the Reaction of Ferric Ion with Thioglycollc Acid in Acidic

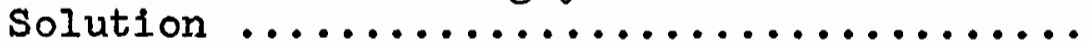

Development of Mechanism for the Iron Catalyzed Reaction in $0.15 \mathrm{M}$ Sulphuric Acld ........ 143

Conditions under which the Uncatalyzed Reaction Should be Investigated .................

SUMMARY AND CONTRIBUTIONS TO KNOWLEDGE $\ldots \ldots \ldots \ldots .163$

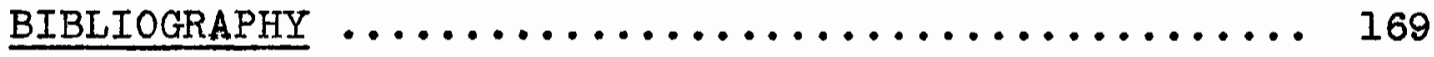




\section{INTRODUCTION}

\section{General Introduction}

The widespread use of peroxide type compounds as Initiators of polymerization reactions has stimulated much interest in their chemical properties in general and in their modes of decomposition in particular. Such initiator systems were observed to be much more effective when a reducing agent was present with the oxidizing agent to form a system usualy designated as a redox catalyst. Potassium peroxydisulphate, more familiarly known as potassium persulphate, is an example of such a compound and has received wide application as a polymerization initiator or catalyst $(1,2,3)$

The present research was planned with the intention of obtaining more information about the reactions of persulphate Ion with organic compounds, a subject which is not well understood. In a previous publication from this laboratory the reactions of persulphate ion with some alkyl mercaptans were discussed (4). However, a mixed solvent of glacial acetic acid - water was employed for this work, and in this mixed solvent potassium persulphate exhibited the properties of a weak electrolyte which introduced certain complications in the interpretation of the data. It was felt that a better understanding of persulphate fon - mercaptan reactions should be obtained. 
Reactions of Persulphate Ion

In spite of the fact that persulphate oxidizes many substances at a slow rate, it is a very strong oxidizing agent with an estimated normal electrode potential of two volts (5). The ion has been assigned the following structure (3):

$$
-0 \cdot \mathrm{SO}_{2} \cdot 0 \cdot 0 \cdot \mathrm{SO}_{2} \cdot 0^{-}
$$

In all of its reactions, ultimate scission of the peroxidic linkage has been postulated.

In general, peroxide compounds are believed (6) to function as polymerization initiators by first decomposing homolytically to produce two radicals which then react with the monomer.

$$
\text { Catalyst } \rightarrow 2 R
$$

Evans and Baxendale (7) suggested that persulphate functioned as a catalyst in a similar fashion, that is, the persulphate Ion decomposed to yield sulphate ion radicals,

$$
\mathrm{S}_{2} \mathrm{O}_{8}=2 \mathrm{SO}_{4}^{-}
$$

These authors also proposed that both toluene and acetic acid were oxidized to dibenzyl and succinic acid respectively by sulphate ion radicals rather than by persulphate ion itself,

and

$$
\begin{aligned}
\mathrm{S}_{2} \mathrm{O}_{8}= & \rightarrow 2 \mathrm{SO}_{4} \dot{-} \\
\mathrm{SO}_{4} \dot{-}+\mathrm{PhCH}_{3} & \rightarrow \mathrm{PhCH}_{2}+\mathrm{HSO}_{4}^{-} \\
2 \mathrm{PhCH}_{2} \cdot & \rightarrow \mathrm{PhCH}_{2}-\mathrm{CH}_{2} \mathrm{Ph} \\
\mathrm{SO}_{4} \dot{-}+\mathrm{CH}_{3} \mathrm{COOH} & \rightarrow{ }^{\circ \mathrm{CH}_{2} \mathrm{COOH}} \\
2 \cdot \mathrm{CH}_{2} \mathrm{COOH} & \rightarrow\left(\mathrm{CH}_{2} \mathrm{COOH}\right)_{2}
\end{aligned}
$$


In aqueous solution persulphate ion has been observed to decompose slowly with the liberation of oxygen $(5,8,9,10)$. Kolthoff and Miller (10) have shown that hydrogen ions catalyzed this decomposition and concluded that two simultaneous reactions occur according to the rate expression,

$$
\begin{aligned}
-\frac{d\left[\mathrm{~S}_{2} \mathrm{O}_{8}=\right]}{d t} & =\mathrm{k}_{1}\left[\mathrm{~S}_{2} \mathrm{O}_{8}=\right]+\mathrm{k}_{2}\left[\mathrm{H}^{+}\right]\left[\mathrm{S}_{2} \mathrm{O}_{8}=\right] \\
& =\mathrm{k}_{0}\left[\mathrm{~S}_{2} \mathrm{O}_{8}=\right]
\end{aligned}
$$

where $k_{0}=k_{1}+k_{2}\left[\mathrm{H}^{+}\right]$.

Their postulated mechanism is:

(A) uncatalyzed reaction:

$$
\begin{aligned}
\mathrm{S}_{2} \mathrm{O}_{8}= & \rightarrow 2 \mathrm{SO}_{4} \dot{-} \\
2 \mathrm{SO}_{4} \dot{-}+2 \mathrm{H}_{2} \mathrm{O} & \rightarrow 2 \mathrm{HSO}_{4}^{-}+2 \mathrm{HO}^{\circ} \\
2 \mathrm{HO} \cdot & \rightarrow 1 / 2 \mathrm{O}_{2}+\mathrm{H}_{2} \mathrm{O}
\end{aligned}
$$

(B) catalyzed reaction:

$$
\begin{aligned}
\mathrm{S}_{2} \mathrm{O}_{8}=+\mathrm{H}^{+} \rightarrow \mathrm{HS}_{2} \mathrm{O}_{8}^{-} & \rightarrow \mathrm{SO}_{4}+\mathrm{HSO}_{4}^{-} \\
\mathrm{SO}_{4} & \rightarrow \mathrm{SO}_{3}+1 / 2 \mathrm{O}_{2} .
\end{aligned}
$$

Bartlett and Nozaki (II) observed that the addition of either ethyl acetate or methanol to aqueous solutions of persulphate increased its rate of dissociation very markedly, and the latter system was investigated more thoroughly by Bartlett and Cotman (9). The results were best explained by the following sequence of reactions.

$$
\begin{aligned}
\mathrm{S}_{2} \mathrm{O}_{8}= & \rightarrow 2 \mathrm{SO}_{4} \dot{-} \\
\mathrm{S}_{2} \mathrm{O}_{8}=+\mathrm{CH}_{3} \mathrm{OH} & \rightarrow \mathrm{CH}_{2} \mathrm{OH}+\mathrm{HSO}_{4}-+\mathrm{SO}_{4} \dot{ } \\
\mathrm{SO}_{4} \dot{-}+\mathrm{CH}_{3} \mathrm{OH} & \rightarrow \mathrm{CH}_{2} \mathrm{OH}+\mathrm{HSO}_{4}^{-}
\end{aligned}
$$




$$
\begin{aligned}
& -4- \\
\mathrm{CH}_{2} \mathrm{OH}+\mathrm{S}_{2} \mathrm{O}_{8}= & \rightarrow \mathrm{CH}_{2} \mathrm{O}+\mathrm{HSO}_{4}^{-}+\mathrm{SO}_{4} \dot{-} \\
2 \mathrm{CH}_{2} \mathrm{OH} & \rightarrow \mathrm{CH}_{2} \mathrm{O}+\mathrm{CH}_{3} \mathrm{OH}
\end{aligned}
$$

The calculated rate expression agreed with that observed experimentally provided step ( $I a$ ) was assumed to be negligible relative to $(I b)$.

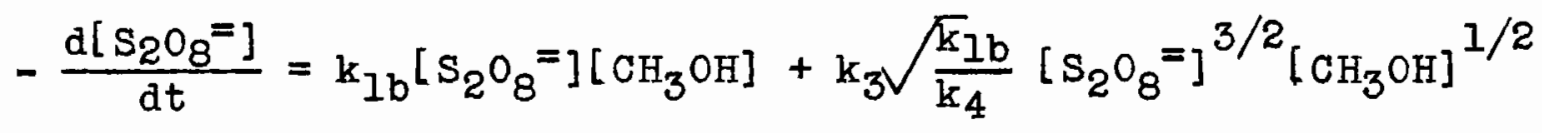

These authors suggested that although the anticipated amounts of formaldehyde were produced, the possibility that two alkoxy radicals combined to form ethylene glycol could not be eliminated.

Whalley and Winkler (12) investigated the reaction between ammonium persulphate and hydrazobenzene and postulated a mechanism which was identical in form with that outlined above. The reaction was studied in a solvent consisting of $100 \mathrm{ml}$. of acrylonitrile and $12.5 \mathrm{ml}$. of water.

$$
\begin{aligned}
& \mathrm{S}_{2} \mathrm{O}_{8}=+\varnothing \mathrm{NHNH} \varnothing \rightarrow \emptyset \mathrm{NNH} \emptyset+\mathrm{HSO}_{4}{ }^{-}+\mathrm{SO}_{4} \dot{-} \\
& \mathrm{SO}_{4} \dot{-}+\varnothing \mathrm{NHNH} \varnothing \rightarrow \emptyset \mathrm{NNH} \emptyset+\mathrm{HSO}_{4}- \\
& \mathrm{S}_{2} \mathrm{O}_{8}=+\varnothing \mathrm{NNH} \varnothing \rightarrow \varnothing \mathrm{NN} \varnothing+\mathrm{HSO}_{4}{ }^{-}+\mathrm{SO}_{4}- \\
& 2 \varnothing \mathrm{NNH} \varnothing \rightarrow \varnothing \mathrm{NN} \varnothing+\varnothing \mathrm{NHNH} \varnothing
\end{aligned}
$$

Kolthoff, Meehan and Carr (13) measured the rate of disappearance of persulphate in the presence and absence of allyl acetate and determined that the inftial rate was not influenced by the presence of this ester. It was observed that in its absence, both methanol and ethanol increased the rate very markedly in agreement with the results of Bartlett 
and Cotman (9). However, neither methanol nor ethanol influenced the rate of disappearance of persulphate in any way when allyl acetate was present. It was concluded that direct reaction between persulphate and methanol did not occur at a measurable rate, but a mechanism to account for the observations was not suggested.

It has been observed that when primary and secondary alcohols (14) are subjected to lonizing radiations the corresponding glycol and hydrogen are generally obtained.

$$
\begin{aligned}
2 \mathrm{CH}_{3} \mathrm{CH}_{2} \mathrm{OH} \rightarrow & \mathrm{CH}_{3} \mathrm{CHOH}+\mathrm{H}_{2} \\
\mathrm{CH}_{3} \mathrm{CHOH} &
\end{aligned}
$$

At the same time the alkoxy radicals may be further oxidized to yield an aldehyde from a primary alcohol or a ketone from a secondary alcohol, in addition to the glycol. Skraba, Burr and Hess (15) observed that irradiation of methanol by $\beta$ particles produced only the glycol and hydrogen, and no formaldehyde was detected. In the light of these observations, it appears very unlikely the methoxy radicals postulated to be present in the persulphate - methanol system undergo disproportionation.

The reaction of persulphate with isopropanol, which has been investigated by Levitt and $\operatorname{Malinowsk1}(16,17,18)$, differs markedly from the persulphate - methanol reaction. Individual experiments showed first rather than three halves order in persulphate concentration and zero order in alcohol concentration. The measured first order rate constant 
increased with increasing alcohol concentration and eventually reached a limiting value provided the initial persulphate concentration was kept constant. Similar results were obtained when the initial persulphate concentration was increased at constant initial concentration of the alcohol. Acetone was suggested as a product of this reaction. No mechanism was proposed to explain the experimental results.

Ball (19) also studied this reaction and reported that his experimental results did not agree with those of Levitt and Malinowski. The addition of a sequestering agent (ethylene diamine tetraacetic acid) decreased the reaction rate, and he postulated that metal ion impurities in the water were involved.

The only consistent observation from these investigations was that, in the presence of a low molecular weight alcohol, the disappearance of the persulphate ion was accelerated. This indicates that in addition to homolytic dissociation of the peroxide link, the persulphate ion was destroyed by an induced reaction. It does seem possible that radicals or trace cationic impurities in the reaction mixtures, or both, might be responsible for this induced decomposition.

The behaviour of persulphate and mercaptans in emulsion polymerization systems has been a subject of much interest and has raised the question of whether direct interaction between these occurred in the polymerization reaction. The addition of mercaptans to these systems not only regulates 
the growth of the polymer chains, but increases the rate of polymerization, and mercaptan groups have been shown to exist in the resulting polymers $(20,21,22)$. However, the complexity of the polymerization systems makes it difficult to determine whether direct reaction between the persulphate and mercaptan occurs to initiate polymerization.

Eager and Winkler (4) observed that in homogeneous solution in an inert solvent $(80 \mathrm{ml}$. glacial acetic acid and $10 \mathrm{ml}$. water) alkyl mercaptans catalyzed the decomposition of persulphate. The first order rate constant for persulphate disappearance was measured, and its value increased with increasing mercaptan concentration to a limiting value which was independent of the mercaptan employed. This limiting value of the rate constant decreased with increase in initial persulphate concentration, and it was concluded that this was due to a secondary salt effect. The following mechanism, which assumes the operation of a solvent cage, was proposed to account for the results.

$$
\begin{aligned}
\mathrm{S}_{2} \mathrm{O}_{8} & =\underset{\text { fast }}{\stackrel{\text { slow }}{\rightleftarrows}} 2 \mathrm{SO}_{4} \dot{ } \\
\mathrm{SO}_{4} \dot{-}+\mathrm{RSH} & \stackrel{\text { fast }}{\longrightarrow} \mathrm{RS} \cdot+\mathrm{HSO}_{4}^{-}
\end{aligned}
$$

Levitt (23) has suggested that the rate of reaction between persulphate and mercaptans was governed by an equilibrium between persulphate ion, sulphate ion and sulphur tetroxide; thus 


$$
\begin{aligned}
-8 & - \\
\mathrm{S}_{2} \mathrm{O}_{8}= & \rightleftarrows \mathrm{SO}_{4}+\mathrm{SO}_{4}= \\
\mathrm{RSH}+\mathrm{SO}_{4} & \rightleftarrows \underset{\mathrm{H}}{\mathrm{R}} \mathrm{RSO}_{3} \rightarrow \mathrm{RS}^{+}+\mathrm{HSO}_{4}^{-} \\
\mathrm{RS}^{+}+\mathrm{RSH} & \rightarrow \mathrm{RSSR}+\mathrm{H}^{+}
\end{aligned}
$$

By using sulphate containing radioactive sulphur, several investigators have shown that the exchange reaction between sulphate ion and persulphate ion was immeasurably slow, and this casts doubt on Lev1tt's proposal. $(24,25,26)$.

An investigation of the reaction of persulphate in aqueous solution with alkyl mercaptans solubilized with saturated fatty acid soaps showed that, under these conditions, direct reaction between persulphate and mercaptan did not occur (27). It was observed that the reaction rate was Independent of the presence or absence of mercaptan, and the suggested mechanism was
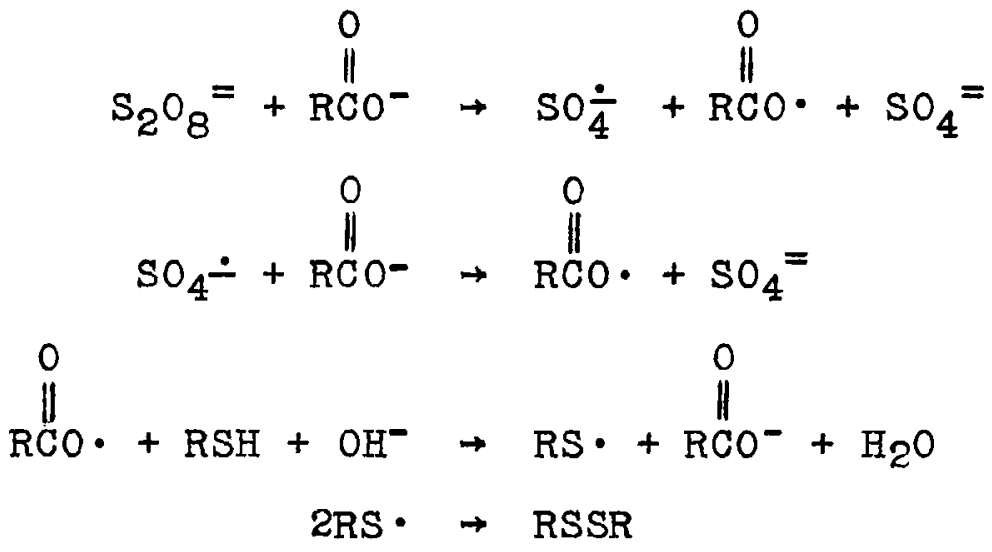

It was proposed that the reaction of olefins with mercaptans in such a system involved a chain mechanism (28). The following two steps were postulated to initiate the chain, 


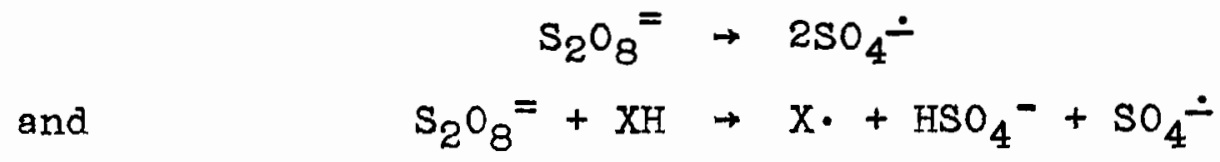

where $X H$ refers to the unsaturate.

Howard and Levitt (29) investigated the reactions

between persulphate and some organic sulphides and sulphoxides. These reaction rates were first order in persulphate concentration and were independent of the concentration of the organic compound. The following sequence of reactions was suggested.

sulphide $\rightarrow$ sulphoxide $\rightarrow$ sulphone
and $\mathrm{R}_{2} \mathrm{SO}+\mathrm{S}_{2} \mathrm{O}_{8}=+2 \mathrm{OH}^{-} \rightarrow \mathrm{R}_{2} \mathrm{SO}_{2}+2 \mathrm{SO}_{4}=+\mathrm{H}_{2} \mathrm{O}$.

Bawn and Margerison (30) followed the decomposition of persulphate in a solvent consisting of a one to one mixture by volume of ethanol and water using diphenyl picryl hydrazyl [DPPH] as a radical capturing agent. They concluded that the hydrazyl did not react with sulphur tetroxide and hence sulphur tetroxide did not possess the properties of a reactive free radical. The rate controlling step for the disappearance of the hydrazyl was postulated to be homolytic dissoclation of the peroxide bond in the persulphate.

$$
\mathrm{S}_{2} \mathrm{O}_{8}=2 \mathrm{SO}_{4} \dot{-}
$$

Tobolsky and Mesrobian (3I) have discussed, in a general way, the modes of decomposition of organic peroxides and hydroperoxides in solution, and according to them the kinetics of many thermal decomposition reactions of peroxides may be 
represented by a rate expression of the type

$$
-\frac{d[P]}{d t}=k_{d}[P]+k_{1}[P]^{x}
$$

where $k_{d}[P]$ represents the rate of the homolytic dissociation and $k_{1}[\mathrm{P}]^{\mathrm{X}}$ represents the rate of an induced reaction. The nature of this induced reaction is dependent upon both the peroxide and the solvent concerned in the reaction. However, until the reactions of persulphate with organic compounds have been more thoroughly investigated, it will be impossible to compare these with the reactions of organic peroxides and hydroperoxides in the presence of organic compounds. These investigations must be planned in such a manner that they will contribute information about possible induced decompositions of persulphate in the presence of alcohols and other organic compounds, and about the cage effect which appeared to be present in the persulphate mercaptan interactions. In both instances, metal ion impurities might play an important part, and this possibility should be carefully considered.

The reactions of persulphate with metallic ions have also been the subject of considerable attention. For the reaction between ferrous ion and persulphate the following mechanism has been proposed $(31,32)$.

$$
\begin{aligned}
& \mathrm{S}_{2} \mathrm{O}_{8}=+\mathrm{Fe}^{++} \rightarrow \mathrm{Fe}^{+++}+\mathrm{SO}_{4}=+\mathrm{SO}_{4} \dot{-} \\
& \mathrm{SO}_{4} \dot{-}+\mathrm{Fe}^{++} \rightarrow \mathrm{Fe}^{+++}+\mathrm{SO}_{4}=
\end{aligned}
$$


The reactions of ferrous ion with persulphate, hydrogen peroxide, organic peroxides and hydroperoxides display similar characteristics and proceed at equivalent rates provided ferrous ion is in excess $(34,35,36,37,38,39)$. Orr and Williams (34) have postulated that, for the hydroperoxide reactions, a complex is formed between the ferrous ion and the hydroperoxide, and this subsequently decomposes to yield ferric ion and a radical.

$$
\mathrm{Fe}^{++}+\mathrm{ROOH} \rightleftharpoons \underset{\substack{\mathrm{Fe}^{++}}}{\mathrm{ROOH}} \rightarrow \mathrm{Fe}^{+++}+\mathrm{OH}^{-}+\mathrm{RO}^{\circ}
$$

Cahill and Taube (40) have suggested that ferrous ion reacts with hydrogen peroxide by two mechanisms, both of which occur simultaneousiy,

and

$$
\begin{aligned}
& \mathrm{Fe}^{++}+\mathrm{H}_{2} \mathrm{O}_{2} \rightarrow \mathrm{Fe}(\mathrm{IV})+2 \mathrm{OH}^{-} \\
& \mathrm{Fe}^{++}+\mathrm{H}_{2} \mathrm{O}_{2} \rightarrow \mathrm{Fe}^{+++}+\mathrm{OH}^{-}+. \mathrm{OH}
\end{aligned}
$$

In the first case, two electrons are transferred in a single step, and in the second there is a single electron transfer. When hydrogen peroxide is added to an excess of ferrous Ion, the stoichiometric ratio $\Delta\left[\mathrm{Fe}^{++}\right] / \Delta\left[\mathrm{H}_{2} \mathrm{O}_{2}\right]$ has been observed to be two. However, Haber and Weiss (4I) discovered that when ferrous ion was added slowly to an excess of hydrogen peroxide, the stoichiometric ratio became less than two and concluded that an induced decomposition of the hydrogen peroxide occurred during the addition of the iron. Kolthoff, Medalia and Ragen (42) were able to reproduce the above results and made a similar study using persulphate. They concluded that an induced decomposition of persulphate 
occurred to a limited extent also.

The induced oxidations of several organic compounds by the persulphate - ferrous ion system have been studied (33, 42, 43), and the following series of reactions for the ethanol reaction were suggested by Kolthoff et al (42),

$$
\begin{aligned}
\mathrm{S}_{2} \mathrm{O}_{8}=+\mathrm{Fe}^{++} & \rightarrow \mathrm{Fe}^{+++}+\mathrm{SO}_{4} \dot{-}+\mathrm{SO}_{4}= \\
\mathrm{SO}_{4} \dot{-}+\mathrm{Fe}^{++} & \rightarrow \mathrm{Fe}^{+++}+\mathrm{SO}_{4}= \\
\mathrm{SO}_{4} \dot{-}+\mathrm{CH}_{3} \mathrm{CH}_{2} \mathrm{OH} & \rightarrow \mathrm{CH}_{3} \mathrm{CHOH}+\mathrm{HSO}_{4}^{-}
\end{aligned}
$$

followed by either

or

$$
\begin{aligned}
& \mathrm{CH}_{3} \mathrm{CHOH}+\mathrm{S}_{2} \mathrm{O}_{8}=\rightarrow \mathrm{CH}_{3} \mathrm{CHO}+\mathrm{HSO}_{4}^{-} \\
& \mathrm{CH}_{3} \mathrm{CHOH}+\mathrm{Fe}^{+++} \rightarrow \mathrm{Fe}^{++}+\mathrm{CH}_{3} \mathrm{CHO}
\end{aligned}
$$

The authors (42) were unable to suggest which of the last two steps was the more important. It was observed that with increase in the ratio of alcohol concentration to ferrous ion concentration the stoichiometric ratio $\Delta\left[\mathrm{Fe}^{++}\right] / \Delta\left[\mathrm{S}_{2} \mathrm{O}_{8}=\right]$ decreased from two to less than one. However, in the presence of oxygen this ratio became greater than two when the organic compounds were present, and it was suggested that oxygen added to the organic radical to produce a peroxy radical $\left(\mathrm{RO}_{2} \cdot\right)$ which was capable of oxidizing ferrous ion. Chloride and bromide ions tended to suppress these induced oxidations both in the presence and absence of oxygen, and the following mechanism has been proposed $(42,44)$.

$$
\begin{aligned}
& \mathrm{SO}_{4} \dot{-}+\mathrm{X}^{-} \rightarrow \mathrm{X} \cdot+\mathrm{SO}_{4}= \\
& \mathrm{X} \cdot+\mathrm{Fe}^{++} \rightarrow \mathrm{Fe}^{+++}+\mathrm{X}^{-}
\end{aligned}
$$


Kolthoff et al $(45,46,47)$ have also studied the induced oxidation of several organic compounds by mixtures of both hydrogen peroxide and iron and cumene hydroxide and Iron in the presence and absence of oxygen. The results of these experiments were similar to those for the persulphate iron series. Suppression of these induced oxidations by halide ions was also observed.

The reactions of persulphate ion with chromic ion, vanadyl ion, manganous ion, cerous ion and hydrazine are interesting since, in the absence of silver ions, they proceed at an immeasurably low rate $(48,49,50,51)$. In the presence of silver ions, the rate was found to be independent of the above substrates, and the following general mechanism was proposed.

$$
\begin{gathered}
\mathrm{S}_{2} \mathrm{O}_{8}=+\mathrm{Ag}^{+} \stackrel{\text { slow }}{\underset{\mathrm{fgst}}{+++} \mathrm{Ag}^{+++}+}+2 \mathrm{SO}_{4}= \\
\mathrm{Ag}^{+}+\text {oxidized form of the } \\
\text { reducing agent. }
\end{gathered}
$$

The rate of reaction between persulphate and ammonia, catalyzed by silver ion, was observed to be about ten times greater than the rates of the reactions with the various ions mentioned above $(52,53,54)$. It was postulated that, with ammonia, the rate controlling step was reaction between persulphate and the complex $\mathrm{Ag}\left(\mathrm{NH}_{3}\right)_{2}{ }^{+}$.

$$
\mathrm{S}_{2} \mathrm{O}_{8}=+\mathrm{Ag}\left(\mathrm{NH}_{3}\right)_{2}^{+} \rightarrow \mathrm{Ag}^{+++}+2 \mathrm{SO}_{4}=+2 \mathrm{NH}_{3}
$$


This would imply that silver ions in a complex with ammonia have increased reactivity toward persulphate.

The effect of complexes in promoting chemical reactions has recently received much attention (55). Sykes (56) demonstrated that sulphate lons and, to a lesser extent, chloride ions retarded the reaction of ferric ions with iodide lons, and he suggested that was due to complexing of the ferric ions. It has also been observed that the rates of many isotopic exchange reactions are increased rather than decreased by the complexing of the cations (57). It appears that although anions may not be involved directly in a reaction, they may exert an enormous influence upon its rate, sometimes to accelerste 1t, and at other times to inhibit it. Orgel (58) has discussed the subject of complexes and related topics at some length.

Persulphate has been observed to oxidize oxalate ion to carbon dioxide and water, but the reaction rates appeared to be affected by trace impurities of metal ions in the distilled water $(59,60)$. Both silver and copper ions were shown to catalyze the reaction very markedly and, in the former case, the reaction rate was very much greater than that of persulphate with free silver ion. Allen (60) has suggested complicated mechanisms for both the uncatalyzed and copper - catalyzed reactions.

The rate of reaction of persulphate with thiosulphate 
to yield tetrathionate was also observed to be influenced by trace impurities in the water $(61,62)$. King and Steinbeck (6I) have studied the catalysis by iodide ions and by cupric ions and were able to estimate the rate of reaction of persulphate with both thiosulphate and with the reduced form of the catalyst. Sorum and Edward (62) investigated the uncatalyzed reaction and found it to be of a complex nature.

The reaction of persulphate with iodide has been thoroughly studied with particular attention to the effect of ionic strength $(63,64,65,66)$. The following mechanism has been postulated (66).

$$
\begin{gathered}
I^{-}+\mathrm{S}_{2} \mathrm{O}_{8}=\underset{\mathrm{k}_{1}}{\stackrel{\mathrm{k}_{2}}{\rightleftarrows}} \mathrm{IS}_{2} \mathrm{O}_{8}= \\
\mathrm{I}^{-}+\mathrm{IS}_{2} \mathrm{O}_{8}=\stackrel{\mathrm{k}_{3}}{\longrightarrow} I_{2}+2 \mathrm{SO}_{4}=
\end{gathered}
$$

The persulphate ion, unlike hydrogen peroxide and some of the organic hydroperoxides, has never been observed to be oxidized. It has been postulated $(35,40,67,68)$ that in the oxidation of these latter substances the $0-\mathrm{H}$ bond rather than the $0-0$ bond is severed, and this could account for the resistance of persulphate to oxidation.

Reactions of Mercaptans and Disulphides

The mercaptan and disulphide groups, since they are present in many proteins, are important in the chemical behaviour of many natural products and during recent jears 
have become the subject of extensive investigations. Interest in mercaptan compounds, especially, has also been strongly stimulated by their wide application as "modifiers" in emulsion polymerization systems. A great deal of attention has also been focussed on the part played by sulphur in the vulcanization of rubber and rubberlike materials, and the chemical and physical properties of many organic sulphur-containing compounds have been studied in an attempt to acquire a better understanding of this process.

Mercaptans, when dissolved in aqueous solution, display the properties of weak acids owing to slight dissociation of the sulphydryl group (-SH). The several pK values listed in the following table demonstrate that the acid properties of this group are influenced by neighbouring substituents. Mild oxidizing agents such as cupric ion, ferric ion and ferricyanide ion react with mercaptans to produce the corresponding disulphides $(70,73,74,75,76)$. Iodine reacts differently with primary mercaptans than with tertiary mercaptans, the former being oxidized to the corresponding disulphides and the latter to sulphengl iodides (77).

$$
\begin{aligned}
& \mathrm{I}_{2}+(\text { primary }) 2 \mathrm{RSH} \\
& \mathrm{I}_{2}+\text { (tertiary)RSH } \rightarrow \mathrm{RSSR}+2 \mathrm{HI} \\
& \text { RS }+\mathrm{HI}
\end{aligned}
$$

In the reaction of iodine with secondary mercaptans a mixture of both the disulphide and the sulphenyl iodide is produced. Oxygen reacts with the sulphydryl group to produce the disulphide and the interaction occurs more readily in alkaline solution than in acidic solution. 


\section{TABLE I}

THE EFFECT OF NEIGHBOURING SUBST ITUENT GROUPS ON THE ACID DISSOCIATION OF THE SULPHYDRYL GROUP

\begin{tabular}{l|c|c|c}
\hline \multicolumn{1}{c|}{ Compound } & $\begin{array}{c}\text { Acid Dissociation } \\
\text { Constant, } \mathrm{K}, \\
(-\mathrm{SH}) \text { group }\end{array}$ & $\mathrm{pK}$ & Reference \\
\hline Cysteine & $5.02 \times 10^{-9}$ & 8.30 & 69 \\
Cysteine & $3.32 \times 10^{-9}$ & 8.48 & 71 \\
Mercapto ethylamine & $2.52 \times 10^{-9}$ & 8.60 & 69 \\
Mercapto ethylamine & $4.47 \times 10^{-9}$ & 8.35 & 71 \\
Mercapto ethanol & $3.16 \times 10^{-10}$ & 9.50 & 69 \\
Thioglycolic acid & $1.66 \times 10^{-10}$ & 9.78 & 71 \\
Thioglycolic acid & $2.10 \times 10^{-11}$ & 10.68 & 72 \\
\hline
\end{tabular}


Stronger oxidizing agents such as permanganate and hydrogen peroxide convert mercaptans and disulphides to sulphonic acids $(73,78,79,80,81,82)$. Under certain conditions, oxygen is also capable of yielding sulphonic acids from mercaptans (78).

$$
\begin{gathered}
(\mathrm{RS})_{2} \mathrm{~Pb} \underset{\left(\mathrm{HNO}_{3}\right)}{\stackrel{0}{(}\left(\mathrm{RSO}_{3}\right)_{2} \mathrm{~Pb} \rightarrow 2 \mathrm{RSO}_{3} \mathrm{H}} \\
\mathrm{RSSR}+5 \mathrm{H}_{2} \mathrm{O}_{2} \rightarrow 2 \mathrm{RSO}_{3} \mathrm{H}+4 \mathrm{H}_{2} \mathrm{O}
\end{gathered}
$$

Rate measurements for the reaction of hydrogen peroxide with dithiodiglycolic acid (80) indicated that a series of consecutive reactions occurred, and that sulphoscetic acld was produced only in the latter stages. It was suggested that the disulphoxide $\left(\begin{array}{c}\text { RSSR } \\ \|\| \\ 00\end{array}\right)$ was one of the intermediates. Ghosh and Kar (8I) observed that this reaction and the reaction of hydrogen peroxide with cystine were catalysed by tungstic acid and molybdic acid sols. However, replacement of these sols by soluble salts of metals such as iron and copper caused these reactions to be extremely slow.

Both chlorine and bromine react with mercaptans and disulphides to produce sulphonyl halides $(83,84,85,86)$.

$$
5 \mathrm{X}_{2}+\mathrm{RSSR}+4 \mathrm{H}_{2} \mathrm{O} \rightarrow 2 \mathrm{RSO}_{2} \mathrm{X}+8 \mathrm{HX}
$$

Free radicals have been observed to react with mercaptans to abstract a hydrogen atom and produce a mercaptyl or thiyl radical. This may be considered as an oxidation of the sulphydryl group.

$$
\begin{aligned}
\mathrm{Y} \cdot+\mathrm{RSH} & \rightarrow \mathrm{RS} \cdot+\mathrm{YH} \\
2 \mathrm{RS} & \rightarrow \mathrm{RSSR}
\end{aligned}
$$


It is because this reaction occurs so readily that mercaptans have found such wide application as "modifiers" or chain transfer agents in emulsion polymerization reactions. In the absence of mercaptans, the molecular weights of these polymers become so large that they are no longer of any practical use. The thiyl radicals produced in the chain transfer reactions between the mercaptan and growing polymer radicals are believed elther to inftiate further polymerization $(22,28)$ or recombine to form the disulphide.

$$
\begin{gathered}
\mathrm{Mn} \cdot+\mathrm{RSH} \rightarrow \mathrm{MnH}+\mathrm{RS} \cdot \\
\mathrm{RS} \cdot+\mathrm{M} \rightarrow \mathrm{RSM} \cdot \rightarrow \mathrm{RSMn} \cdot \\
2 \mathrm{RS} \cdot \rightarrow \mathrm{RSSR} .
\end{gathered}
$$

Investigations of the addition of thiyl radicals to olefinic linkages in non polymerizable compounds have been conducted (87).

Disulphides react very much more slowly with free radicals than the corresponding mercaptans $(88,89)$. Ionizing radiations have been observed to oxidize cysteine almost completely to cystine before the cystine in turn was attacked (14).

Mercaptans have been observed to take part in nucleophilic exchange reactions with disulphides in aqueous solution. The system composed of cystine and either thioglycolic acid or its disulphide has been studied by Kolthoff, Stricks and Kapoor (90), and the following reactions were postulated to occur. 


$$
\begin{aligned}
\text { RSSR (cystine) }+2 \mathrm{TSH} & \rightleftarrows \mathrm{TSST}+2 \mathrm{RSH} \\
\mathrm{RSSR}+\mathrm{TSH} & \rightleftarrows \mathrm{RSST}+\mathrm{RSH} \\
\mathrm{RSST}+\mathrm{TSH} & \rightleftarrows \mathrm{TSST}+\mathrm{RSH} \\
\mathrm{RSSR}+\mathrm{TSST} & \rightleftarrows \mathrm{RSST}
\end{aligned}
$$

Using the measured equilibrium constants of these reactions and the known oxidation - reduction potential for the cysteine-cystine system (91) (+0.08 volts measured against the normal hydrogen electrode), the oxidation reduction potential of the thioglycolic acid - dithiodiglycolic acid system was estimated to be +0.095 volts.

$$
-\mathrm{TSST}^{-}+2 \mathrm{H}^{+}+2 \mathrm{e} \rightleftarrows 2 \mathrm{TSH}^{-}
$$

These equilibria were attained more rapidly in alkaline than in acidic solution.

Rates of exchange between a disulphide and the corresponding mercaptan, which contained radioactive sulphur, were measured at several values of $\mathrm{pH}$ and the results could be accounted for by the following mechanism (92).

$$
\begin{aligned}
\mathrm{RS}^{*} \mathrm{H}+\mathrm{OH}^{-} \rightleftarrows \mathrm{RS}^{*-}+\mathrm{H}_{2} \mathrm{O} \\
\mathrm{RSSR}+\mathrm{RS}^{*-} \rightleftarrows \mathrm{RSS}^{*} \mathrm{R}+\mathrm{RS}^{-}
\end{aligned}
$$

No evidence was found to indicate the appreciable occurrence of

$$
\begin{gathered}
\mathrm{RSSR}+\mathrm{OH}^{-} \rightleftarrows \mathrm{RSOH}+\mathrm{RS}^{-} \\
\mathrm{RSOH}+\mathrm{RS}^{*-} \rightleftarrows \mathrm{RSS}^{*} \mathrm{R}+\mathrm{OH}^{-}
\end{gathered}
$$

The latter mechanism, although it does not describe the results, was suggested earlier, since the disulphide linkage is prone to cleavage in alkaline solution $(90,93,94)$. 


\section{$2 \mathrm{RSSR}+2 \mathrm{H}_{2} \mathrm{O} \rightleftharpoons 3 \mathrm{RSH}+\mathrm{RSOOH}$}

Both direct hydrolysis of the S-S bond and ionization of the proton adjacent to one of the sulphur atoms have been postulated to be the inftial step in the reaction. Swan (95) has suggested a mechanism for the cleavage of the disulphide bond in cystine which differed from both of these.

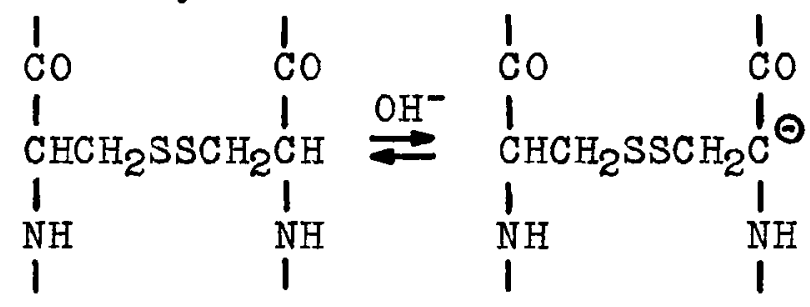

The cleavage of the disulphide bond, whether by nucleophilic exchange with thiol groups or by alkaline hydrolysis, has been a subject of much importance since by means of such reactions protein molecules which contain this group may be markedly altered and in some cases converted to much less complex entities. It is usually desirable that the reagents employed for cleaving the disulphide linkages should not Interact with any of the other groups present in the molecule.

Sulphite ions have also been used to cleave disulphide bonds in proteins. Stricks and Kolthoff (96) have investigated the equilibria of sulphite ion with both cystine and dithiodiglycolic acid.

$$
\mathrm{RSSR}(\mathrm{TSST})+\mathrm{SO}_{3}=\rightleftharpoons \mathrm{RS}-\left(\mathrm{TS}^{-}\right)+\mathrm{RSSO}_{3}{ }^{-}\left(\mathrm{TSSO}_{3}{ }^{-}\right)
$$

These equilibria were attalned more rapidly in alkaline solution than in acidic solution.

Mercaptans react with the ions of many metals to form either soluble or insoluble metal mercaptides. The reaction 
with silver ions has frequently been employed in the quantitative determination of thiol groups (97). Mercuric ions have been observed to form two complexes with thioglycolic acid in aqueous solution, $\mathrm{Hg}(\mathrm{TS})_{2}$ which was soluble and $\mathrm{Hg}_{2}(\mathrm{TS})_{2}$ which precipitated (98). It was suggested that the first mercuric ion was firmly bound to the mercaptan group, and that the second was loosely bound to the carboxylic group. Similar complexes are formed between mercuric ions and both cysteine and glutathione and, in addition, a third with the structure $\mathrm{Hg}_{3}(\mathrm{RS})_{2}$ has been observed (99).

Cuprous ion reacts with cysteine in ammonical solution to form cuprous cysteinate (100).

$$
\mathrm{Cu}^{+}+\mathrm{RSH} \rightleftharpoons \mathrm{RSCu}+\mathrm{H}^{+}
$$

It has been shown that cuprous cysteinate is a product of the oxidation of cysteine in ammonical solution by cupric ion, and that in excess cupric ion the complex is in turn oxidized (75).

$$
\begin{aligned}
4 \mathrm{RS}^{-}+2 \mathrm{Cu}^{++} & \Rightarrow 2 \mathrm{RSCu}+\mathrm{RSSR} \\
2 \mathrm{RSCu}+2 \mathrm{Cu}^{++} & \rightleftharpoons \mathrm{RSSR}+4 \mathrm{Cu}^{+}
\end{aligned}
$$

Ii and Manning (7I) have investigated the complexes of lead, zinc and cadmium ions with several sulphur containing amino acids and suggested that chelates were formed.

Both thioglycolic acid and cysteine form several complexes with dissolved iron. Kolthoff and Leussing (101) have shown that in acid solution with the $\mathrm{pH}=4$, ferrous ion and 
thioglycolic react to form a precipitate having the structure FeRS. In alkaline solution two soluble complexes are formed and the following two equilibria were postulated.

$$
\begin{aligned}
& \mathrm{Fe}(\mathrm{OH})\left(\mathrm{RS}^{-}\right)+2 \mathrm{H}^{+} \rightleftarrows \mathrm{Fe}^{++}+\mathrm{RSH}^{-}+\mathrm{H}_{2} \mathrm{O} \\
& \mathrm{Fe}(\mathrm{RS})_{2}{ }^{+}+2 \mathrm{H}^{+} \rightleftharpoons \mathrm{Fe}^{++}+2 \mathrm{RSH}^{-}
\end{aligned}
$$

Tanaka, Kolthoff and Stricks (102) have observed that cysteine and ferrous ion form a similar series of complexes.

Ferric ion reacts with both compounds in acid solution $(\mathrm{pH}<3)$ to form a blue complex which fades very rapidly (103, 104, 105, 106). Page (104) studied the equilibrium between ferric ion and cysteine under these conditions and suggested that the blue complex possessed the structure FeRSH. The dissociation constant was observed to be proportional to the square of the hydrogen ion concentration. Lamfrom and Nielsen (105) showed that the blue ferric ion - thioglycolic acid complex disappeared by a first order process at $-35^{\circ} \mathrm{C}$ in a solvent consisting of 6 parts by volume of ethanol to 10 parts water.

Red complexes of thioglycolic acid and cysteine with ferric ion were more stable in weakly acidic solution ( $\mathrm{pH}>4.6$ ) and in alkaline solution than the blue complexes in strong ac1d (103, 105). It was shown that one red complex with thioglycolic acid, $\mathrm{Fe}(\mathrm{OH})(\mathrm{RS})_{2}=$, and two with cysteine, $\mathrm{Fe}(\mathrm{OH})(\mathrm{RS})_{2}=$ and $\mathrm{Fe}(\mathrm{RS})_{3}=$, were capable of formation in the weakly acid or alkaline media (101, 102), 


$$
\mathrm{Fe}(\mathrm{OH})(\mathrm{RS})_{2}=+3 \mathrm{H}^{+} \rightleftharpoons \mathrm{Fe}^{+++}+2 \mathrm{RSH}^{-}+\mathrm{H}_{2} \mathrm{O}
$$

and when RSH refers to cysteine

$$
\mathrm{Fe}(\mathrm{OH})(\mathrm{RS})_{2}=+\mathrm{RS}^{=} \rightleftarrows \mathrm{Fe}(\mathrm{RS})_{3}=+\mathrm{OH}^{-}
$$

Page (104) observed that the red complex of ferric ion and cysteine at $\mathrm{pH}=7.40$ contained one ferric ion for every three molecules of cysteine.

The optical densities of solutions of ferric ion in the presence of either thioglycollc acid or cysteine in alkaline solution decreased by a second order process, and hydrogen ions catalyzed the reactions (102, 107). Leussing and Newman (107) examined the former case and suggested the following mechanism.

$$
\begin{aligned}
2 \mathrm{FeOH}(\mathrm{RS})_{2}= & \Rightarrow \mathrm{Fe}_{2}(\mathrm{OH})_{2}(\mathrm{RS})_{4}= \\
\mathrm{Fe}(\mathrm{OH})_{2}(\mathrm{RS})_{4}^{4-} & +2 \mathrm{Fe}^{++}+-\mathrm{RSSR}^{-} \\
\mathrm{Fe}(\mathrm{OH})(\mathrm{RS})_{2}=\mathrm{H}_{2} \mathrm{O} & \Rightarrow \mathrm{Fe}(\mathrm{OH})_{2}(\mathrm{RS})^{-}+\mathrm{RSH}^{-} \\
\mathrm{Fe}(\mathrm{OH})(\mathrm{RS})_{2}=\mathrm{Fe}(\mathrm{OH})_{2}(\mathrm{RS})- & \rightarrow \mathrm{Fe}_{2}(\mathrm{OH})_{3}(\mathrm{RS})_{3}= \\
\mathrm{Fe}_{2}(\mathrm{OH})_{3}(\mathrm{RS})_{3}= & \rightarrow 2 \mathrm{Fe}^{++}+\mathrm{RSSR}^{-} \\
\mathrm{Fe}(\mathrm{OH})(\mathrm{RS})_{2}+\mathrm{H}^{+} & \rightarrow \mathrm{Fe}(\mathrm{OH})(\mathrm{RS})^{-}+\mathrm{RSH}^{-} \\
\mathrm{Fe}(\mathrm{OH})(\mathrm{RS})_{2}=\mathrm{Fe}_{2}(\mathrm{OH})(\mathrm{RS}) & \Rightarrow \mathrm{Fe}_{2}(\mathrm{OH})_{2}(\mathrm{RS})_{3}= \\
\mathrm{Fe}_{2}(\mathrm{OH})_{2}(\mathrm{RS})_{3}= & \rightarrow 2 \mathrm{Fe}^{++}+-\mathrm{RSSR}^{-}
\end{aligned}
$$

Lamfrom and Nielsen (105) extended these measurements to the $\mathrm{pH}$ range of 4.6 to 5.8 and under these conditions observed similar behaviour. They suggested that in their experiments only the last three steps in the above mechanism were operative. 
These authors (105) also measured the rate of uptake of oxygen by the ferric ion - thioglycollc acid system. It was observed to be about one hundred times greater than predicted by the last three steps of the above mechanism. The following reactions were tentatively suggested to account for these observations.

$$
\begin{aligned}
\mathrm{O}_{2}+\mathrm{Fe}(\mathrm{II}) \mathrm{RS}-\mathrm{complex} & \rightarrow \mathrm{Fe}(\mathrm{III}) \mathrm{RS}-\mathrm{complex}+\mathrm{O}_{2}^{-} \\
\mathrm{O}_{2}^{-}+\mathrm{HSR}^{-} & \rightarrow \mathrm{HO}_{2}^{-}+\mathrm{SR}^{-} \\
\mathrm{SR}^{-}+\mathrm{Fe}(\mathrm{III}) \mathrm{RS}-\mathrm{complex} & \rightarrow \mathrm{Fe}(\mathrm{II}) \mathrm{RS}-\mathrm{complex}+{ }^{-} \mathrm{RSSR}^{-}
\end{aligned}
$$

Neville (105) has briefly described the oxidation of cysteine by iron and hydrogen peroxide in both acidic and alkaline solution.

Kolthoff, Stricks and Tanaka (108) observed that under certain conditions ferrous ion in the presence of cysteine was capable of reducing cystine.

$$
\begin{aligned}
2 \mathrm{Fe}(\mathrm{II})(\mathrm{RS})_{2}+\mathrm{RSSR}^{-} \rightleftharpoons 2 \mathrm{Fe}(\mathrm{III})(\mathrm{RS})_{3}+2 \mathrm{e} \\
2 \mathrm{H}^{+}+2 \mathrm{Fe}^{++}+-\mathrm{RSSR}^{-} \rightleftharpoons 2 \mathrm{Fe}^{+++}+2 \mathrm{RSH}^{+}
\end{aligned}
$$

The equilibrium constants for these two reactions were determined and with these the oxidation - reduction potential of the cysteine - cystine system was calculated to 0.08 volt. This value is in good agreement with that determined by Ghosh $(91)$.

The polarographic behaviour of cysteine (109) and thioglycolic acid (70) and of their corresponding disulphides (70, 110) has been investigated. "Prewaves" were observed prior to the wave corresponding to reduction of the disulphide $(110,111)$, and it was concluded that the prewaves were due 
to the following reaction.

$$
\mathrm{RSSR}+2 \mathrm{H}^{+}+2 \mathrm{2e} \rightleftharpoons 2 \mathrm{RSH}
$$

It was proposed that this reaction was the net result of the two processes shown below.

$$
\begin{aligned}
\mathrm{RSSR}+\mathrm{Hg} & \rightleftharpoons \mathrm{HgRS}+\mathrm{RS} \cdot \rightleftharpoons \mathrm{Hg}(\mathrm{RS})_{2} \\
2 \mathrm{H}^{+}+\mathrm{Hg}(\mathrm{RS})_{2}+2 \theta & \rightleftharpoons \mathrm{Hg}+2 \mathrm{RSH}
\end{aligned}
$$

Oxidation - reduction potentials of the cysteine - cystine and thioglycollc acid - dithiodiglycolic acid systems were calculated using the results obtained in a study of these prewaves. The values were +0.076 and +0.073 volts respectively for the two systems and were in good agreement with earlier determinations $(90,91,108)$.

Both ferrous and ferric ions were observed to increase the helght of the prewaves of the cystine system and it was postulated that this was due to a catalysis by the iron (112).

$$
\begin{aligned}
& \mathrm{RSSR}+\mathrm{Hg} \rightleftharpoons \mathrm{HgRS}+\mathrm{RS} \cdot \rightleftharpoons \mathrm{Hg}(\mathrm{RS})_{2} \\
& \mathrm{Fe}^{++}+\mathrm{RS} \cdot \rightleftharpoons \mathrm{Fe}^{+++}+\mathrm{RS}^{-} \\
& \mathrm{Fe}^{+++}+\theta \rightleftharpoons \mathrm{Fe}^{++} \\
& \mathrm{HgRS}+\theta=\mathrm{Hg}+\mathrm{RS}^{-} \\
& \mathrm{RSSR}+\mathrm{Fe}^{++} \rightleftharpoons \mathrm{RS}^{\cdot}+\mathrm{Fe}^{+++}+\mathrm{RS}^{-} \\
& \mathrm{RS} \cdot+\mathrm{e} \rightarrow \mathrm{RS}^{-}
\end{aligned}
$$

It was found that the results could be accounted for equally well by either steps $2,5,3$ and 4 or by 6,4 and 7 . The dithiodiglycolic acid prewaves were not affected by iron.

In the above discussion the reactions of persulphate ion, mercaptans and disulphides have been reviewed briefly. 
This thesis was conceived, as was mentioned earlier, in an attempt to obtain more information about the reactions of persulphate ion with mercaptans in homogeneous solution. It was decided to employ thioglycolic acid for this purpose, since, due to its large solubility in water, experiments could be made in aqueous solution. Hence, the difficulties encountered in an earlier investigation (4) when a mixed solvent of glacial acetic acid - water was employed could be avoided. 


\section{EXPER IMENTAL METHODS AND RESULTS}

Without exception the experiments were conducted in aqueous solution using laboratory distilled water from a Barnstead electric still.

Fisher "purified" thioglycolic acid was distilled rapidly at a pressure of $8 \mathrm{~mm}$. Hg and a temperature of $95^{\circ} \mathrm{C}$ (70), and the distillate was stored under an atmosphere of nitrogen at $0^{\circ} \mathrm{C}$. The yield of pure material was small unless the distillation was performed rapidiy. The decrease in yield with slow distillation was probably due to polymerization of the thioglycolic acid. The purity of the distillate was found by diluting a weighed portion with water in a volumetric flask and titrating aliquots with standard iodine solution using starch as an indicator and with standard sodium hydroxide solution using phenol red as an indicator (70). The thioglycolic acid employed in the experiments was $99.5 \%$ pure.

Reagent grade potassium persulphate was supplied by Brickman and Company (Montreal). Its purity was checked by dissolving a weighed portion in a known volume of water and analyzing aliquots of this solution iodometrically (113). The purity of the persulphate was estimated to be approximately 99.95\%. Consequently this salt was used without further purification.

All other chemicals used in this work were of reagent grade and were employed without further purification. 
The reaction mixtures were prepared volumetrically in either Erlenmeyer or volumetric flasks by mixing standardized solutions of the various reactants. Prior to mixing, the solutions were adjusted to the temperature of the experiment and were swept with Linde nitrogen (99.99\%) which was used without further purification. The nitrogen was saturated with water vapour by passing it through distilled water before it was bubbled through the solutions. The reaction mixtures were swept with moist nitrogen while the experiments were in progress.

When reaction mixtures were made in volumetric flasks, a measured amount of one solution was added and diluted with water until slightly more space remained than was required for the solution of the second reactant. This was added from a pipette while the mixture was swirled rapidly, and then the flask was quickly filled to the mark with water and shaken vigourously. The whole operation never required more than 45 seconds. The stop watch was started when one half the second reactant had drained from the pipette.

The experiments were conducted at $24.8^{\circ} \mathrm{C}$ in a well stirred water bath, the temperature of which was maintained constant within $\pm 0.02^{\circ} \mathrm{C}$ by a mercury filled thermoregulator which operated a magnetic relay in the heater circuit. A 300 watt immersion heater was used and cold water was passed through a copper cooling coil when required. 
The progress of the reaction was determined by removing aliquots of the reaction mixture and estimating the thioglycolic acid content by titration with a standard solution of lodine in a solution of potassium iodide. The titer of the lodine solution was checked daily with standard sodium thiosulphate solution. Persulphate, if present in the aliquot, would react slowly with iodide ions to produce iodine and thus cause a negative titration error. However, the titrations were always completed within one minute and as expected the error was found to be negligible (114). Smooth curves were generally obtained for the disappearance of thioglycolic acid with reaction time.

Previous investigations (4, 27) indicated that hydrogen ions were produced when persulphate reacted with mercaptans. In a few experiments the progress of the reaction was followed by titrating simultaneous aliquots with iodine solution and with standard sodium hydroxide solution using phenol red as an indicator. Typical of the results obtained are the following data (Table II and Figure 1). Apparently the rate of production of hydrogen ion was only very slightly less than the rate of oxidation of thioglycolic acid. This behaviour might merely indicate that because the disulphide (product) was a weaker acid (115) than thioglycolic acid itself; the phenol red was not an appropriate indicator for the alkali titration. The results are adequate, however, to 
TABLE II

RATE OF APPEARANCE OF HYDROGEN ION AND

RATE OF DISAPPEARANCE OF THIOGLYCOLIC ACID

Initial Conc. Potassium Persulphate $0.00500 \mathrm{M} / \mathrm{I}$

(Exp. 1)

\begin{tabular}{c|c|c|c|c|c}
\hline $\begin{array}{c}\text { Time } \\
(\min .)\end{array}$ & $\begin{array}{c}{[\mathrm{TSH}]} \\
\mathrm{M} / 1 \\
\times 10^{3}\end{array}$ & $\begin{array}{c}\text { Time } \\
(\min .)\end{array}$ & $\begin{array}{c}{\left[\mathrm{H}^{+}\right]} \\
\mathrm{M} / 1 \\
\times 10^{3}\end{array}$ & $\begin{array}{c}\text { Time } \\
(\mathrm{min} .)\end{array}$ & $\begin{array}{c}\text { Stoichiometric } \\
\text { Ratio } \\
{[\mathrm{TSH}]}\end{array}$ \\
\hline 0 & 5.60 & 0 & 5.60 & 100 & 1.22 \\
16 & 5.41 & 19 & 5.75 & 200 & 1.03 \\
79 & 5.00 & 82 & 6.20 & 300 & 1.11 \\
136 & 4.65 & 139 & 6.50 & 400 & 1.07 \\
220 & 4.34 & 224 & 6.81 & 500 & 1.09 \\
300 & 4.05 & 303 & 7.09 & & \\
382 & 3.71 & 386 & 7.40 & & \\
456 & 3.44 & 459 & 7.60 & & \\
\hline
\end{tabular}


$-32-$

FIGURE 1

RATE OF APPEARANCE OF HYDROGEN ION AND

RATE OF DISAPPFARANCE OF THIOGLYCOLIC ACID 


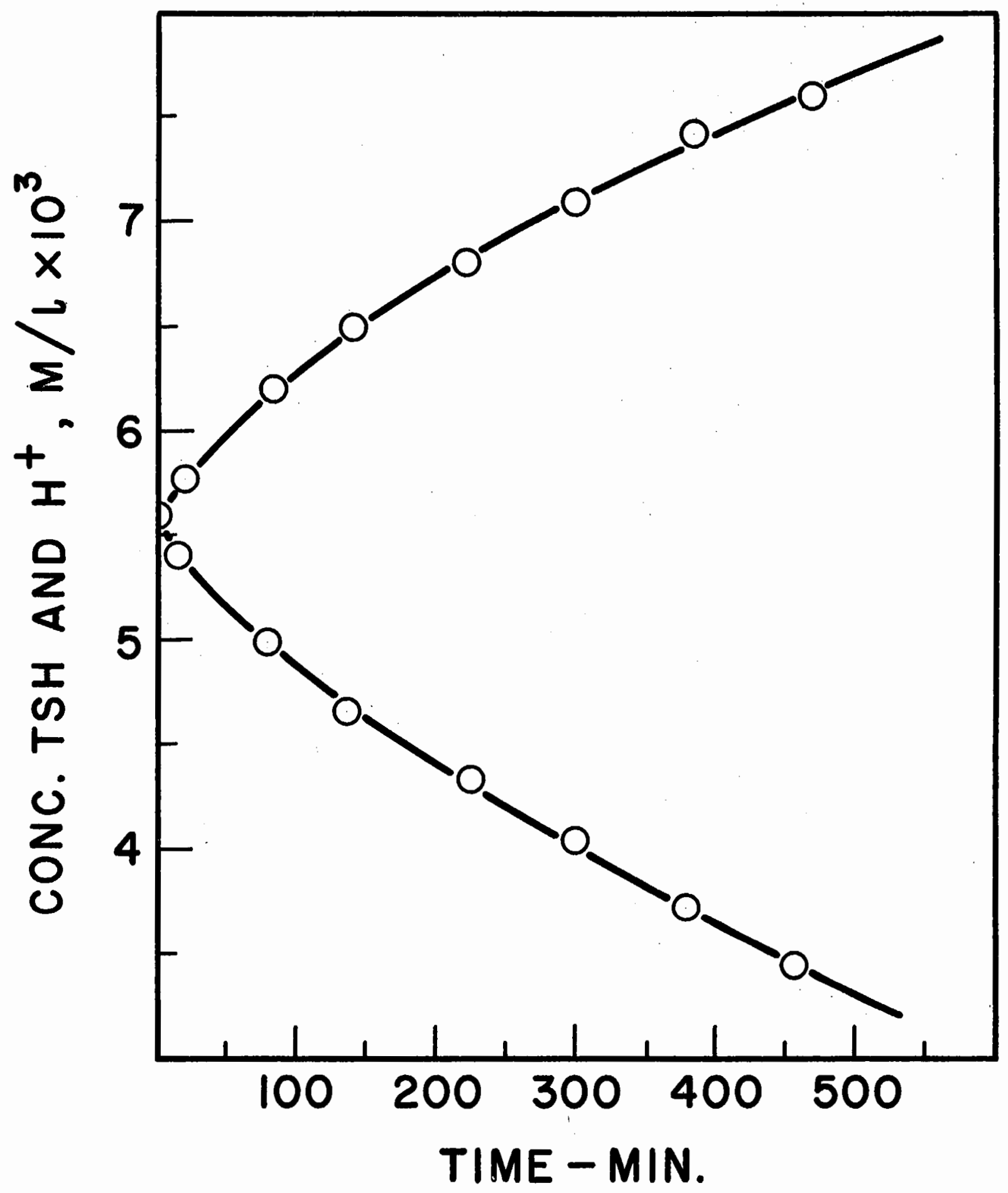


Indicate that one hydrogen ion was produced for each mercaptan group destroyed.

It was observed that the reaction mixture gradually acquired a very disagreeable odour which could not be attributed to the disulphide, and was presumably due to the formation of some other product. In previous work, Fager and Winkler (4) found that, when excess persulphate was added to mercaptan, three moles of persulphate disappeared for each mole of mercaptan that underwent reaction. However, as pointed out by these authors, it does not follow that this stoichiometric ratio prevalled during the early stages of the reaction. Determination of this stoichiometric ratio as a function of time was attempted for the present reaction to obtain some indication of the importance of any reactions of either persulphate or of sulphate ion radicals with substances other than thioglycolic acid. However, many weeks of experimental work falled to produce a method by which persulphate could be analyzed directly in the presence of thioglycollo acid. In general, chemical methods involve reduction of persulphate and apparently the oxidation product of the reducing agent used always reacted with thioglycolic acid.

Polarography with a dropping mercury electrode was considered but not attempted since inspection of the polarograms of persulphate (116), thioglycolic acid (70) and dithiodiglycolic acid (70) indicated that it would be practically impossible to choose a voltage where persulphate alone reacted at the electrode. 
Experiments were conducted to determine if the thioglycolic acid could be effectively removed from the system by some means which would not subsequently interfere with the persulphate analysis. Precipitation of the thioglycolic acid with mercuric nitrate, followed by the usual reduction of persulphate with ferrous ion and titration of excess ferrous ion with ceric ion, Jielded results which, though not reproducible, were within $10 \%$ of the correct value. Removal of the precipitate by filtration brought about no improvement. Oxidation of the mercaptan with strong oxidizing agents such as permanganate and ceric ion, followed by reduction of the persulphate as above, again yielded results which were not reproducible but were within $10 \%$ of the correct value.

Both permanganate and ceric ion were found to react sluggishly with thioglycollc acid at room temperature and it was difficult to know when a sufficient amount had been added. A deliberate excess had to be avoided since its subsequent removal would have required the addition of a reducing agent which might also have reacted with some of the persulphate present. This general scheme was not pursued further experimentally.

In retrospect, it seems possible that by using either chlorine or bromine as oxidizing agents many of the difficulties mentioned above could have been overcome. However, the l1kely advantages of these halogens were not realized at the time, and no experiments have been conducted in which they were 
used. Both are known to oxidize mercaptans rapidiy to sulphonyl halides at room temperature and thus should presumably avoid sluggish behaviour (86). Furthermore, it is known that neither bromide nor chloride ions interfere with the reduction of persulphate by ferrous ion. In fact, they are effective in suppressing induced oxidation of organic compounds by persulphate - ferrous ion mixtures ( 42 , 113). Finally, since both of these halogens are volatile, a deliberate excess could easily be removed by passing nitrogen through the solution.

Another approach which was considered and attempted experimentally was to estimate the ferric ion produced from ferrous ion by persulphate, the reaction between ferric ion and thioglycolic acid being inhibited by complexing the ferric ion. The coloured complex ferric - thiocyanate ion in 0.05 to 0.50 molar hydrochloric acid was observed to be stable in the presence of small amounts of thioglycolic acid provided the solution was also dilute in ferric ion. Thus, an allquot containing persulphate and thioglycolic acid could be diluted and added to a large excess of ferrous ion in the presence of thiocyanate. The concentration of ferrous ion was in great excess to scavenge sulphate ion radicals that might be present. However, the results could not be reproduced and it was demonstrated that there was some reaction between persulphate or sulphate ion radicals and thiocyanate. Hence to develop an analytical method along these lines, it 
appeared necessary either to find a substance which formed a coloured complex with ferric ion, but which did not interact with persulphate or sulphate ion radicals, or to find a radical scavenger which did not affect the accuracy of the analysis. Since no method of meeting either of these conditions was apparent, it was decided to discontinue attempts to analyze for persulphate directly in the presence of the mercaptan.

However, the important quantity to be measured was the stoichiometric ratio as a function of time, and a method which did not involve the direct determination of persulphate was finally employed. It is known that when persulphate reacts with lodide ion one mole of lodine is produced for each mole of persulphate destroyed (113).

$$
\mathrm{S}_{2} \mathrm{O}_{8}=+2 \mathrm{I}^{-} \rightarrow \mathrm{I}_{2}+2 \mathrm{SO}_{4}=
$$

It is also known that one mole of iodine oxidizes two moles of thioglycolic acid to form the disulphide (70).

$$
\mathrm{I}_{2}+2 \mathrm{TSH} \rightarrow \mathrm{TSST}+2 \mathrm{H}^{+}+2 \mathrm{I}^{-}
$$

However, it is not obvious that when these two reactions are occurring simultaneously the net reaction will be represented by the sum of the two individual reactions.

$$
\mathrm{S}_{2} \mathrm{O}_{8}=+2 \mathrm{TSH} \rightarrow \mathrm{TSST}+2 \mathrm{HSO}_{4}^{-}
$$

It is possible that intermediate species, such as sulphate Ion radicals, might exist, and that these could be capable of reacting with the disulphide, for example. 
However, assuming that the net reaction can be represented by the above equation, it should be possible to calculate the persulphate concentration in the presence of mercaptan by adding an allquot containing both persulphate and thioglycolic acid to a large excess of iodide ion. The persulphate would be completely destroyed, and depending upon the initial ratio of persulphate concentration to mercaptan concentration in the aliquot, elther lodine or thioglycolic acid would remain when the reactions had gone to completion. Fither of these two substances could be determined easily and provided the concentration of thioglycolic acid in the aliquot was known, the persulphate concentration could be calculated.

Similar arguments are applicable when iodide ions are replaced by ferrous ions.

$$
\begin{aligned}
& \mathrm{S}_{2} \mathrm{O}_{8}=+2 \mathrm{Fe}^{++} \rightarrow 2 \mathrm{Fe}^{+++}+2 \mathrm{SO}_{4}= \\
& 2 \mathrm{Fe}^{+++}+2 \mathrm{TSH} \rightarrow \mathrm{TSST}+2 \mathrm{H}^{+}+2 \mathrm{Fe}^{++} \\
& \mathrm{S}_{2} \mathrm{O}_{8}=+2 \mathrm{TSH} \rightarrow \mathrm{TSST}+2 \mathrm{HSO}_{4}^{-}
\end{aligned}
$$

The assumption pertaining to the net reaction was shown experimentally to be valid by adding known amounts of persulphate to known amounts of thioglycolic acid in the presence of either excess iodide ion or excess ferrous ion. The amount of iodine remaining after the persulphate had been destroyed was determined by titrating the sample with standard thiosulphate solution, and the amount of ferric ion remaining 
in similar instances was measured colourimetrically using potassium thiocyanate as the reagent. Application of the assumed stoichiometry enabled calculation of the quantity of persulphate added, and this value agreed in all cases with the amount of persulphate known to be present. The data are summarized in Tables III and IV.

Three experiments were made to determine the stoichiometric ratio in which persulphate and thioglycollc acid reacted. The progress of these reactions was followed by determining the concentration of the mercaptan iodimetrically. Persulphate concentrations in these reaction mixtures were determined by adding aliquots to either an excess of iodide Ion or of ferrous ion and measuring the amount of thioglycolic acid or iodine (ferric ion) remaining when all the reactions had gone to completion. The results given in Table $\mathrm{V}$ indicate quite clearly that one mole of persulphate reacted with two moles of thioglycolic acid during the initial stages of the reaction at least. This observation was independent of the initial concentrations.

For a given reaction between persulphate and thioglycolic acid, it was observed that after adding an aliquot to an excess of iodide ion (or of ferrous lon) and allowing the reactions to go to completion, the concentration of either the thioglycolic acid or of the lodine (ferric ion) remaining was independent of time. This provided additional evidence that two moles of thioglycolic acid disappeared for each mole 
TABLE III

ADDITION OF POTASSIUM PERSULPHATE TO MIXTURES OF

THIOGLYCOLIC ACID AND EXCESS IODIDE ION

\begin{tabular}{|c|c|c|c|c|}
\hline $\begin{array}{l}\text { Initial } \\
\text { Amount TSH } \\
\text { (m.moles) }\end{array}$ & $\begin{array}{l}\text { Final } \\
\text { Amount } \mathrm{TSH} \\
\text { (m.moles) }\end{array}$ & $\begin{array}{l}\text { Amount } I_{2} \\
\text { (m.moles) }\end{array}$ & $\begin{array}{c}\text { Amount } \mathrm{S}_{2} \mathrm{O}_{8}^{=} \\
\text {(calculated) } \\
\text { (m.moles) }\end{array}$ & $\begin{array}{c}\text { Amount } \mathrm{S}_{2} \mathrm{O}_{8}= \\
\text { (by analysis) } \\
(\mathrm{m} \text {.moles) }\end{array}$ \\
\hline 0.980 & 0.773 & 0.000 & 0.108 & 0.104 \\
\hline 0.098 & 0.000 & 0.059 & 0.108 & 0.108 \\
\hline 0.049 & 0.000 & 0.082 & 0.108 & 0.107 \\
\hline
\end{tabular}




\section{TABLE IV}

\section{ADDITION OF POTASSIUM PERSULPHATE TO MIXTURES OF \\ THIOGLYCOLIC ACID AND EXCESS FERROUS ION}

\begin{tabular}{l|c|c|c|c}
\hline $\begin{array}{c}\text { Initial } \\
\text { Amount TSH } \\
(\mathrm{m} . \mathrm{moles})\end{array}$ & $\begin{array}{c}\text { Final } \\
\text { Amount TSH } \\
(\mathrm{m} . \mathrm{moles})\end{array}$ & $\begin{array}{c}\text { Amount } \\
\mathrm{Fe}+++ \\
(\mathrm{m} . \mathrm{moles})\end{array}$ & $\begin{array}{c}\text { Amount } \mathrm{S}_{2} \mathrm{O}_{8}= \\
(\mathrm{calculated}) \\
(\mathrm{m} . \mathrm{moles})\end{array}$ & $\begin{array}{c}\text { Amount } \mathrm{S}_{20}= \\
\text { (by analysis) } \\
(\mathrm{m} . \mathrm{moles})\end{array}$ \\
\hline 0.967 & 0.748 & 0.000 & 0.108 & 0.110 \\
0.085 & 0.000 & 0.210 & 0.108 & 0.105 \\
0.049 & 0.000 & 0.217 & 0.108 & 0.109 \\
\hline
\end{tabular}




\section{TABLE V}

RATE OF DISAPPEARANCE OF THIOGLYCOLIC ACID AND OF

PERSULPHATE AT DIFFERENT INITIAL CONCENTRATIONS

\begin{tabular}{|c|c|c|c|c|c|c|c|c|}
\hline \multicolumn{3}{|c|}{ (Exp. 2) } & \multicolumn{3}{|c|}{$(\operatorname{Exp}, 3)$} & \multicolumn{3}{|c|}{ (Exp. 4) } \\
\hline $\begin{array}{l}\operatorname{Time} \\
\min .\end{array}$ & $\begin{array}{c}{[\mathrm{TSH}]} \\
\mathrm{M} / 1 \\
\times 10^{3}\end{array}$ & $\begin{array}{c}{\left[\mathrm{S}_{2} \mathrm{O}_{8}=\right]} \\
\mathrm{M} / 1 \\
\times 10^{3}\end{array}$ & $\begin{array}{l}\text { Time } \\
\text { (min. }\end{array}$ & $\begin{array}{l}{[\mathrm{TSH}]} \\
\mathrm{M} / 1 \\
\times 10^{3}\end{array}$ & $\begin{array}{c}{\left[\mathrm{S}_{2} \mathrm{O}_{8}=\right]} \\
\mathrm{M} / 1 \\
\times 10^{3}\end{array}$ & $\begin{array}{l}\text { Time } \\
\text { (min. }\end{array}$ & $\begin{array}{c}{[\mathrm{TSH}]} \\
M / 1 \\
\times 10^{3}\end{array}$ & $\begin{array}{c}{\left[\mathrm{S}_{2} \mathrm{O}_{8}=\right]} \\
\mathrm{M} / 1 \\
\times 10^{3}\end{array}$ \\
\hline 0 & 5.65 & 9.74 & 0 & 5.50 & 5.00 & 0 & 5.70 & 1.04 \\
\hline 20 & 4.81 & 9.45 & 15 & 5.36 & 4.93 & 10 & 5.67 & 1.02 \\
\hline 59 & 4.66 & 9.19 & 57 & 5.05 & 4.78 & 56 & 5.54 & 0.96 \\
\hline 120 & 4.12 & 8.92 & 119 & 4.85 & 4.68 & 117 & 5.42 & 0.90 \\
\hline 191 & 3.64 & 8.68 & 189 & 4.43 & 4.47 & 186 & 5.29 & 0.83 \\
\hline 262 & 3.30 & 8.51 & 261 & 4.28 & 4.39 & 259 & 5.14 & 0.76 \\
\hline 320 & 2.96 & 8.34 & $3: 13$ & 4.12 & 4.31 & 307 & 5.09 & 0.73 \\
\hline 405 & 2.42 & 8.07 & 401 & 3.94 & 4.22 & 396 & 4.95 & 0.66 \\
\hline 498 & 1.97 & 7.80 & 488 & 3.69 & 4.10 & 483 & 4.89 & 0.63 \\
\hline 578 & 1.55 & 7.51 & 574 & 3.30 & 3.90 & 569 & 4.82 & 0.60 \\
\hline
\end{tabular}


of persulphate, since, otherwise, the above quantities would have been functions of time.

The experimental data obtained thus far indicated that persulphate reacted slowly with thioglycolic acid, that two moles of thioglycolic acid disappeared for each mole of persulphate that underwent reaction and that one mole of hydrogen ion was produced for each mercaptan group which was destroyed. These results suggested that the reaction may be represented by the following stoichiometric equation:

$$
\mathrm{S}_{2} \mathrm{O}_{8}=+2 \mathrm{TSH} \rightarrow \mathrm{TSST}+2 \mathrm{HSO}_{4}-\text {. }
$$

Consequently, it appeared that the disagreeable odour generated in the reaction mixture as reaction progressed was due to the production of a trace amount of substance which had a negligible effect upon the stoichiometry of the reaction, at least during the early stages. The results obtained here using persulphate and thioglycolic acid lend support to the assumption that the stolchiometric ratio of two applied also to the initial stages of the reactions between persulphate and alkyl mercaptans which were investigated by Eager and Winkler (4).

A series of experiments was made in which initial concentrations of both persulphate and thioglycolic acid were varied over a considerable range, the intention being to determine the order of reaction in respect of each reactant. Besides following the progress of reaction with time by determining thioglycolic acid iodimetrically, aliquots were added to excess fodide ion and, after destruction of the 
residual persulphate, either the iodine or the thioglycolic acid remaining was determined to permit calculation of the persulphate concentrations. These date are summarized in Tables VI and VII. Again it was observed that for a given reaction either the concentration of lodine or thioglycolic acid remaining after the destruction of the persulphate was independent of time. Consequently, it appears certain that two moles of thioglycolic acid were destroyed for each mole of persulphate reacted, and all subsequent reactions were followed by determining thioglycolic acid concentration as a function of time and assuming the stoichiometric ratio to be two.

The initial rates of the above reactions were examined and appeared to be functions of both the persulphate and the thioglycolic acid concentrations. However, these rates were not investigated in a quantitative fashion since there was also evidence that the results were not reproducible. Typical of many of the data obtained are the results from experiments 8,9 and 12 which are illustrated in Figure 2. Assuming that these results were reproducible it would be extremely difficult to suggest a mechanism which accounted for the shapes of these reaction - time curves and for the relation between initial rate and the initial concentrations of persulphate and thioglycolic acid.

Since reproducible results were prerequisite to further progress in the investigation, experiments were made to 
TABLE VI

RATE OF DISAPPEARANCE OF THIOGLYCOLIC ACID AND PERSULPHATE

WITH DIFFERENT INITIAL CONCENTRATIONS OF THIOGLYCOLIC ACID

Initial Conc. Potassium Persulphate $0.00500 \mathrm{M} / \mathrm{I}$

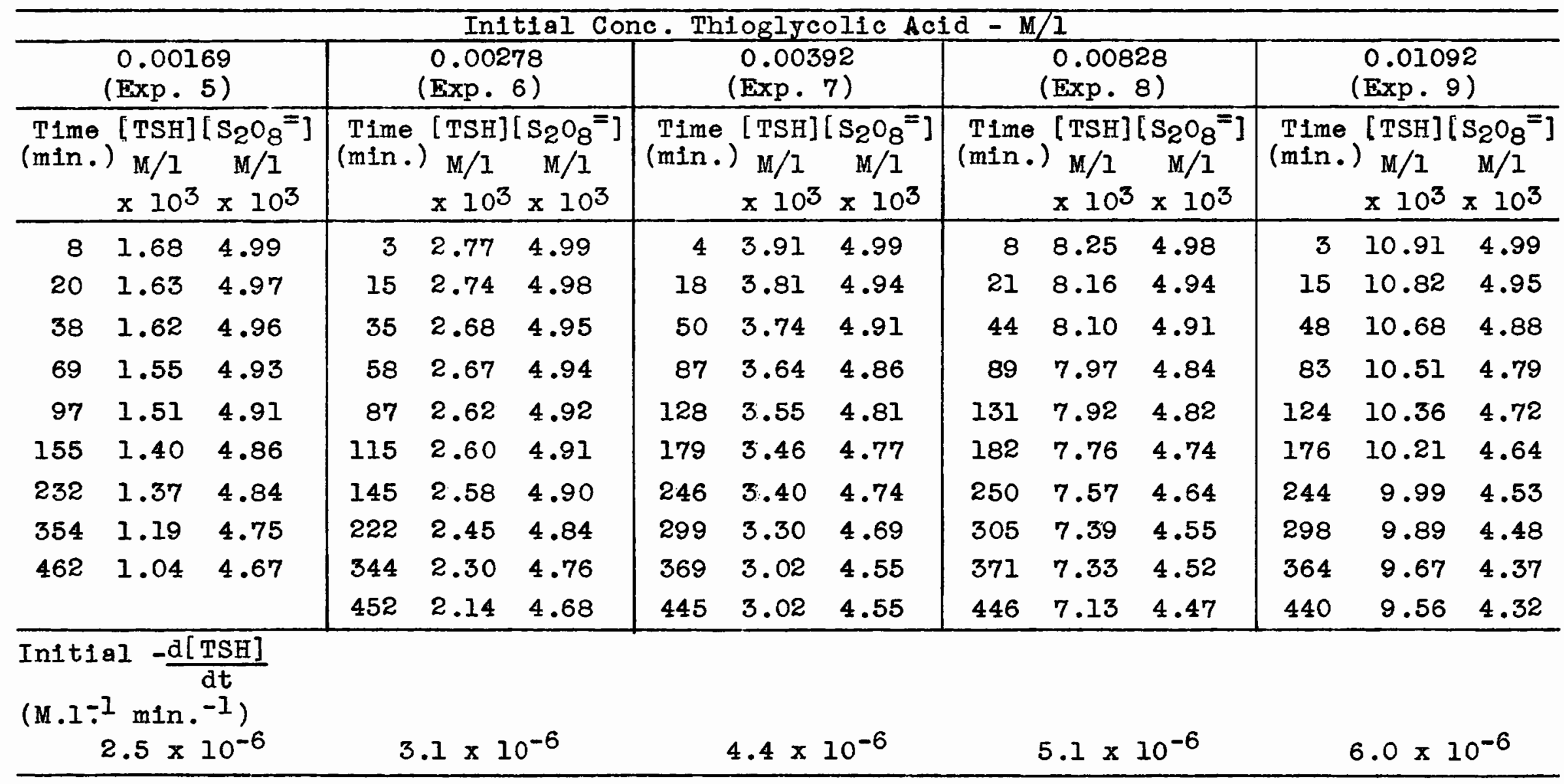


TABLE VII

RATE OF DISAPPEARANCE OF THIOGLYCOLIC ACID AND PERSULPHATE

WITH DIFFERENT INITIAL CONCENTRATIONS OF PERSULPHATE

Initial Conc. Thioglycolic Acid $0.00550 \mathrm{M} / 1$

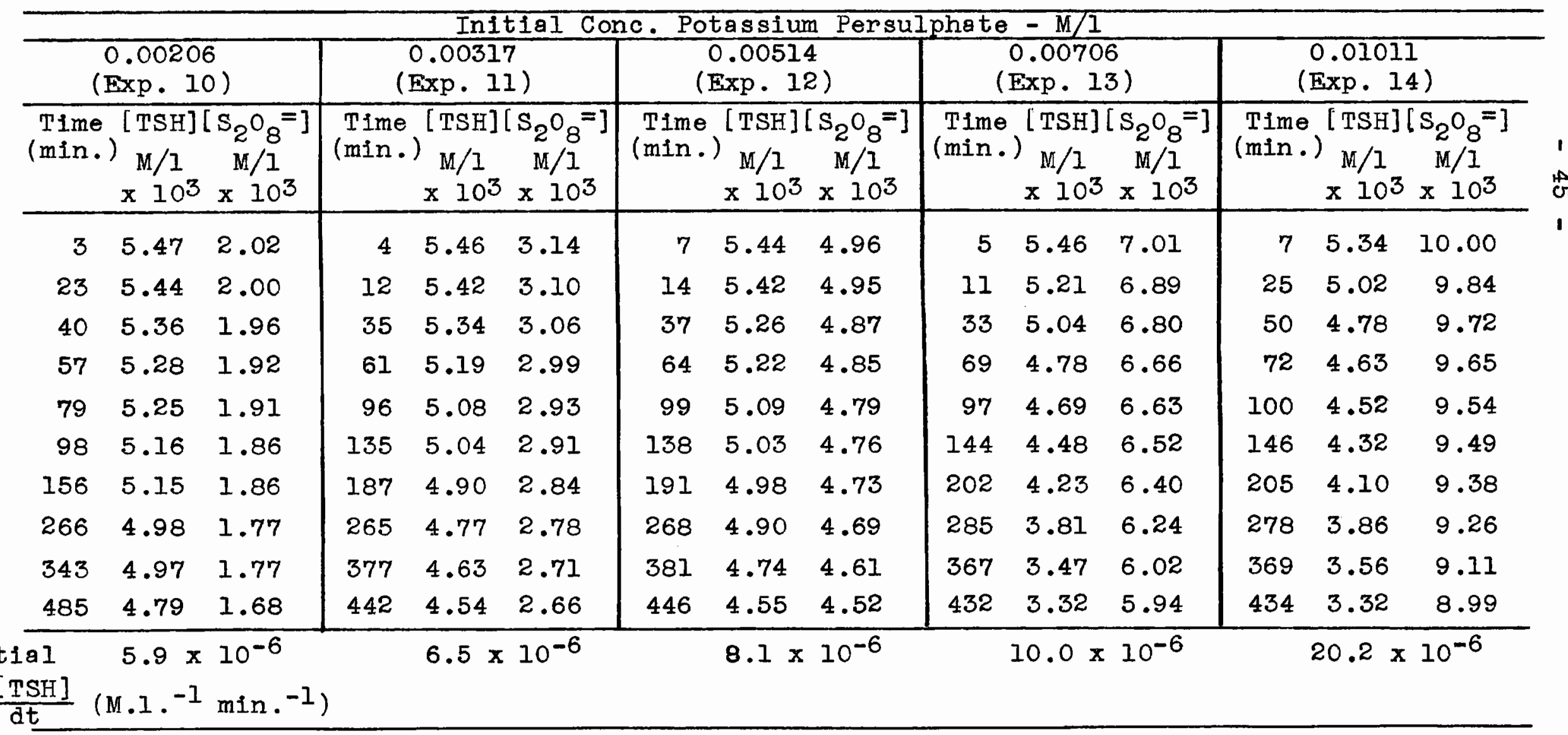


FIGURE 2

RATE OF DISAPPEARANCE OF PERSULPHATE WITH DIFFERENT

INITIAL CONCENTRATIONS OF THIOGLYCOLIC ACID

Initial Conc. $\mathrm{S}_{2} \mathrm{O}_{8}=0.00500 \mathrm{M} / 1$

O Exp. 8 Initial Conc. TSH $0.00828 \mathrm{M} / 1$

$\square " 9 \quad " \quad$ " $90.01092 \mathrm{M} / 1$

- " 12 " " $0.00514 \mathrm{M} / \mathrm{i}$ 


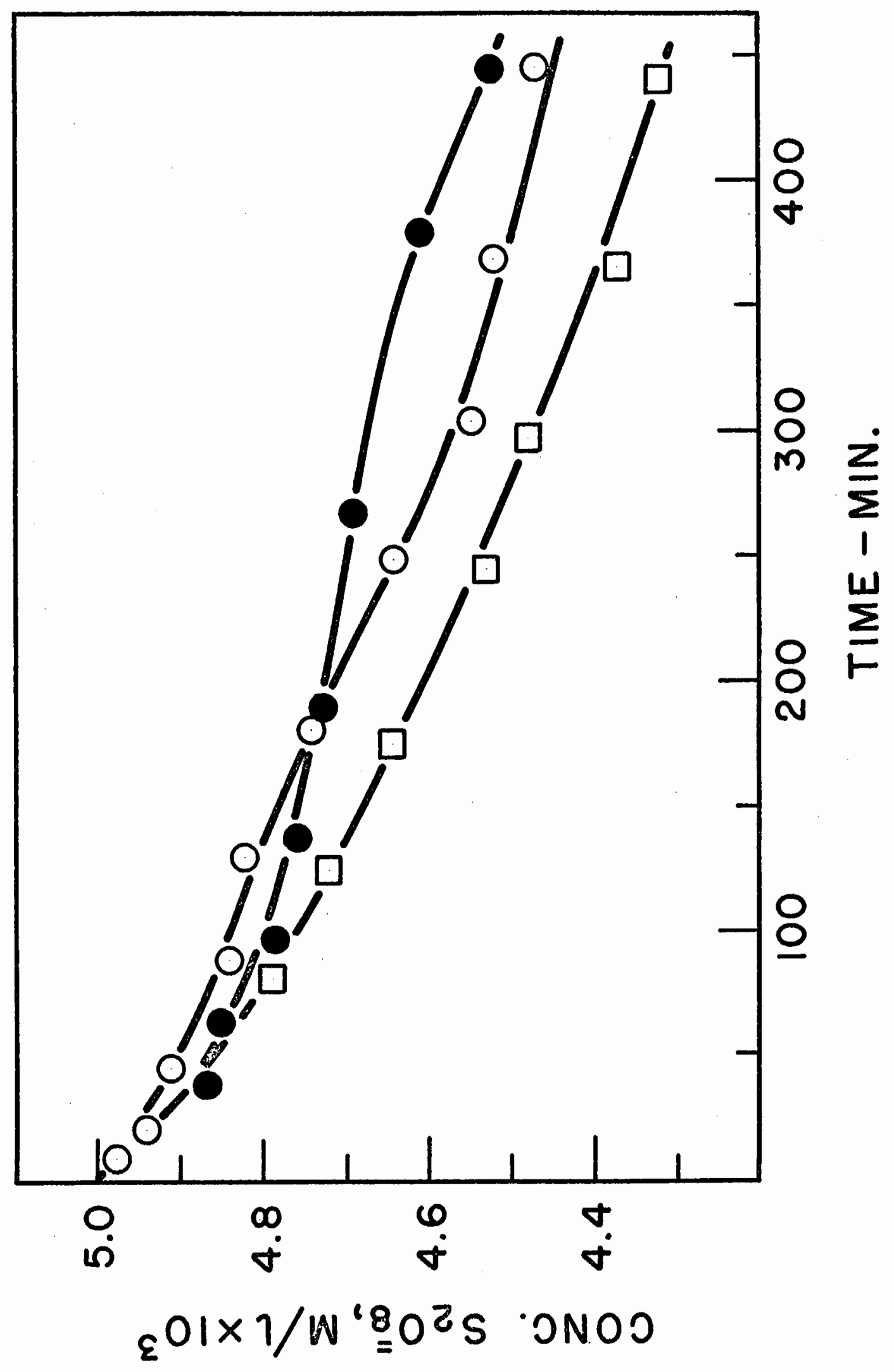


determine, if possible, the reason for the apparent irreproducibility. Two standard solutions of thioglycolic acid of the same concentration and two standard solutions of persulphate of the same concentration were prepared. Water from the same source was used to prepare these solutions and the reaction mixtures. For two experiments (Nos. 15 and 16) two new Erlenmeyer flasks were rinsed with distilled water and then dried in the oven. In one experiment (No. 15) one pair of persulphate and thioglycolic acid solutions was used and in the other experiment (No. 16) the second pair of solutions was used. The rate of experiment 15 was greater than that of experiment 16. A third new Erlenmeyer flask was then rinsed with cleaning solution followed by tap water and finally by distilled water, and was then dried in the oven. This flask was used for experiment 17 for which the first pair of solutions was employed. A flask which had been used for a previous experiment was cleaned in exactly the same manner as for experiment 17 and was used for experiment 18 in which the second pair of solutions was used. The results of these experiments are shown in Table VIII and in Figure 3. Examination of the figure indicates that the rates for the two mixtures made from the second pair of solutions were consistently intermediate between the rates for the mixtures prepared from the first pair of solutions. Moreover, the rate did not seem to depend upon the stock solutions used in preparing reaction mixtures. 
$\underline{\text { TABLE VIII }}$

RATE OF DISAPPEARANCE OF THIOGLYCOLIC ACID

Intial Conc. Potassium Persulphate $0.0100 \mathrm{M} / \mathrm{l}$

Initial Conc. Thioglycolic Acid $0.00570 \mathrm{M} / \mathrm{I}$

\begin{tabular}{|c|c|c|c|c|c|c|c|}
\hline \multicolumn{2}{|c|}{ (Exp, 15) } & \multicolumn{2}{|c|}{$(\operatorname{Exp} \cdot 16)$} & \multicolumn{2}{|c|}{ (Exp. 17) } & \multicolumn{2}{|c|}{$(\operatorname{Exp}, 18)$} \\
\hline $\begin{array}{l}\text { Time } \\
(\min .)\end{array}$ & $\begin{array}{c}{[\mathrm{TSH}]} \\
\mathrm{M} / 1 \\
\times 10^{3}\end{array}$ & $\begin{array}{l}\text { Time } \\
(\min .)\end{array}$ & $\begin{array}{c}{[\mathrm{TSH}]} \\
\mathrm{M} / 1 \\
\times 10^{3} \\
\end{array}$ & $\begin{array}{c}\text { Time } \\
(\min .)\end{array}$ & $\begin{array}{c}{[\mathrm{TSH}]} \\
\mathrm{M} / 1 \\
\times 10^{3} \\
\end{array}$ & $\begin{array}{l}\text { Time } \\
(\min .)\end{array}$ & $\begin{array}{c}{[\mathrm{TSH}]} \\
\mathrm{M} / 1 \\
\times 10^{3} \\
\end{array}$ \\
\hline 8 & 5.57 & 8 & 5.50 & 14 & 5.48 & 22 & 5.37 \\
\hline 29 & 5.14 & 29 & 5.16 & 38 & 5.34 & 38 & 5.24 \\
\hline 60 & 4.74 & 60 & 4.85 & 66 & 5.09 & 66 & 5.02 \\
\hline 104 & 4.29 & 105 & 4.41 & 113 & 4.81 & 115 & 4.71 \\
\hline 146 & 3.90 & 147 & 4.01 & 153 & 4.73 & 153 & 4.43 \\
\hline $22 I$ & 3.18 & 221 & 3.53 & 226 & 4.46 & 228 & 3.96 \\
\hline 262 & 2.87 & 261 & 3.22 & 266 & 4.32 & 266 & 3.67 \\
\hline 327 & 2.24 & 327 & 2.72 & 332 & 4.08 & 333 & 3.24 \\
\hline 374 & 1.95 & 374 & 2.42 & 379 & 3.89 & 380 & 2.92 \\
\hline 431 & 1.49 & 431 & 2.05 & 436 & 3.68 & 438 & 2.58 \\
\hline
\end{tabular}




\section{FIGURE 3}

RATE OF DISAPPEARANCE OF THIOGLYCOLIC ACID

$$
\begin{aligned}
& \text { Initial Conc. } \mathrm{S}_{2} \mathrm{O}_{8}=0.0100 \mathrm{M} / 1 \\
& \text { Initial Cone. TSH } 0.00570 \mathrm{M} / 1
\end{aligned}
$$

O Exp. 15

口 " 16

$\triangle \quad " 17$

- 18 


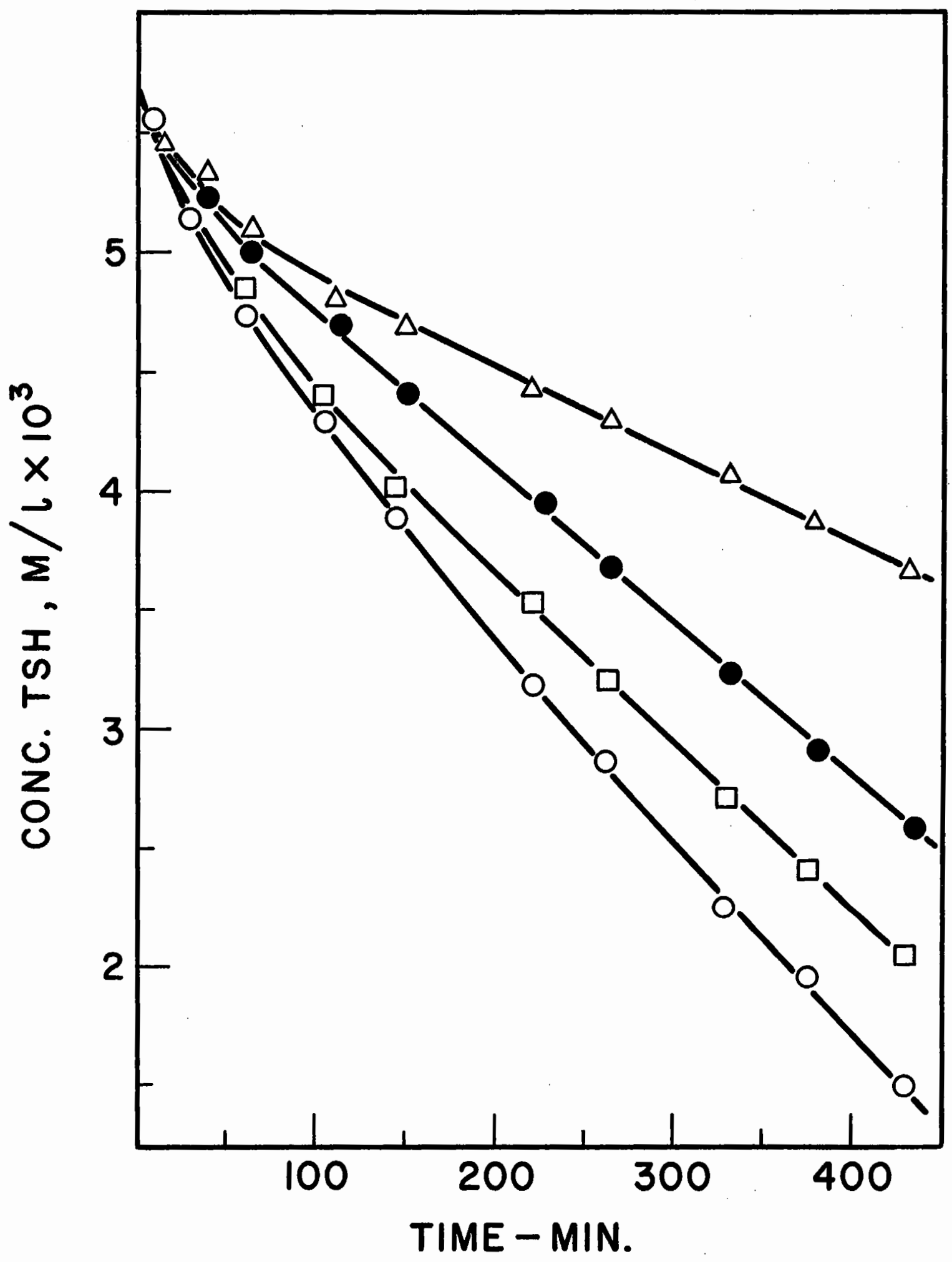


Four experiments were conducted in Erlenmeyer flasks, two of which were coated with paraffin and two with a silicone polymer. The results are shown in Table IX and Figure 4. It is apparent that the glass surface was not wholly, and perhaps not at all, responsible for the irreproducible rates of reaction observed in previous experiments.

Since only laboratory distilled water was used it seemed possible that trace cation impurities were responsible for the difficulties, especially since similar difficulties were known to occur in the reaction of persulphate with thiosulphate (62) and with oxalate ion (60). Accordingly, some experiments were made with identical concentrations of persulphate and mercaptan and with the other experimental conditions identical, with the exception that small concentrations of different cations were added. The addition of cupric ion was observed to accelerate the reaction slightly, but the results still could not be reproduced. Ferric ions were observed to have a very pronounced effect upon the rate and the results appeared to be reproducible. When dissolved iron was present in reaction mixtures, the progress of reaction was followed by adding aliquots to $25 \mathrm{ml}$. of approximately $20 \%$ phosphoric acld and determining the mercaptan iodimetrically. The phosphoric acid, by complexing the ferric ion, served to slow the reaction and prevent possible complications in the subsequent titration with iodine. These results are 
TABLE IX

RATE OF DISAPPEARANCE OF THIOGLYCOLIC ACID IN

VESSELS COATED WITH PARAFFIN AND SILICONE

Initial Conc. Potassium Persulphate $0.0100 \mathrm{M} / \mathrm{I}$

Initial Conc. Thioglycolic Acid $0.00550 \mathrm{M} / \mathrm{I}$

\begin{tabular}{|c|c|c|c|c|c|c|c|}
\hline \multicolumn{2}{|c|}{ (Exp, 19) } & \multicolumn{2}{|c|}{$(\operatorname{Exp}, 20)$} & \multicolumn{2}{|c|}{ (Exp. 2I) } & \multicolumn{2}{|c|}{$(\operatorname{Exp}, 22)$} \\
\hline $\begin{array}{l}\text { Time } \\
(\min .)\end{array}$ & $\begin{array}{c}{[\mathrm{TSH}]} \\
\mathrm{M} / 1 \\
\times 10^{3} \\
\end{array}$ & $\begin{array}{l}\text { Time } \\
(\min .)\end{array}$ & $\begin{array}{c}{[\mathrm{TSH}]} \\
\mathrm{M} / 1 \\
\times 10^{3} \\
\end{array}$ & $\begin{array}{l}\text { Time } \\
(\min .)\end{array}$ & $\begin{array}{c}{[\mathrm{TSH}]} \\
\mathrm{M} / 1 \\
\times 10^{3} \\
\end{array}$ & $\begin{array}{c}\text { Time } \\
(\min .)\end{array}$ & $\begin{array}{l}{[\mathrm{TSH}]} \\
\mathrm{M} / 1 \\
\times 10^{3} \\
\end{array}$ \\
\hline 8 & 5.18 & 13 & 5.32 & 11 & 5.40 & 15 & 5.38 \\
\hline 28 & 4.36 & 31 & 5.20 & 29 & 5.19 & 34 & 5.32 \\
\hline 40 & 3.76 & 69 & 4.97 & 67 & 5.03 & 71 & 5.06 \\
\hline 65 & 2.89 & 106 & 4.80 & 104 & 4.91 & 108 & 4.86 \\
\hline 102 & 1.76 & 154 & 4.62 & 154 & 4.71 & 156 & 4.62 \\
\hline 151 & 0.67 & 223 & 4.27 & 221 & 4.49 & 225 & 4.22 \\
\hline 219 & 0.19 & 299 & 3.92 & 296 & 4.16 & 301 & 3.88 \\
\hline & & 403 & 3.51 & 401 & 3.79 & 406 & 3.34 \\
\hline
\end{tabular}




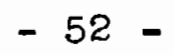

FIGURE 4

RATE OF DISAPPEARANCE OF THIOGLYCOLIC ACID IN

VESSELS COATED WITH PARAFFIN AND SILICONE

$$
\begin{aligned}
& \text { Initial Conc. } \mathrm{S}_{2} \mathrm{O}_{8}=0.0100 \mathrm{M} / 1 \\
& \text { Initial Conc. TSH } 0.00550 \mathrm{M} / 1
\end{aligned}
$$

O Exp. 19

$\square \quad$ " 20

$\triangle \quad " 21$

- " 22 


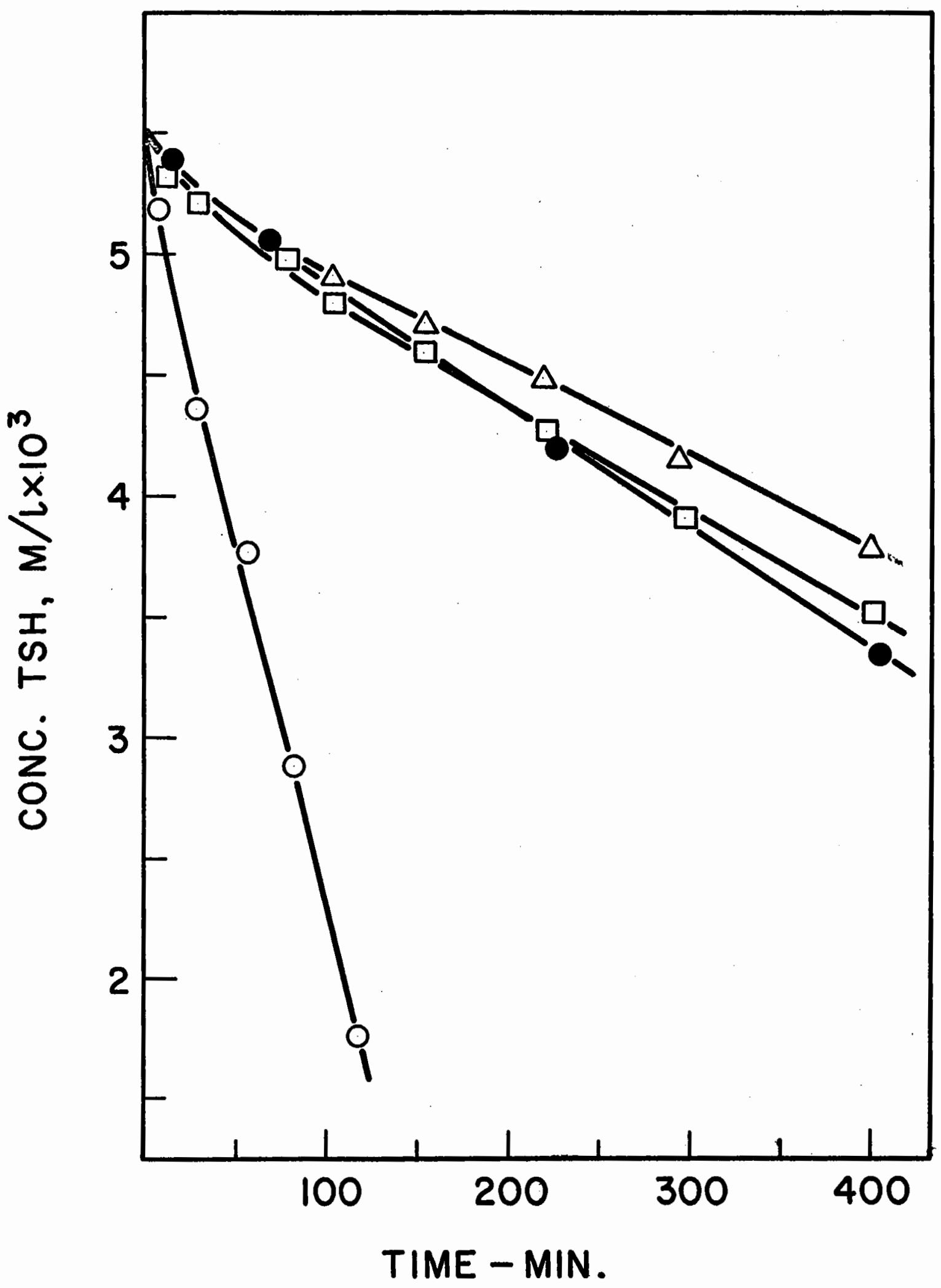


summarized in Tables $X$ and XI. Semi-logarithmic plots of persulphate concentration against time were drawn (Figure 5) and slopes at zero time were measured to obtain pseudo first order rate constants, $k_{i}^{\prime}$. Later experiments indicated that these semi-logarithmic plots were curved because the ionic strength in the reaction mixtures was changing with time. When these constants, each for a different iron concentration, were plotted against the concentration of dissolved iron, the resulting line was found to extrapolate to zero for zero concentration of iron (Figure 6). This indicated that, in the absence of iron, the reaction of persulphate with thioglycolic acld was very slow, indeed negligible.

A plot of the half-life for the reaction against the concentration of added iron (Figure 7) showed that this quantity was more sensitive to the concentration of dissolved iron as the concentration of added iron was decreased. It is interesting to note that experiments 27 and 28 were identical in every way except in 28 salicylic acid was also present. Experiment 28 was initiated by adding thioglycolic acid to persulphate and ferric ion, and the violet-coloured complex formed by ferric ions and salicylic acid disappeared almost instantly upon the addition of the thioglycolic acid and did not reappear. Thus it would seem that if ferric ions were present in the reaction mixture they were prevented by the thioglycolic acid from forming 


\section{TABLE X}

RATE OF DISAPPEARANCE OF THIOGLYCOLIC ACID WITH DIFFERENT INITIAL CONCENTRATIONS OF CUPRIC ION

Initial Conc. Potassium Persulphate $0.00160 \mathrm{M} / \mathrm{l}$ Initial Conc. Thioglycolic Acid $0.00450 \mathrm{M} / \mathrm{I}$

\begin{tabular}{|c|c|c|c|c|c|c|c|}
\hline $\begin{array}{l}4.0 \mathrm{x} \\
(\operatorname{Exp} .\end{array}$ & $\begin{array}{l}10^{-5} \\
23)\end{array}$ & $\begin{array}{r}10.0 \mathrm{x} \\
(\mathrm{Exp} .\end{array}$ & $\begin{array}{l}10^{-5} \\
24)\end{array}$ & $\begin{array}{r}10.0 x \\
(\mathrm{Exp}\end{array}$ & $\begin{array}{l}10^{-5} \\
25)\end{array}$ & $\begin{array}{r}20.0 x \\
(\operatorname{Exp} .\end{array}$ & $\begin{array}{l}10^{-5} \\
26)\end{array}$ \\
\hline $\begin{array}{c}\text { Time } \\
(\min .)\end{array}$ & $\begin{array}{c}{[\mathrm{TSH}]} \\
\mathrm{M} / 1 \\
\times 10^{3} \\
\end{array}$ & $\begin{array}{l}\text { Time } \\
(\min .)\end{array}$ & $\begin{array}{l}{[\mathrm{TSH}]} \\
\mathrm{M} / 1 \\
\times 10^{3} \\
\end{array}$ & $\begin{array}{c}\operatorname{Time} \\
(\min .)\end{array}$ & $\begin{array}{c}{[\mathrm{TSH}]} \\
\mathrm{M} / 1 \\
\times 10^{3} \\
\end{array}$ & $\begin{array}{l}\text { Time } \\
(\min .)\end{array}$ & $\begin{array}{c}{[\mathrm{TSH}]} \\
\mathrm{M} / 1 \\
\times 10^{3} \\
\end{array}$ \\
\hline 3 & 4.47 & 4 & 4.37 & 4 & 4.31 & 4 & 4.22 \\
\hline 17 & 4.12 & 7 & 4.21 & 24 & 3.78 & 27 & 3.53 \\
\hline 27 & 4.07 & 18 & 4.00 & 53 & 3.28 & 62 & 2.78 \\
\hline 41 & 4.12 & 35 & 3.68 & 74 & 3.08 & 101 & 2.42 \\
\hline 63 & 4.12 & 71 & 3.51 & 100 & 2.88 & & \\
\hline 90 & 3.94 & 99 & 3.41 & & & & \\
\hline 123 & 3.79 & & & & & & \\
\hline
\end{tabular}




\section{TABLE XI}

RATE OF DISAPPEARANCE OF THIOGLYCOLIC ACID WITH DIFFERENT

INITIAL CONCENTRATIONS OF FERRIC ION

Initial Conc. Potassium Persulphate $0.00160 \mathrm{M} / 1$

Initial Conc. Thioglycolic Acid $0.00460 \mathrm{M} / \mathrm{I}$

\begin{tabular}{|c|c|c|c|c|c|c|c|}
\hline & & & Initial Conc & - Ferric Ion & $-M / I$ & & \\
\hline $\begin{array}{r}10.0 \times 10^{-5} \\
(\operatorname{Exp} .27) \\
\end{array}$ & $\begin{array}{r}10.0 \times 10^{-5} \\
(\operatorname{Exp} \cdot 28)^{*}\end{array}$ & $\begin{array}{r}4.0 \times 10^{-5} \\
(\mathrm{Exp} .29) \\
\end{array}$ & $\begin{array}{r}4.0 \times 10^{-5} \\
(\operatorname{Exp} .30)\end{array}$ & $\begin{array}{r}2.0 \times 10^{-5} \\
(\operatorname{Exp} .31)\end{array}$ & $\begin{array}{r}0.8 \times 10^{-5} \\
(\mathrm{Exp} .32) \\
\end{array}$ & $\begin{array}{r}0.4 \times 10^{-5} \\
(\operatorname{Exp} .33)\end{array}$ & $\begin{array}{c}0.08 \times 10^{-5} \\
(\operatorname{Exp} .34)\end{array}$ \\
\hline $\begin{array}{r}\text { Time }[\mathrm{TSH}] \\
(\min .) \mathrm{M} / 1 \\
\times 10^{3}\end{array}$ & 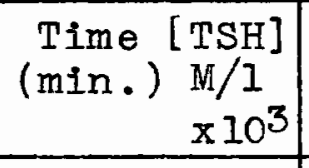 & $\begin{array}{r}\text { Time }[\mathrm{TSH}] \\
(\min .) \mathrm{M} / 1 \\
\times 10^{3}\end{array}$ & $\left.\begin{array}{rc}\text { Time }[\mathrm{TSH}] \\
(\min .) \\
\mathrm{M} / 1 \\
\times 10^{3}\end{array}\right]$ & $\begin{array}{r}\text { Time }[\mathrm{TSH}] \\
(\min .) \\
\mathrm{M} / 1 \\
\times 10^{3}\end{array}$ & $\begin{array}{r}\text { Time }[\mathrm{TSH}] \\
(\min .) \\
\mathrm{M} / 1 \\
\times 10^{3}\end{array}$ & $\begin{array}{r}\text { Time }[\mathrm{TSH}] \\
(\min .) \\
\mathrm{M} / 1 \\
\times 10^{3}\end{array}$ & $\begin{array}{r}\text { Time }[\mathrm{TSH}] \\
(\min .) \mathrm{M} / 1 \\
\times 10^{3} \\
\end{array}$ \\
\hline $3.0 \quad 2.72$ & $3.0 \quad 2.88$ & $2.5 \quad 3.70$ & $3.5 \quad 3.55$ & $3.5 \quad 3.86$ & $3.0 \quad 4.33$ & 3.54 .33 & 3.54 .60 \\
\hline $6.0 \quad 2.11$ & 6.02 .08 & $5.0 \quad 3.05$ & $8.0 \quad 2.51$ & $6.0 \quad 3.38$ & $8.0 \quad 3.71$ & $7.0 \quad 4.24$ & $11.0 \quad 4.45$ \\
\hline 9.01 .78 & $14.0 \quad 1.65$ & 8.02 .53 & $19.0 \quad 1.83$ & $9.0 \quad 2.95$ & $15.0 \quad 3.13$ & $12.0 \quad 3.88$ & $19.0 \quad 4.33$ \\
\hline $18.0 \quad 1.64$ & $23.0 \quad 1.57$ & $14.0 \quad 2.03$ & $25.0 \quad 1.73$ & $16.0 \quad 2.34$ & $22.5 \quad 2.71$ & $21.0 \quad 3.46$ & $29.0 \quad 4.12$ \\
\hline $32.0 \quad 1.59$ & $32.0 \quad 1.50$ & $25.0 \quad 1.69$ & $31.0 \quad 1.74$ & $\begin{array}{ll}23.0 & 2.08 \\
30.0 & 1.85\end{array}$ & $32.5 \quad 2.36$ & $29.0 \quad 3.24$ & \\
\hline$\left.{ }^{-1}\right) 0.267$ & 0.267 & 0.129 & 0.129 & 0.081 & 0.041 & 0.018 & 0.005 \\
\hline ife & 2.0 & 5.6 & 5.6 & 9.1 & 17.5 & & \\
\hline
\end{tabular}

* Exp. 28 was made in $0.0025 \mathrm{M}$ salicylic acid. 
TABLE XII

VARIATION OF $k_{1}^{\prime}$ AND THE REACTION HALF-LIFE WITH INITIAL CONCENTRATION OF FERRIC ION

\begin{tabular}{l|c|c|c}
\hline Exp. No. & $\begin{array}{r}\text { Initial } \\
{\left[F e^{+++}\right]} \\
\mathrm{M} / 1 \times 10^{5}\end{array}$ & $\begin{array}{c}\mathrm{k}_{1}^{\prime} \\
\left.(\mathrm{min})^{-1}\right)\end{array}$ & $\begin{array}{r}\text { Half-Iife } \\
\text { (min.) }\end{array}$ \\
\hline 27 & 10.0 & 0.267 & 2.0 \\
28 & 10.0 & 0.267 & 2.0 \\
29 & 4.0 & 0.129 & 5.6 \\
30 & 4.0 & 0.129 & 5.6 \\
31 & 2.0 & 0.081 & 9.1 \\
32 & 0.8 & 0.041 & 17.5 \\
33 & 0.4 & 0.018 & \\
34 & 0.08 & 0.005 & \\
\hline
\end{tabular}


FIGURE 5

FFFECT OF DIFFERENT INITIAL CONCENTRATIONS OF FERRIC ION

$$
\begin{aligned}
& \text { Initial Conc. } \mathrm{S}_{2} \mathrm{O}_{8}=0.00160 \mathrm{M} / 1 \\
& \text { Initial Conc. TSH } 0.00460 \mathrm{M} / 1
\end{aligned}
$$

\begin{tabular}{|c|c|c|c|c|c|c|}
\hline 0 & Exp. & 27 & Initial & Conc. & $\mathrm{Fe}^{+++}$ & $10.0 \times 10^{-5}$ \\
\hline & $"$ & 30 & $"$ & $"$ & $n$ & $4.0 \times 10^{-5}$ \\
\hline & $"$ & 31 & $"$ & $n$ & $n$ & $2.0 \times 10^{-5}$ \\
\hline & $n$ & 32 & $"$ & $n$ & $n$ & $0.8 \times 10^{-5}$ \\
\hline & $n$ & 33 & $"$ & $\pi$ & $"$ & $0.4 \times 10^{-5}$ \\
\hline
\end{tabular}




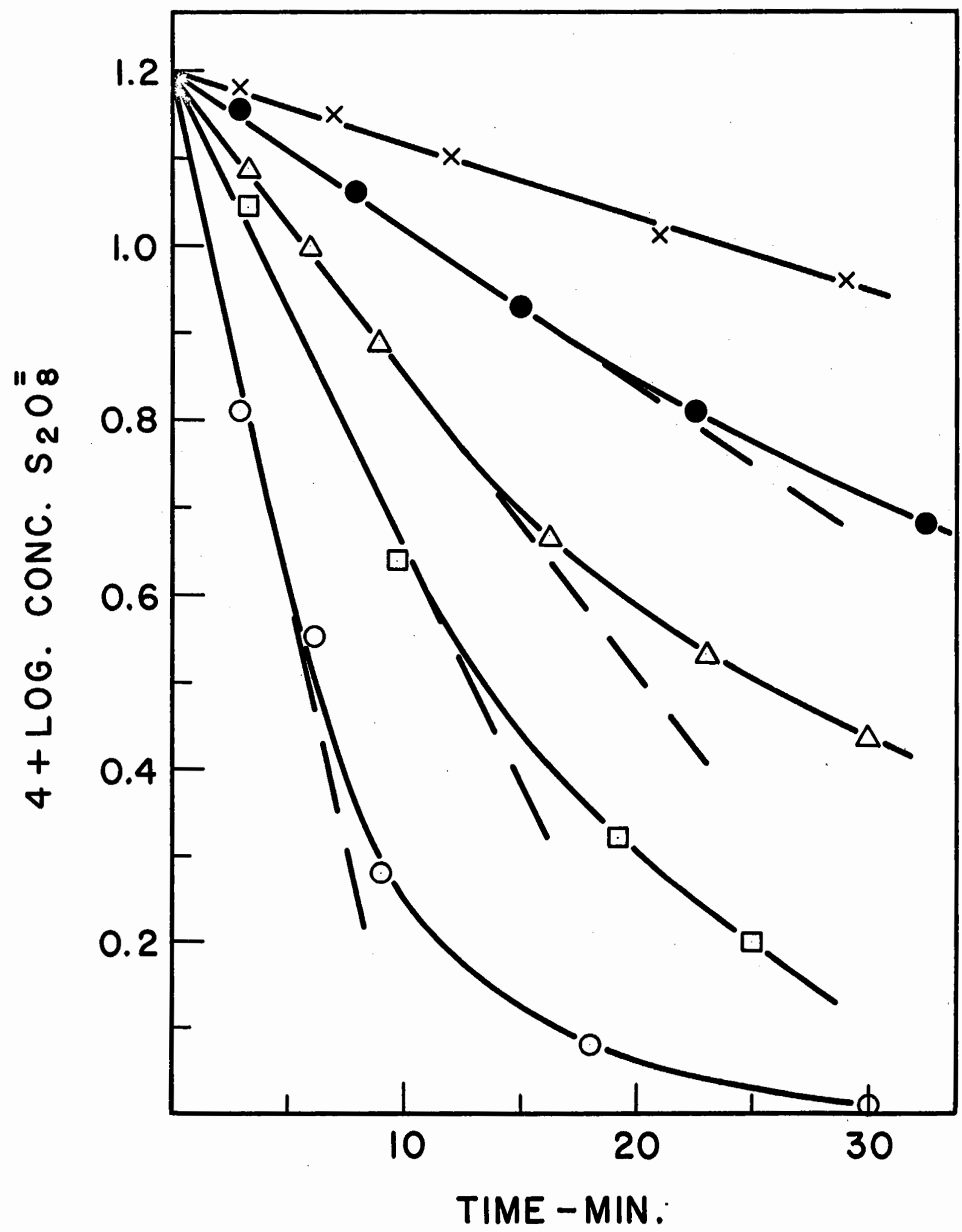


$\underline{\text { FIGURE } 6}$

EFFECT OF DIFFERENT INITIAL CONCENTRATIONS OF FERRIC

ION ON $k_{1}^{\prime}$, THE PSEUDO FIRST ORDER RATE CONSTANT

Initial Conc. $\mathrm{S}_{2} \mathrm{O}_{8}=0.00160 \mathrm{M} / 1$

Initial Conc. TSH $0.00460 \mathrm{M} / 1$ 


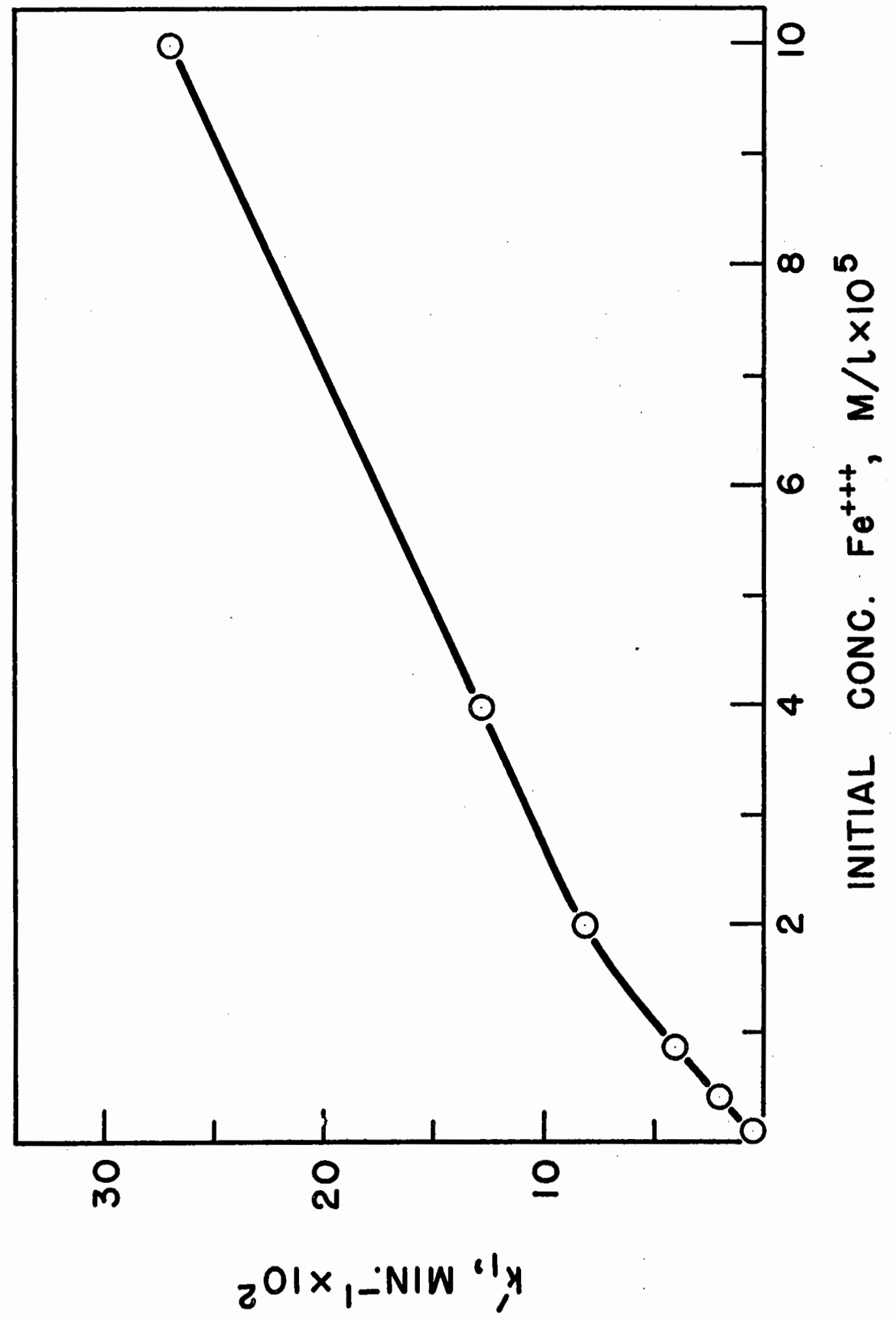


FIGURE 7

EFFECT OF DIFFERENT INITIAL CONCENTRATIONS OF FERRIC

ION ON THE REACTION HALF-LIFE

Initial Conc. $\mathrm{S}_{2} \mathrm{O}_{8}=0.00160 \mathrm{M} / 1$

Initial Conc. TSH $0.00460 \mathrm{M} / 1$ 


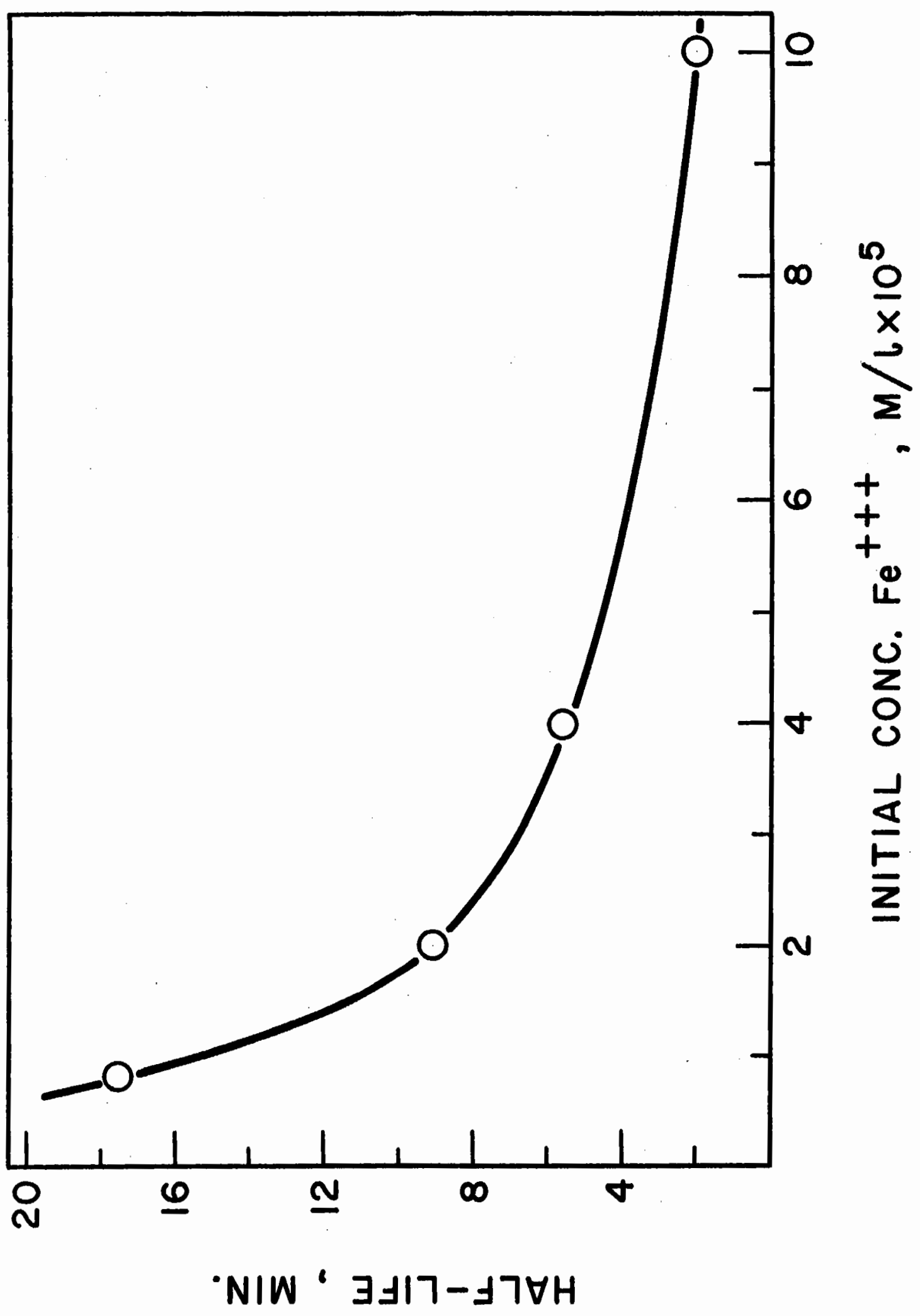


the violet complex with salicylic acid. The reaction rate was uninfluenced by the salicylic acid.

These results indicated that soluble iron salts are capable of markedly catalyzing the reaction of persulphate with thioglycolic acid, and that trace impurities of ferric ion in the water could have an appreciable effect upon the rate of reaction. Hence, the irreproducibility of the results in the absence of added iron could very well be due to a variation in the concentration of this impurity from one reaction mixture to another. However, these experiments cannot be regarded as proof that the reaction of persulphate with thioglycolic acid observed in the absence of added iron is due to the presence of only iron as an impurity. Other impurities than iron might also catalyze the reaction. Neither do the experiments prove that impurities are essential for the reaction between persulphate and mercaptan to occur. To investigate this latter question it would be necessary to purify both the water and the reagents extensively or, alternatively, to search for a sequestering agent capable of eliminating the effect of cation impurities without itself interfering in the reaction. Since either of these courses would have been completely empirical and quite doubtful of yielding unequivocal results, attention was turned to a study of the reaction in the presence of deliberately added soluble salts of iron. 
In all of the experiments to be described henceforth, ionic strength was controlled by adding known amounts of potassium sulphate, sulphuric acid and mixtures of potassium sulphate and sulphuric acid to the reaction mixtures. Under certain conditions, neither $\mathrm{KSO}_{4}^{-}$nor $\mathrm{HSO}_{4}^{-}$ions dissociate completely to form potassium, hydrogen and sulphate ions (117, 118)

$$
\begin{aligned}
& \mathrm{HSO}_{4}^{-} \rightleftharpoons \mathrm{H}^{+}+\mathrm{SO}_{4}= \\
& \mathrm{KSO}_{4}^{-} \rightleftharpoons \mathrm{K}^{+}+\mathrm{SO}_{4}=
\end{aligned}
$$

Consequently, it was necessary to use the following equation to calculate values of the ionic strength.

$$
I=3 m_{1}+3 m_{2}-2 \alpha-2 \beta
$$

where

$m_{1}$ represents the concentration of sulphuric acid in moles/liter

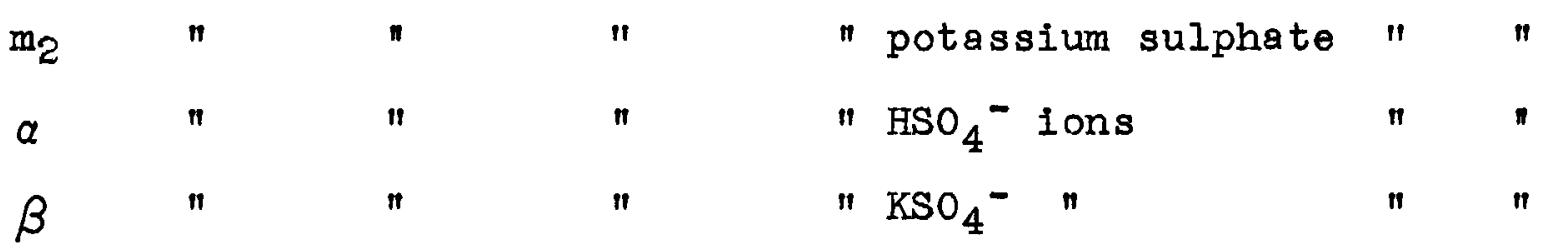

The dissociation constants of $\mathrm{HSO}_{4}-$ and $\mathrm{KSO}_{4}^{-}$at $25^{\circ} \mathrm{C}$ and zero ionic strength are 0.0102 (117) and 0.11 (118) respectively and are given by the following relations:

$$
K_{1}=\frac{\left[\mathrm{H}^{+}\right]\left[\mathrm{SO}_{4}=\right]}{\left[\mathrm{HSO}_{4}^{-}\right]} \cdot \frac{\mathrm{f}_{\mathrm{H}^{+}}^{+\mathrm{fSO}_{4}}=}{\mathrm{f}_{\mathrm{HSO}_{4}}-}
$$




$$
\begin{aligned}
& \text { - } 62- \\
& =\frac{\left(2 m_{1}-\alpha\right)\left(m_{1}+m_{2}-\alpha-\beta\right)}{\alpha} \frac{f_{\mathrm{H}}+f_{\mathrm{SO}_{4}}=}{\mathrm{f}_{\mathrm{HSO}_{4}}-} \\
& \mathrm{K}_{2}=\frac{\left(2 \mathrm{~m}_{2}-\beta\right)\left(\mathrm{m}_{1}+\mathrm{m}_{2}^{-\alpha-\beta)}\right.}{\beta} \frac{\mathrm{f}_{\mathrm{K}^{+} \mathrm{f}_{\mathrm{SO}_{4}}}=}{\mathrm{f}_{\mathrm{KSO}_{4}}{ }^{-}}
\end{aligned}
$$

Equation (3) rearranges to

$$
\log \beta=\log \left(2 m_{2}-\beta\right)\left(m_{1}+m_{2}-\alpha-\beta\right)-\log K_{2}+\log \frac{f_{K^{+f_{S_{0}}}}=}{f_{\mathrm{KSO}_{4}}{ }^{-}}
$$

Values of $\alpha$ and $\beta$ were obtained by using equations (1), (2) and (4) and taking successive approximations. It was assumed that the activity ratios, $\mathrm{f}_{\mathrm{H}^{+}} \mathrm{f}_{\mathrm{SO}_{4}}=/ \mathrm{f}_{\mathrm{HSO}_{4}}$ - and $\mathrm{f}_{\mathrm{K}^{+}} \mathrm{f}_{\mathrm{SO}_{4}}=/ \mathrm{f}_{\mathrm{KSO}_{4}}$ were equal at corresponding values of lonic strength over the range of lonic strengths employed.

Several experiments were made to determine the effect on reaction rate of the concentrations of persulphate and of thloglycolic at given concentrations of added iron, potassium sulphate being used to control ionic strength. Provided thiogiycolic acid was in excess, semi-logarithmic plots of persulphate concentration against time yielded straight lines, the slopes of which were independent of the initial concentrations of both persulphate and thioglycolic acid. Decrease in the inftial thioglycolic acid concentration had very little effect upon the initial rate, but the reaction rate fell off slightly more rapidly with time when persulphate was 
In excess to cause deviation from linearity in the first order plots. For a given value of ionic strength it was observed that the ratio of this pseudo first order rate constant, $k_{l}^{\prime}$, to the concentration of dissolved iron (i.e. $k_{1}^{\prime} /[\mathrm{Fe}]$ ) yielded another constant $k_{I}$, which was independent of the concentration of iron. These data are shown in more detail in Tables XIII and XIV and in Figure 8.

The effect of ionic strength on the reaction rate was determined by varying the concentration of potassium sulphate. The logarithm of $k_{1}$, plotted against the square root of the ionic strength, yielded a straight line with a slope of -4 (Figure 9). These results are also shown in Table XVI. In the same figure is shown a straight line, the points of which were calculated from results of a study of the persulphate - ferrous ion reaction described by Fordham and Williams (32), together with one experimental point determined by Orr and Williams (33) for the same reaction.

In spite of the fact that values of the constant $k_{1}$ were about 50\% those obtained by Williams and co-workers for the persulphate - ferrous reaction, it seemed that the rate controlling step in the reaction studied here was oxidation of ferrous ion by persulphate, followed by very rapid reduction of ferric ion by thioglycolic acid.

In the above experiments hydrogen ion concentration was not controlled but was probably always greater than $0.001 \mathrm{M}$ 


\section{TABLE XIII}

RATE OF DISAPPEARANCE OF THIOGLYCOLIC ACID WITH DIFFERENT INITIAL CONCENTRATIONS OF THIOGLYCOLIC ACID AND POTASSIUN PERSULPHATE

Conc. Potassium Sulphate $0.10 \mathrm{M} / \mathrm{l}$ Ionic Strength 0.269 Initial Conc. Ferric Ion $-10.0 \times 10^{-5} \mathrm{M} / \mathrm{I}$

\begin{tabular}{|c|c|c|c|c|c|c|c|}
\hline \multicolumn{2}{|r|}{ Inftial } & \multicolumn{2}{|c|}{ Conc. Potassium } & \multicolumn{4}{|c|}{ Persulphate - M/I } \\
\hline \multicolumn{2}{|c|}{$\begin{array}{c}0.00160 \\
(\text { Exp. 35) }\end{array}$} & \multicolumn{2}{|c|}{$\begin{array}{c}0.00320 \\
(\operatorname{Exp} .36)\end{array}$} & \multicolumn{2}{|c|}{$\begin{array}{c}0.00640 \\
(\text { Exp. 37) }\end{array}$} & \multicolumn{2}{|c|}{$\begin{array}{c}0.00640 \\
(\operatorname{Exp} .38) \\
\end{array}$} \\
\hline $\begin{array}{c}\operatorname{Tim} \theta \\
(\min .)\end{array}$ & $\begin{array}{c}\text { [TSH] } \\
M / 1 \\
\times \quad 10^{3} \\
\end{array}$ & $\begin{array}{c}\text { Time } \\
(\min .)\end{array}$ & $\begin{array}{c}\mathrm{TSH}] \\
\mathrm{M} / 1 \\
\times 10^{3} \\
\end{array}$ & Time & $\begin{array}{c}\text { [TSH] } \\
\mathrm{M} / 1 \\
\times 10^{3} \\
\end{array}$ & $\begin{array}{c}\operatorname{Tim} \theta \\
(\min .)\end{array}$ & $\begin{array}{c}{[\mathrm{TSH}]} \\
\mathrm{M} / 1 \\
\times 10^{3} \\
\end{array}$ \\
\hline 0 & 4.50 & 0 & 9.00 & 0 & 13.50 & 0 & 4.50 \\
\hline 3.5 & 3.99 & 3.5 & 7.95 & 4.0 & 11.10 & 3.5 & 2.93 \\
\hline 6.5 & 3.56 & 6.0 & 7.27 & 7.0 & 9.75 & 5.5 & 2.00 \\
\hline 9.0 & 3.31 & 9.0 & 6.60 & 9.5 & 7.79 & 8.0 & 1.20 \\
\hline 12.5 & 2.96 & 12.5 & 5.93 & 13.5 & 7.40 & 10.0 & 0.59 \\
\hline 19.0 & 2.48 & 18.0 & 5.19 & 19.5 & 5.94 & 11.5 & 0.29 \\
\hline 25.0 & 2.22 & 26.0 & 4.35 & 26.0 & 4.54 & & \\
\hline 32.5 & 1.95 & 31.5 & 4.06 & 33.5 & 3.48 & & \\
\hline 40.5 & 1.75 & 41.0 & 3.44 & 42.0 & 2.64 & & \\
\hline 49.0 & 1.57 & 50.5 & 3.18 & 50.0 & 2.15 & & \\
\hline 57.0 & 1.49 & 58.0 & 2.94 & 59.0 & 1.83 & & \\
\hline.-1$)$ & .0492 & & .0497 & & .0460 & & .0380 \\
\hline
\end{tabular}


TABLE XIV

RATE OF DISAPPEARANCE OF THIOGLYCOLIC ACID WITH DIFFERENT

INITIAL CONCENTRATIONS OF THIOGLYCOLIC ACID

AND FERRIC ION

Conc. Potassium Sulphate $0.020 \mathrm{M} / 1$

Ionic Strength 0.075

Initial Conc. Potassium Persulphate $0.00640 \mathrm{M} / 1$

\begin{tabular}{|c|c|c|c|c|}
\hline \multicolumn{5}{|c|}{ Initial Conc. Ferric Ion - $\mathrm{M} / \mathrm{I}$} \\
\hline $\begin{array}{l}2.0 \times 10^{-5} \\
(\operatorname{Exp} .39)\end{array}$ & $\begin{array}{l}2.0 \times 10^{-5} \\
(\operatorname{Exp} .40\end{array}$ & \begin{tabular}{|c|}
$0.80 \times 10^{-5}$ \\
$(\operatorname{Exp} .41)$ \\
\end{tabular} & $\begin{array}{c}0.80 \times 10^{-5} \\
(\mathrm{Exp} .42)\end{array}$ & $\begin{array}{c}0.80 \times 10^{-5} \\
(\mathrm{Exp} \cdot 43) \\
\end{array}$ \\
\hline $\begin{array}{r}\text { Time }[\mathrm{TSH}] \\
(\min .) \mathrm{M} / 1 \\
\times 10^{3}\end{array}$ & $\begin{array}{r}\text { Time [TSH] } \\
(\text { min.) } \mathrm{M} / 1 \\
\times 10^{3}\end{array}$ & $\begin{array}{r}\text { Time }[\text { TSH] } \\
(\text { min.) } \\
\mathrm{M} / 1 \\
\times 10^{3}\end{array}$ & 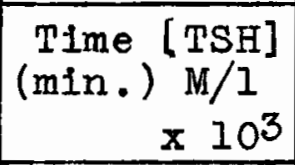 & $\begin{array}{r}\text { Time [TSH] } \\
(\min .) \mathrm{M} / 1 \\
\times 10^{3}\end{array}$ \\
\hline $0.0 \quad 13.50$ & 4.50 & $0.0 \quad 13.50$ & 4.50 & 1.80 \\
\hline $3.5 \quad 12.51$ & 3.70 & $3.0 \quad 13.12$ & 3.94 & 1.46 \\
\hline $10.0 \quad 10.52$ & 2.99 & 12.011 .82 & 20.5 & 1.13 \\
\hline 20.0 & 2.11 & $30.0 \quad 9.90$ & 29.5 & 0.85 \\
\hline 30.0 & 15.0 & $52.0 \quad 7.86$ & 36.5 & 11.0 \\
\hline 42.0 & 19.0 & $76.5 \quad 7.51$ & & 14.0 \\
\hline 60.5 & & $96.6 \quad 5.42$ & & \\
\hline \multirow[t]{3}{*}{92.0} & & $114.0 \quad 4.67$ & & \\
\hline & & $141.0 \quad 3.71$ & & \\
\hline & & $162.5 \quad 3.25$ & & \\
\hline.$\left.^{-1}\right) .0248$ & .0232 & .0110 & .0115 & .0092 \\
\hline.$\left.^{-1}\right) 1240$ & 1160 & 1370 & 1430 & 1150 \\
\hline
\end{tabular}


$-66-$

FIGURE 8

EFFECT OF DIFFERENT INITIAL CONCENTRATIONS

OF PERSULPHATE, OF THIOGLYCOLIC ACID AND

FERRIC ION

O $\operatorname{Exp} \cdot 35$

$\times \quad$ " 36

$\triangle \quad " \quad 39$

- $\quad 40$ 


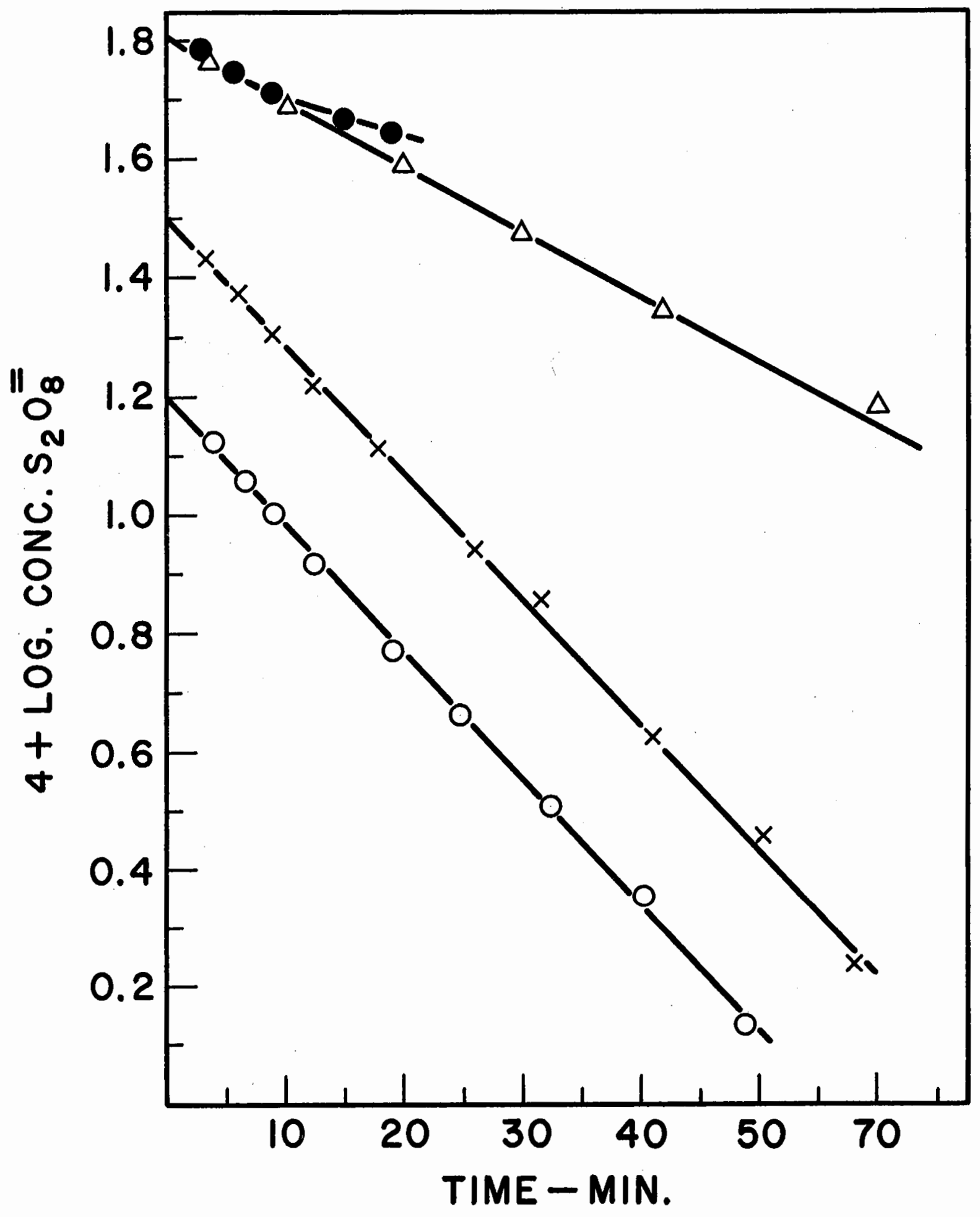




\section{TABLE XV}

RATE OF DISAPPEARANCE OF THIOGLYCOLIC ACID WITH DIFFERFNT

\section{GONCENTRATIONS OF POTASSIUM SULPHATE}

Initial Conc. Potassium Persulphate $0.00160 \mathrm{M} / 1$

Initial Conc. Thioglycolic Acid $0.00450 \mathrm{M} / \mathrm{I}$

Initial Conc. Ferric Ion $4.0 \times 10^{-5} \mathrm{M} / 1$

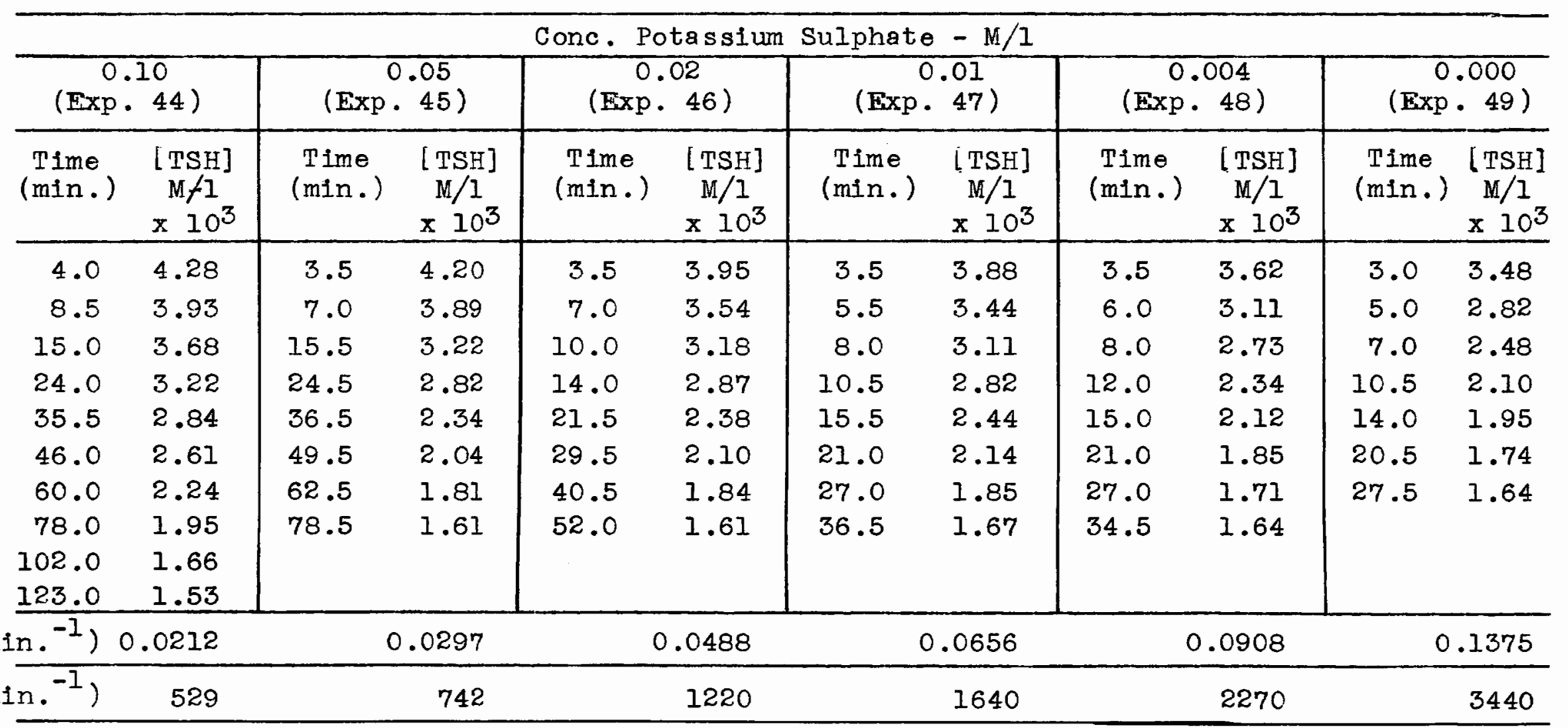




\section{TABLE XVI}

VARIATION OF THE SECOND ORDER RATE CONSTANT, $\mathrm{k}_{1}$,

WITH IONIC STRENGTH

\begin{tabular}{c|c|c|c}
\hline Exp. No. & $\begin{array}{c}\text { Initial } \\
{\left[\mathrm{Fe}^{+++}\right]} \\
\mathrm{M} / 1 \\
\times 10^{5}\end{array}$ & $\begin{array}{c}\text { Ionic } \\
\text { Strength } \\
(\mu)\end{array}$ & $\begin{array}{c}\mathrm{k}_{1} \\
\left(1 . \mathrm{M}^{-1} \mathrm{I}_{\mathrm{min}}-\mathrm{I}\right)\end{array}$ \\
\hline 35 & 10.0 & 0.269 & 492 \\
39 & 2.0 & 0.075 & 1240 \\
41 & 0.8 & 0.075 & 1370 \\
44 & 4.0 & 0.269 & 529 \\
45 & 4.0 & 0.139 & 742 \\
46 & 4.0 & 0.061 & 1220 \\
47 & 4.0 & 0.033 & 1640 \\
48 & 4.0 & 0.017 & 2270 \\
49 & 4.0 & 0.005 & 3440 \\
\hline
\end{tabular}


- $69-$

FIGURE 9

VARIATION OF THE SECOND ORDER RATE CONSTANT, $\mathrm{k}_{1}$, WITH THE IONIC STRENGTH

$--\square--$ See $r e f .(32)$, (33) 


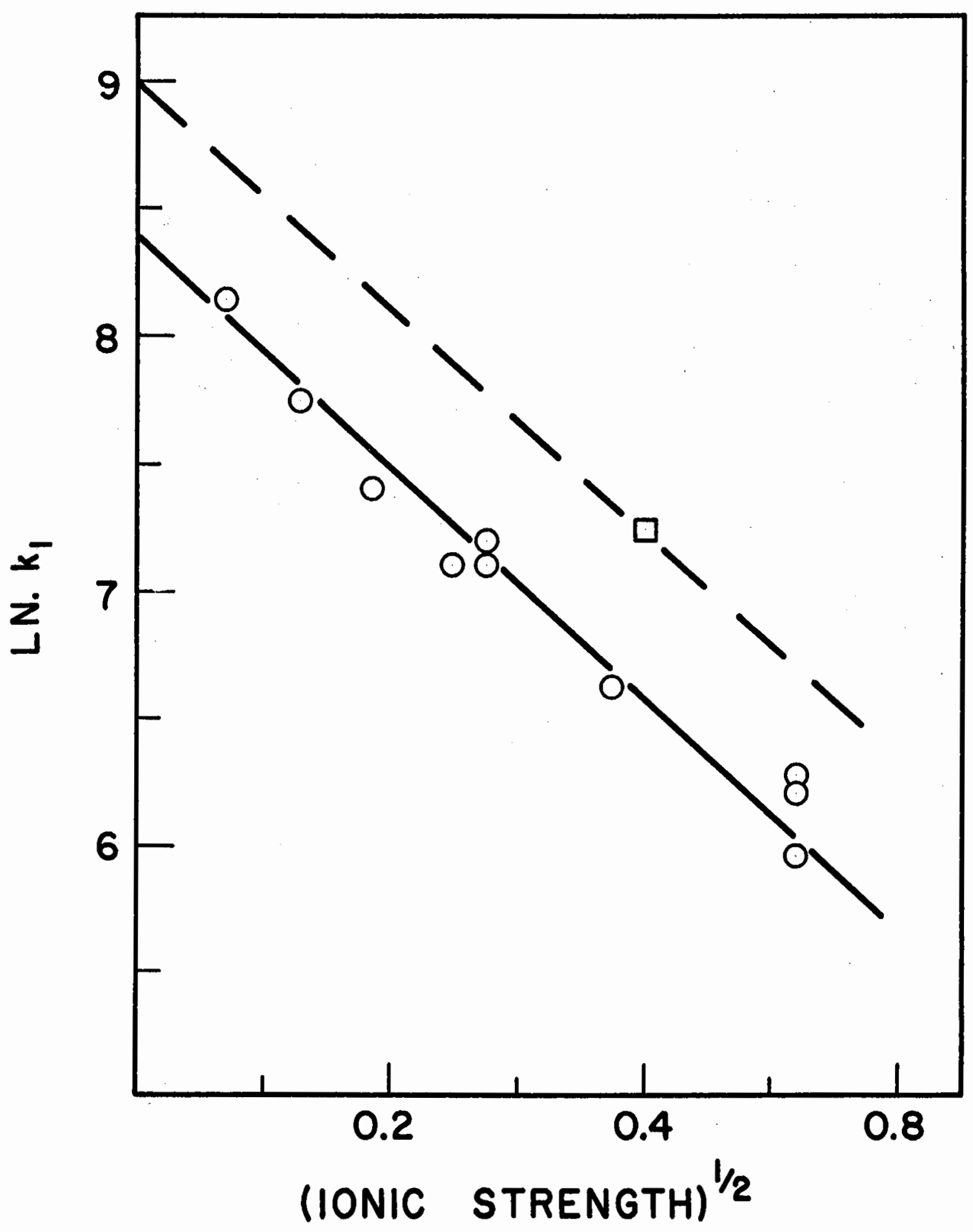


and would not be expected to change very much with thioglycolic acid concentration. However, substantially the same observations were made when low concentrations of sulphuric acid were added to control the $\mathrm{pH}$ of the reaction mixture (Table XVII). Again, change of thioglycolic acid concentration had no significant effect upon the initial rate, while the rate of reaction decreased more rapidly with time as the inftial concentration of the mercaptan was decreased in the presence of excess persulphate.

Variation of initial persulphate concentration had no effect upon the slope of semi-logarithmic plots of persulphate concentration against time. On the other hand, the reaction rate was shown to be directly proportional to the concentration of dissolved iron (Tables XVIII and XIX). In Figure 10, the Inear plot of the pseudo first order rate constant, $k_{l}^{\prime}$, against the total concentration of iron in the system is seen to extrapolate to the origin, thus confirming results of earlier experiments that direct reaction of persulphate with thioglycolic acid in the absence of iron had a negligible rate relative to the rates observed in the presence of iron. Comparison of results in Tables XVII, XVIII and XIX with those in Figure 9 (Table XX) indicated that addition of sulphuric acid in small quantities did not alter significantly the observation that values of $k_{l}^{\prime} /[\mathrm{Fe}]=\mathrm{k}_{1}$ were $50 \%$ of those described by Williams et al. (32, 33). 


\section{TABLE XVII}

RATE OF DISAPPEARANCE OF THIOGLYCOLIC ACID WITH DIFFERENT

INITIAL CONCENTRATIONS OF THIOGLYCOLIC ACID

IN DILUTE SULPHURIC ACID

Conc. Potassium Sulphate $0.010 \mathrm{M} / 1$

Conc. Sulphuric Acid $0.0057 \mathrm{M} / 1$

Ionic Strength 0.038

Inftial Conc. Ferric Ion $4.0 \times 10^{-5} \mathrm{M} / \mathrm{I}$

Initial Conc. Potassium Persulphate $0.00319 \mathrm{M} / \mathrm{l}$

\begin{tabular}{|c|c|c|c|c|c|}
\hline \multicolumn{2}{|c|}{$\begin{array}{l}0.00972 \\
(\operatorname{Exp} .50)\end{array}$} & \multicolumn{2}{|c|}{$\begin{array}{c}0.00486 \\
(\operatorname{Exp} .51) \\
\end{array}$} & \multicolumn{2}{|c|}{$\begin{array}{c}0.00194 \\
(\mathrm{Exp} .52) \\
\end{array}$} \\
\hline $\begin{array}{l}\text { Time } \\
\text { (min.) }\end{array}$ & $\begin{array}{c}{[\mathrm{TSH}]} \\
\mathrm{M} / 1 \\
\times 10^{3} \\
\end{array}$ & $\begin{array}{l}\text { Time } \\
\text { (min.) }\end{array}$ & $\begin{array}{c}\text { [TSH] } \\
\mathrm{M} / 1 \\
\times 10^{3} \\
\end{array}$ & $\begin{array}{c}\text { Time } \\
(\min .)\end{array}$ & $\begin{array}{c}{[\mathrm{TSH}]} \\
\mathrm{M} / 1 \\
\times \quad 10^{3} \\
\end{array}$ \\
\hline 2.75 & 9.07 & 3.25 & 4.15 & 2.75 & 1.37 \\
\hline 5.50 & 8.22 & 6.25 & 3.36 & 5.00 & 0.86 \\
\hline 8.50 & 7.46 & 10.00 & 2.52 & 7.25 & 0.52 \\
\hline 12.25 & 6.82 & 15.00 & 1.82 & 10.00 & 0.22 \\
\hline 19.00 & 5.85 & 20.50 & 1.26 & & \\
\hline 24.25 & 5.30 & 28.25 & 0.68 & & \\
\hline 34.00 & 4.64 & & & & \\
\hline 50.25 & 4.07 & & & & \\
\hline 66.75 & 3.72 & & & & \\
\hline $\left.\min .^{-1}\right)$ & 0.066 & & 0.066 & & 0.066 \\
\hline $\left.\min .^{-1}\right)$ & 1650 & & 1650 & & 1650 \\
\hline
\end{tabular}


TABLE XVIII

RATE OF DISAPPEARANCE OF THIOGLYCOLIC ACID WITH DIFFERENT

INITIAL CONCENTRATIONS OF POTASSIUM PERSULPHATE

IN DILUTE SULPHURIC ACID

Conc. Potassium Sulphate $0.10 \mathrm{M} / 1$

Conc. Sulphuric Acid $0.0095 \mathrm{M} / \mathrm{I}$

Ionic Strength 0.272

Initial Conc. Fer ric Ion $2.0 \times 10^{-5} \mathrm{M} / 1$

Initial Conc. Thioglycolic Acid $0.00940 \mathrm{M} / \mathrm{I}$

\begin{tabular}{|c|c|c|c|c|c|c|c|}
\hline \multicolumn{8}{|c|}{ Initial Conc. Potassium Persulphate - M/l } \\
\hline \multicolumn{2}{|c|}{$\begin{array}{c}0.00800 \\
(\operatorname{Exp} .53)\end{array}$} & \multicolumn{2}{|c|}{$\begin{array}{c}0.00400 \\
(\operatorname{Exp} .54)\end{array}$} & \multicolumn{2}{|c|}{$\begin{array}{c}0.00240 \\
(\operatorname{Exp} .55)\end{array}$} & \multicolumn{2}{|c|}{$\begin{array}{c}0.00160 \\
(\operatorname{Exp} .56)\end{array}$} \\
\hline $\begin{array}{l}\operatorname{Time} \\
(\min .)\end{array}$ & $\begin{array}{c}\text { [TSH] } \\
\mathrm{M} / 1 \\
\times \quad 10^{3} \\
\end{array}$ & $\begin{array}{c}\operatorname{Tim} \theta \\
(\min .)\end{array}$ & $\begin{array}{c}{[\mathrm{TSH}]} \\
\mathrm{M} / 1 \\
\times \quad 10^{3} \\
\end{array}$ & $\begin{array}{c}\text { Time } \\
(\min .)\end{array}$ & $\begin{array}{c}{[\mathrm{TSH}]} \\
\mathrm{M} / 1 \\
\times 10^{3} \\
\end{array}$ & $\begin{array}{c}\text { Time } \\
\text { (min.) }\end{array}$ & $\begin{array}{c}{[\mathrm{TSH}]} \\
\mathrm{M} / 1 \\
\times 10^{3} \\
\end{array}$ \\
\hline 3.75 & 9.06 & 2.75 & 9.29 & 5.0 & 9.34 & 7.0 & 9.32 \\
\hline 8.50 & 8.55 & 8.50 & 8.85 & 18.0 & 8.75 & 14.0 & 9.23 \\
\hline 14.50 & 7.69 & 23.75 & 8.00 & 42.0 & 7.97 & 39.0 & 8.65 \\
\hline 23.25 & 6.76 & 36.50 & 7.25 & 64.5 & 7.55 & 67.0 & 8.09 \\
\hline 30.25 & 5.90 & 51.00 & 6.66 & 96.0 & 6.88 & 92.0 & 7.83 \\
\hline 42.00 & 4.71 & 70.00 & 5.98 & 125.0 & 6.43 & 126.0 & 7.42 \\
\hline 54.75 & 3.72 & 91.00 & 5.30 & 165.0 & 5.95 & 160.0 & 7.10 \\
\hline 67.50 & 2.67 & 120.00 & 4.50 & & & & \\
\hline 80.25 & 1.96 & 151.00 & 3.88 & & & & \\
\hline 92.75 & 1.36 & & & & & & \\
\hline$\left(.^{-1}\right)$ & .00782 & & 00794 & & 00782 & & .00794 \\
\hline$\left(n .^{-1}\right)$ & 391 & & 397 & & 391 & & 397 \\
\hline
\end{tabular}




\section{TABIE XIX}

RATE OF DISAPPEARANCE OF THIOGLYCOLIC ACID WITH DIFFERENT

INITIAL CONCENTRATIONS OF FERRIC ION

IN DILUTE SULPHURIC ACID

Gonc. Potassium Sulphate $0.10 \mathrm{M} / \mathrm{I}$

Conc. Sulphuric Acid $0.0095 \mathrm{M} / 1$

Ionic Strength 0.272

Initial Conc. Potassium Persulphate $0.00400 \mathrm{M} / 1$

Initial Conc. Thioglycolic Acid $0.00935 \mathrm{M} / 1$

\begin{tabular}{|c|c|c|c|c|c|}
\hline \multicolumn{6}{|c|}{ Initial Conc. Ferric Ion - M/I } \\
\hline \multicolumn{2}{|c|}{$\begin{array}{r}0.8 \times 10^{-5} \\
(E \times p .57) \\
\end{array}$} & \multicolumn{2}{|c|}{$\begin{array}{r}4.0 \times 10^{-5} \\
(\operatorname{Exp} .58)\end{array}$} & \multicolumn{2}{|c|}{$\begin{array}{c}10.0 \times 10^{-5} \\
(\operatorname{Exp} .59)\end{array}$} \\
\hline $\begin{array}{l}\text { Time } \\
(\min .)\end{array}$ & $\begin{array}{c}{[\mathrm{TSH}]} \\
\mathrm{M} / 1 \\
\times 10^{3} \\
\end{array}$ & Time $)$ & $\begin{array}{c}{[\mathrm{TSH}]} \\
\mathrm{M} / 1 \\
\times 10^{3} \\
\end{array}$ & $\begin{array}{c}\text { Time } \\
(\min .)\end{array}$ & $\begin{array}{c}{[\mathrm{TSH}]} \\
\mathrm{M} / 1 \\
\times 10^{3} \\
\end{array}$ \\
\hline 5.0 & 9.16 & 6.0 & 8.44 & 2.5 & 8.48 \\
\hline 11.0 & 9.11 & 12.0 & 7.78 & 5.0 & 7.62 \\
\hline 20.5 & 8.65 & 24.0 & 6.63 & 8.5 & 6.91 \\
\hline 42.0 & 8.23 & 33.0 & 6.03 & 13.0 & 6.04 \\
\hline 75.0 & 7.57 & 44.0 & 5.21 & 18.0 & 5.23 \\
\hline 143.5 & 6.22 & 55.0 & 4.72 & 23.0 & 4.50 \\
\hline 203.5 & 5.33 & 76.5 & 3.68 & 30.0 & 3.89 \\
\hline 272.5 & 4.52 & 111.0 & 2.88 & 36.5 & 3.30 \\
\hline \multirow[t]{2}{*}{310.0} & 4.17 & 137.5 & 2.19 & 44.0 & 2.94 \\
\hline & & & & 56.5 & 2.45 \\
\hline \multicolumn{2}{|c|}{$i^{\prime}\left(\min .^{-1}\right) .00329$} & \multicolumn{3}{|c|}{.01640} & .0398 \\
\hline $\min .^{-1}$ & 410 & \multicolumn{3}{|c|}{410} & 398 \\
\hline
\end{tabular}


FIGURE 10

EFFECT OF DIFFERENT INITIAL CONCENTRATIONS OF FERRIC ION ON $k_{l}^{\prime}$, THE PSEUDO FIRST ORDER RATE CONSTANT

Initial Conc. $\mathrm{S}_{2} \mathrm{O}_{8}=0.00400 \mathrm{M} / \mathrm{I}$

Initial Conc. TSH $0.00935 \mathrm{M} / 1$

Ionic Strength 0.272 


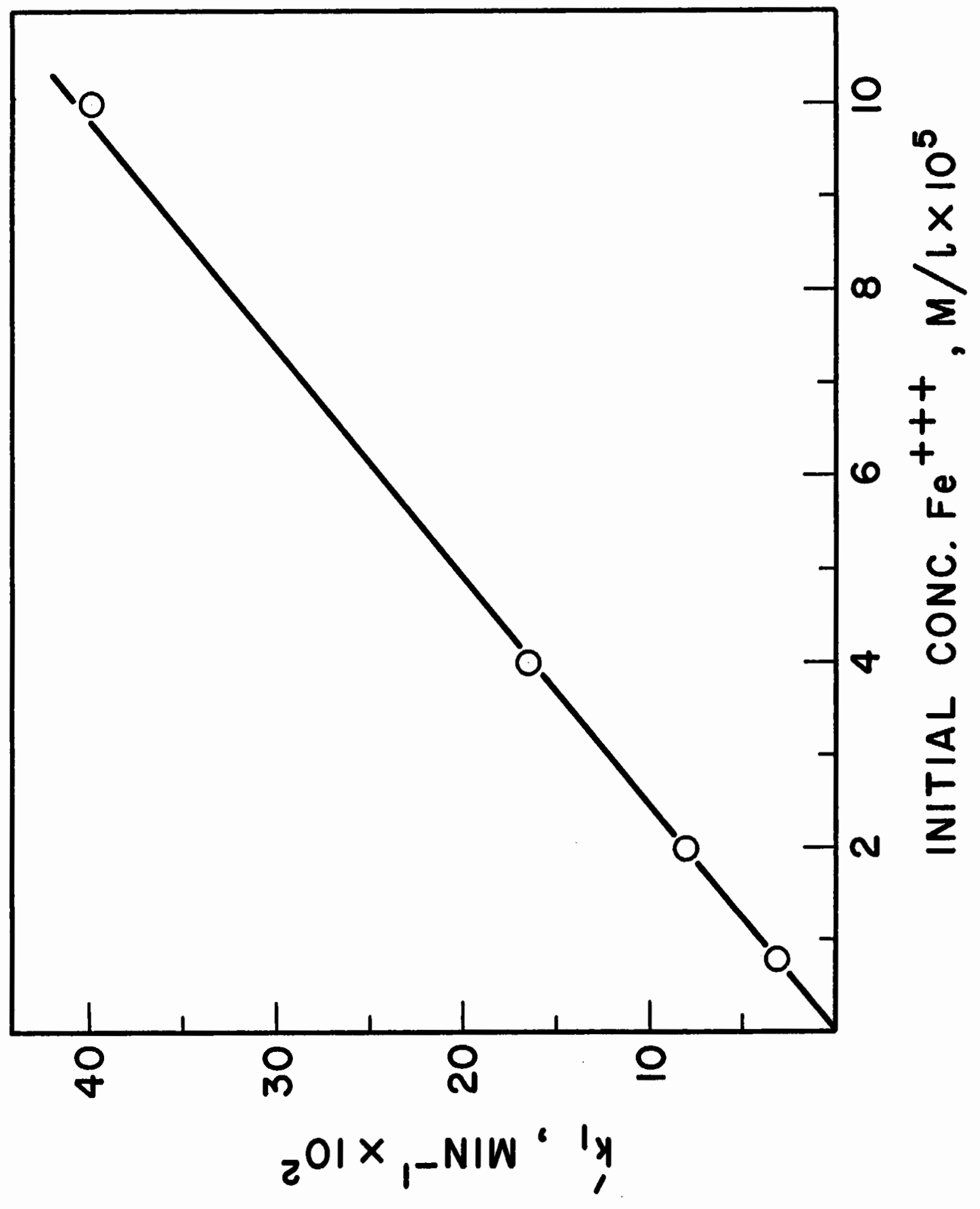


TABIE XX

VARIATION OF THE SECOND ORDER RATE CONSTANT, $k_{1}$, WITH IONIC STRENGTH IN DILUTE SULPHURIC ACID

\begin{tabular}{c|c|c|c|c|c}
\hline Exp.No. & $\begin{array}{c}\text { Initia }] \\
{\left[\mathrm{Fe}^{+++}\right]} \\
\mathrm{x} 10^{5}\end{array}$ & $\begin{array}{c}{\left[\mathrm{H}_{2} \mathrm{SO}_{4}\right]} \\
\mathrm{M} / 1\end{array}$ & $\begin{array}{c}\text { Ionic } \\
\text { Strength } \\
(\mu)\end{array}$ & $\begin{array}{c}\mathrm{k}_{1} \\
\left(1 . \mathrm{M}^{-1}{ }_{\mathrm{min}}^{-1}\right)\end{array}$ & $\begin{array}{c}\mathrm{k}_{1}{ }^{*} \\
50-52\end{array}$ \\
4.0 & 0.0057 & 0.038 & 1650 & 1740 \\
$53-56$ & 2.0 & 0.0095 & 0.272 & 394 & 448 \\
57 & 0.8 & 0.0095 & 0.272 & 410 & 448 \\
58 & 4.0 & 0.0095 & 0.272 & 410 & 448 \\
59 & 10.0 & 0.0095 & 0.272 & 398 & 448 \\
\hline
\end{tabular}

* See Figure 9. 
However, when the concentration of sulphuric acid in the reaction mixture was increased to $0.10 \mathrm{M}$, the reaction rate was decreased to a greater extent than could be explained in terms of a change in ionic strength (Tables XXI and XXII). Also, the semi-logarithmic plots of persulphate concentration against time were no longer linear, and the values of $k_{l}^{\prime}$ and $\mathrm{k}_{1}$ increased with increasing initial concentration of thioglycolic acid and decreased with increasing initial persulphate concentration. In Figures 11 and 12 the logarithms of the initial reaction rates are plotted against the initial concentration of one of the reactants when the initial concentration of the other reactant was kept constant. From these plots it may be concluded that the reaction was 0.50 order in respect of initial persulphate concentration and 0.44 order in respect of initial mercaptan concentration. For the experiments in which the initial persulphate concentration was varied the iron was initially in the ferric state, and it was observed that the reaction was preceded by a short induction period. In the other experiments in which the initial mercaptan concentration was varied, the iron was initially in the ferrous state, and there was no induction period. In the former case, the rate of reaction, after this induction effect had disappeared, was taken as the initial rate, and similarly the pseudo first order rate constants, $k_{l}^{\prime}$, were determined for the faster reaction which followed the induction period. 


\section{$\underline{\text { TABLE XXI }}$}

RATE OF DISAPPEARANCE OF THIOGLYCOLIC ACID WITH DIFFERENT

INITIAL CONCENTRATIONS OF THIOGLYCOLIC ACID

IN $0.10 \mathrm{M}$ SULPHURIC ACID

\section{Ionic Strength 0.155}

Initial Conc. Ferrous Ion $2.0 \times 10^{-5} \mathrm{M} / \mathrm{I}$

Initial Conc. Potassium Persulphate $0.00400 \mathrm{M} / 1$

\begin{tabular}{|c|c|c|c|c|c|c|c|}
\hline (Exp. & 64) & (Exp. & 65) & ( $\mathrm{Fxp}$. & 66) & (Exp & $67)$ \\
\hline $\begin{array}{l}\text { Time } \\
(\min .)\end{array}$ & $\begin{array}{c}{[\mathrm{TSH}]} \\
\mathrm{M} / 1 \\
\times \quad 10^{3} \\
\end{array}$ & $\begin{array}{c}\text { Time } \\
\text { (min.) }\end{array}$ & $\begin{array}{c}{[\mathrm{TSH}]} \\
\mathrm{M} / 1 \\
\times \quad 10^{3} \\
\end{array}$ & $\begin{array}{c}\text { Time } \\
(\min .)\end{array}$ & $\begin{array}{c}{[\mathrm{TSH}]} \\
\mathrm{M} / 1 \\
\times 10^{3} \\
\end{array}$ & $\begin{array}{l}\text { Time } \\
(\min .)\end{array}$ & $\begin{array}{c}{[\mathrm{TSH}]} \\
\mathrm{M} / \mathrm{I} \\
\times 10^{3} \\
\end{array}$ \\
\hline 4.0 & 14.65 & 6.0 & 9.59 & 3.5 & 5.00 & 3.0 & 2.09 \\
\hline 12.0 & 14.05 & 14.0 & 9.12 & 10.5 & 4.59 & 7.5 & 2.01 \\
\hline 26.5 & 13.03 & 28.0 & 8.23 & 23.5 & 4.00 & 18.5 & 1.59 \\
\hline 44.5 & 11.88 & 47.0 & 7.20 & 41.5 & 3.37 & 33.0 & 1.19 \\
\hline 65.0 & 10.80 & 68.0 & 6.24 & 67.5 & 2.33 & 45.5 & 0.96 \\
\hline 99.0 & 9.50 & 101.5 & 5.03 & 86.0 & 1.88 & 59.5 & 0.83 \\
\hline 122.0 & 8.71 & 135.5 & 4.15 & 101.0 & 1.57 & 74.0 & 0.63 \\
\hline 160.0 & 8.22 & 163.5 & 3.69 & 115.5 & 1.30 & & \\
\hline
\end{tabular}

Initial

\begin{tabular}{|c|c|c|c|}
\hline $\begin{array}{l}-\frac{\mathrm{d}\left[\mathrm{S}_{2 \mathrm{O}_{8}}\right]}{\mathrm{dt}} 3.80 \times 10^{-5} \\
\left(\mathrm{M} .1 .^{\left.-I_{\min }{ }^{-I}\right)}\right.\end{array}$ & $3.15 \times 10^{-5}$ & $2.43 \times 10^{-5}$ & $1.65 \times 10^{-5}$ \\
\hline$k_{1}^{\prime}\left(\min .^{-1}\right)$ & .00920 & .00630 & .00414 \\
\hline $\mathrm{k}_{1}\left(\mathrm{I} . \mathrm{M}^{-1} \mathrm{~min}^{-1}\right) 503$ & 460 & 315 & 207 \\
\hline
\end{tabular}


TABLE XXII

RATE OF DISAPPEARANCE OF THIOGLYCOLIC ACID WITH DIFFERENT

INITIAL CONCENTRATIONS OF POTASSIUM PERSULPHATE

IN $0.10 \mathrm{M}$ SULPHURIC ACID

Ionic Strength 0.155

Initial Conc. Ferric Ion $2.0 \times 10^{-5} \mathrm{~m} / \mathrm{I}$

Initial Conc. Thioglycolic Acid $0.00490 \mathrm{M} / \mathrm{l}$

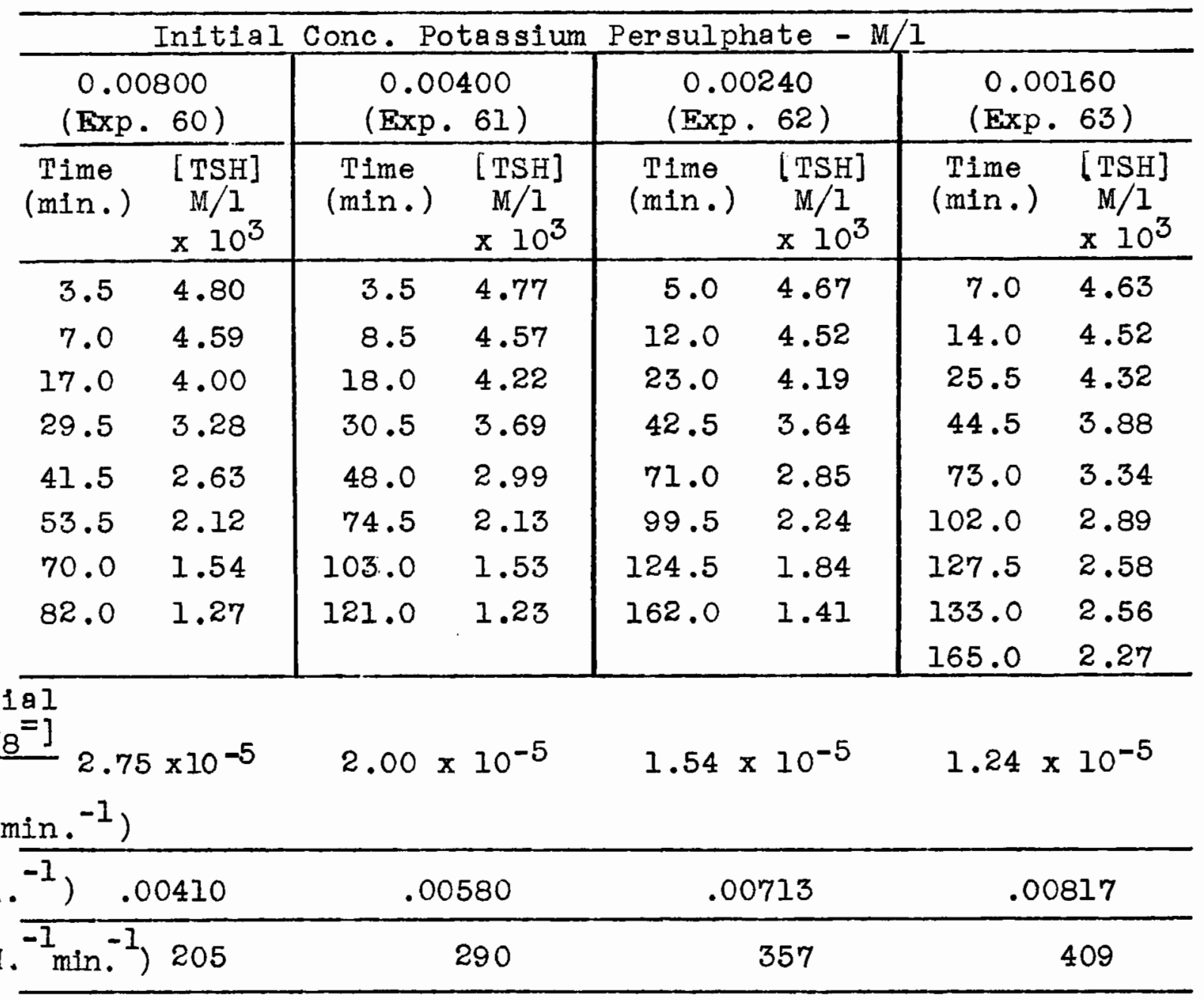


FIGURES 11, 12

Figure II

EFFECT OF DIFFERENT INITIAL CONCENTRATIONS OF

THIOGLYCOLIC ACID ON THE INITIAL RATE OF DISAPPEARANCE

OF PERSULPHATE IN $0.10 \mathrm{M}$ SULPHURIC ACID

Initial Conc. $\mathrm{S}_{2} \mathrm{O}_{8}=0.00400 \mathrm{M} / 1$

Figure 12

EFFECT OF DIFFERENT INITIAL CONCENTRATIONS OF

PFRSULPHATE ON THE INITIAL RATE OF DISAPPEARANCE

OF PERSULPHATE IN $0.10 \mathrm{M}$ SULPHURIC ACID

Initial Conc. TSH $0.00490 \mathrm{~m} / 1$ 

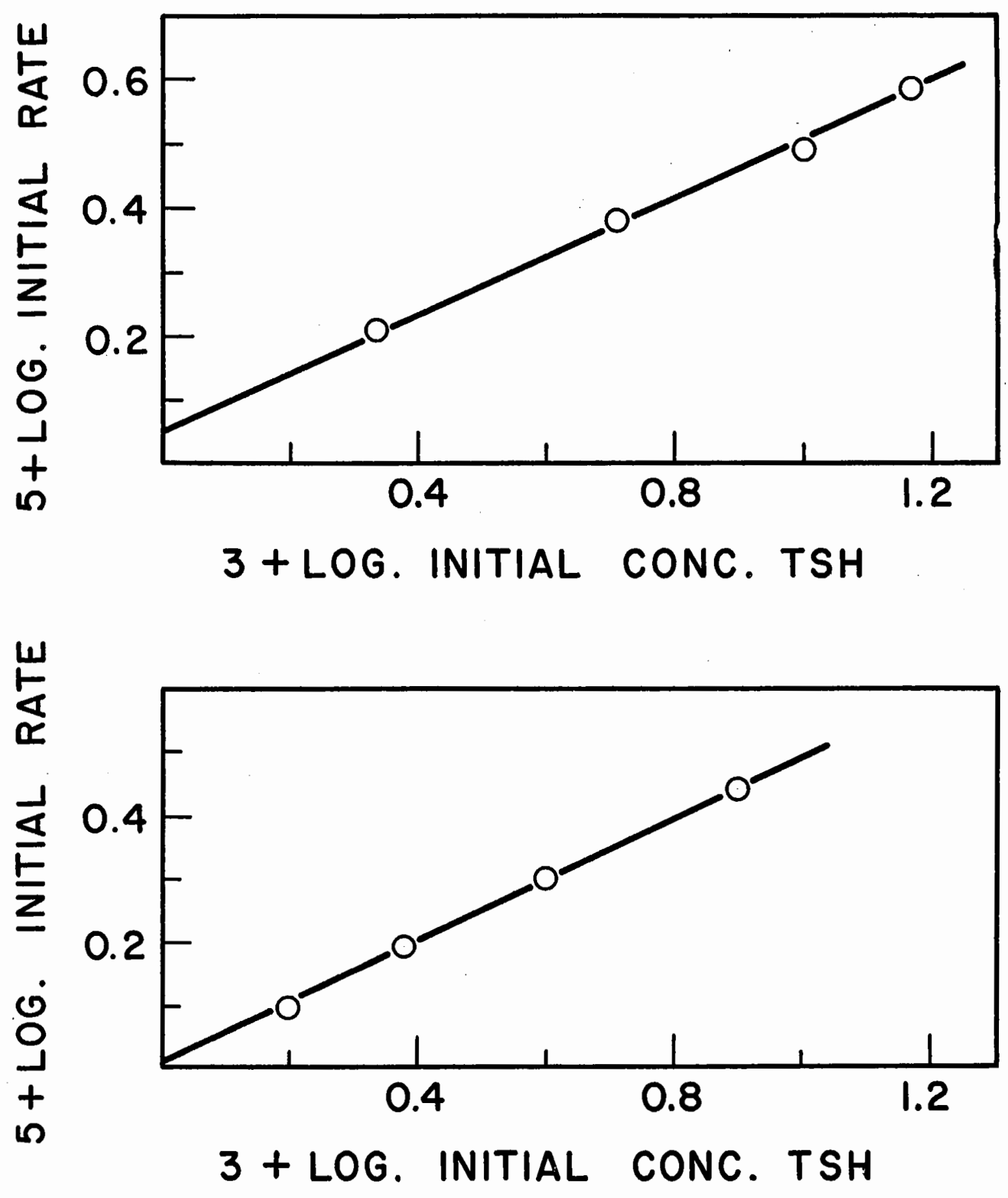
Thus, it appeared that, with the higher concentration of acid present, the reaction of ferric ion with thioglycolic no longer proceeded at a rate that far exceeded that of the reaction between persulphate and ferrous ion.

This conclusion prompted an investigation of the reaction of ferric ion with thioglycolic acid in acidic solution. Earlier investigations of this system (103, 105, 107) suggested that the rate of this reaction was markedly catalyzed by hydrogen Ion and was almost instantaneous in strongly acid solution, although practicaliy no rate measurements had been made at pH values less than 4. However, the present study showed that the rate could be measured in $0.0142 \mathrm{M}$ sulphuric acid provided the initial concentrations of ferric ion and of thioglycolic acid were low.

The reaction was followed by periodically adding $10 \mathrm{ml}$. aliquots of the reaction mixture (ferric ion solution and thioglycolic acid solution) to $2 \mathrm{ml}$. of $2 \mathrm{M}$ hydrochloric acid and $5 \mathrm{ml}$. of $2 \mathrm{M}$ potassium thiocyanate solutions 1 n $25 \mathrm{ml}$. volumetric flasks and diluting to the mark with water. The concentration of ferric ion was then estimated from the optical density of the red ferric ion - thiocyanate complex. For this purpose a calibration curve to relate optical density to concentration of ferric ion had first to be established. A standard solution of ferric ion was obtained by adding aliquots of standard persulphate solution to an excess of ferrous ion. 
Various amounts of this solution were then added to the hydrochloric acid and thiocyanate solutions for estimation of the optical densities. Preparation of the standard ferric Ion solutions by addition of standard permanganate or standard ceric ion solutions to excess ferrous ion yielded identical results.

The results obtained for the rate of the ferric ion thioglycolic acid reaction are shown in Table XXIII and Figure 13. The reaction velocity was observed to decrease with time much more rapidly than for a second order process, and the measurement of initial rates was difficult. However, the values obtained indicated that the initial rate was given by the following expression.

$$
-\frac{d[f e r r i c]}{d t}=k_{4}^{\prime \prime \prime}[\text { ferric }]^{2}[\mathrm{TSH}]^{2}
$$

where [ferric] represents the total concentration of ferric Ion in the system, in contrast to $\left[\mathrm{Fe}^{+++}\right]$which represents the concentration of free or uncomplexed ferric ion. Integration of the fourth order rate expression yielded the following relation,

$$
k_{4} t=\frac{2.3}{(b-a)^{2}}\left\{\log _{10} \frac{b(a-2 x)}{a(b-2 x)}+\frac{b-a}{2}\left[\frac{1}{a-2 x}-\frac{1}{a}+\frac{1}{b-2 x}-\frac{1}{b}\right]\right\}
$$

where a represents the initial concentration of ferric ion and $b$ represents the initial concentration of mercaptan. 


\section{TABLE XXIII}

RATE OF REACTION OF FERRIC ION WITH THIOGLYCOLIC ACID WITH DIFFERENT INITIAL CONCENTRATIONS OF FERRIC ION AND THIOGLYCOLIC ACID

\begin{tabular}{|c|c|c|c|c|c|c|c|c|c|c|}
\hline \multicolumn{11}{|c|}{ Conc. Sulphuric Acid - $M / I$} \\
\hline \multicolumn{3}{|c|}{0.030} & \multicolumn{3}{|c|}{0.030} & 0.030 & \multicolumn{2}{|l|}{0.020} & \multicolumn{2}{|l|}{0.010} \\
\hline \multicolumn{11}{|c|}{ Conc. Thioglycolic Acid - M/I } \\
\hline \multicolumn{3}{|c|}{$\begin{array}{c}5.00 \times 10^{-5} \\
(\mathrm{Exp} .68)\end{array}$} & \multicolumn{3}{|c|}{$\begin{array}{c}8.32 \times 10^{-5} \\
(\text { Exp. } 69)\end{array}$} & $\begin{array}{c}5.00 \times 10^{-5} \\
(\mathrm{Exp} .70)\end{array}$ & \multicolumn{2}{|c|}{$\begin{array}{c}5.00 \times 10^{-5} \\
(\mathrm{Exp} .71) \\
\end{array}$} & \multicolumn{2}{|c|}{$\begin{array}{c}5.00 \times 10^{-5} \\
(\mathrm{Exp} .72)\end{array}$} \\
\hline \multicolumn{3}{|c|}{ 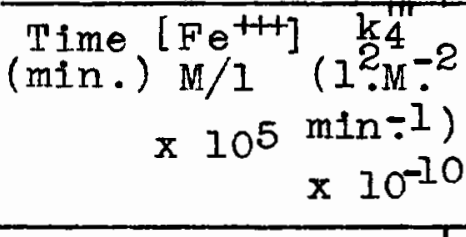 } & \multicolumn{3}{|c|}{$\begin{array}{rc}\text { Time }\left[\mathrm{Fe}^{++}\right] & \mathrm{k}_{4}^{\prime \prime} \\
(\min .) \mathrm{M} / 1 & \left(1^{2} \cdot \mathrm{M}^{-2}\right. \\
\times & \left.10^{5} \min ^{-1}\right) \\
& \times 10^{-10}\end{array}$} & 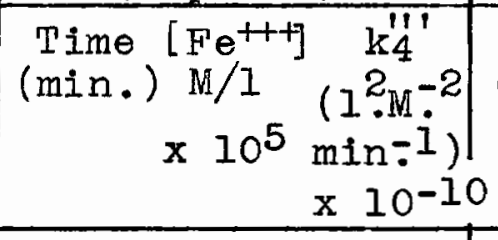 & \multicolumn{2}{|c|}{ 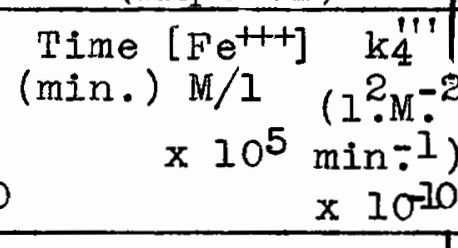 } & \multicolumn{2}{|c|}{$\begin{array}{l}\text { Time }\left[\mathrm{Fe}^{+++}\right] \mathrm{k}^{\prime \prime \prime} \\
(\min .) \mathrm{M} / 1=\left(1 . \mathrm{M}^{-2}\right. \\
\left.\times 10^{5} \min ^{-1}\right) \\
\times 10^{-10}\end{array}$} \\
\hline 0.00 & 11.20 & & 0.00 & 11.20 & & $0.00 \quad 5.50$ & 0.0011 .20 & & 0.0011 .20 & \\
\hline 3.75 & 9.81 & 6.61 & 2.75 & 9.64 & 9.45 & $3.25 \quad 5.23$ & $3.25 \quad 9.45$ & 15.1 & $2.25 \quad 7.83$ & 107.0 \\
\hline 10.00 & 9.26 & 6.40 & 7.50 & 8.61 & 5.74 & $9.25 \quad 4.97$ & $8.75 \quad 8.51$ & 14.2 & $7.00 \quad 7.23$ & 70.3 \\
\hline 22.75 & 8.44 & 6.23 & 16.00 & 7.70 & 5.07 & $19.75 \quad 4.57$ & $16.25 \quad 7.81$ & 15.3 & $13.50 \quad 6.78$ & 76.3 \\
\hline 38.50 & 8.06 & 5.40 & 27.00 & 6.94 & 5.41 & 43.003 .98 & $31.25 \quad 7.21$ & 16.3 & $23.75 \quad 6.74$ & 45.3 \\
\hline 63.50 & 7.52 & 6.14 & 55.00 & 6.31 & 4.32 & $62.25 \quad 3.85$ & $51.75 \quad 7.07$ & 12.1 & 45.00 & 34.4 \\
\hline 77.75 & 7.36 & 6.23 & 75.00 & 5.80 & 4.93 & $85.00 \quad 3.45$ & 78.25 & 10.3 & & \\
\hline
\end{tabular}




\section{FIGURE 13}

\section{EFFECT OF DIFFERENT INITIAL CONCENTRATIONS OF \\ FERRIC ION, OF THIOGLYCOLIC ACID AND OF SULPHURIC ACID ON \\ THE RATE OF REACTION OF FERRIC ION WITH THIOGLYCOLIC ACID}
O Exp. 68
口 " 69
$\Delta \quad " 70$
- $\quad 71$ 


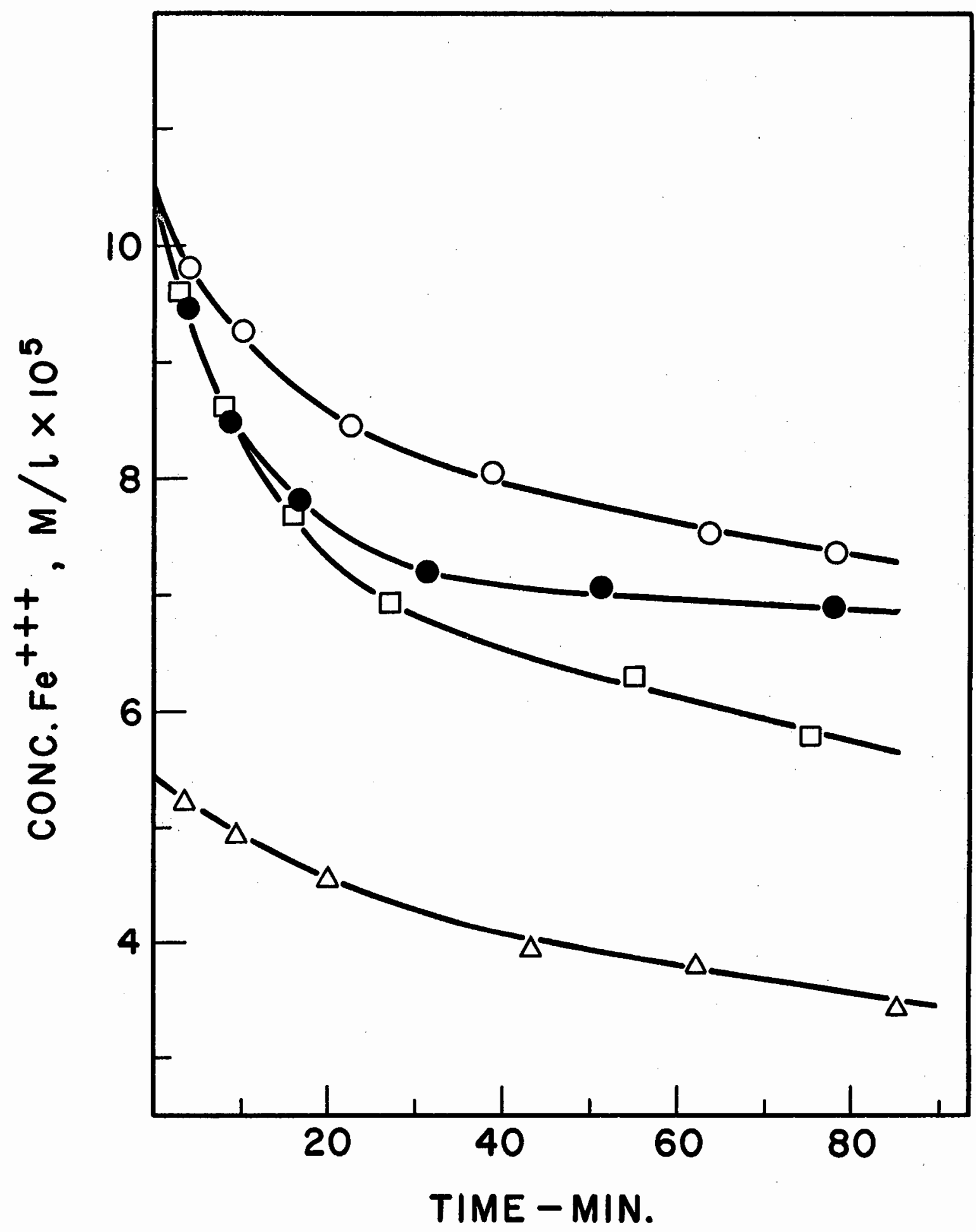


The values of $k_{4}^{\prime \prime}$ calculated from this expression were not constant and, except in one case, decreased with time. However, unless initial conditions are known with excellent precision, the calculated values of $k_{4}^{\prime \prime \prime}$ would not be very reliable and would probably show a drift. The concentration of sulphuric acid had a marked effect upon the rate constant, the reaction velocity decreasing with increase in sulphuric acid concentration.

By working in $0.10 \mathrm{M}$ sulphuric acid, the reaction was slowed down sufficientiy to enable a large excess of thioglycolic acid over ferric ion to be used, so that the concentration of the former might be taken to be constant during the reaction. Complexes of ferric ions with sulphate ions absorb light quite strongly at $305 \mathrm{~m} \mu$ and the association constants indicate that practically $100 \%$ of the ferric ion should be complexed in this way in $0.10 \mathrm{M}$ sulphuric acid (119), i.e. $\quad[$ ferric $]=\left[\mathrm{FeSO}_{4}{ }^{+}\right]+\left[\mathrm{Fe}\left(\mathrm{SO}_{4}\right)_{2}^{-}\right]$

After preparing a reaction mixture, a sample was placed in a Beckmann DK spectrophotometer and a record of optical density with time was taken at $305 \mathrm{~m} \mu$. Experiments were made to study the effect of initial concentrations of both reactants, ferric ion and thioglycollc acid, upon the reaction rate. The results, shown in Tables XXIV, XXV and XXVI and in Figure 14, suggest a rate of decrease of optical density, $D$, given by 


\section{TABLE XXIV}

RATE OF DECRFASE OF OPTICAL DENS ITY AT $305 \mathrm{~m} \mu$ WITH DIFFERENT

INITIAL CONCENTRATIONS OF FERRIC ION AND OF THIOGLYCOLIC ACID

Extinction Coefficient at $305 \mathrm{~m} \mu 2600 \mathrm{I} . \mathrm{M}^{-1}$

Conc. Sulphuric Acid $0.10 \mathrm{M} / 1$

\begin{tabular}{|c|c|c|c|c|c|c|c|c|c|}
\hline \multicolumn{2}{|c|}{$\begin{array}{c}0.00488 \\
(\operatorname{Exp} .73)\end{array}$} & \multicolumn{2}{|c|}{$\begin{array}{r}0.00488 \\
(\operatorname{Exp} .74) \\
\end{array}$} & \multicolumn{2}{|c|}{$\begin{array}{c}0.00488 \\
(\operatorname{Exp} .75) \\
\end{array}$} & \multicolumn{2}{|c|}{$\begin{array}{c}0.01220 \\
(\operatorname{Exp} .76) \\
\end{array}$} & \multicolumn{2}{|c|}{$\begin{array}{c}0.00488 \\
(\operatorname{Exp} .77) \\
\end{array}$} \\
\hline $\begin{array}{l}\text { Time } \\
\text { (min.) }\end{array}$ & $\begin{array}{l}\text { Optical } \\
\text { Density } \\
\text { D305 }\end{array}$ & $\begin{array}{l}\text { Time } \\
(\min .)\end{array}$ & $\begin{array}{c}\text { Optical } \\
\text { Density } \\
D_{305}\end{array}$ & $\begin{array}{l}\text { Time } \\
\text { (min.) }\end{array}$ & $\begin{array}{c}\text { Optical } \\
\text { Density } \\
D_{305}\end{array}$ & $\begin{array}{l}\text { Time } \\
(\min .)\end{array}$ & $\begin{array}{c}\text { Optical } \\
\text { Density } \\
D_{305}\end{array}$ & $\begin{array}{c}\text { Time } \\
(\min .)\end{array}$ & $\begin{array}{c}\text { Optical } \\
\text { Density } \\
D_{305}\end{array}$ \\
\hline 0.00 & 0.288 & 0.00 & 0.575 & 0.00 & 0.863 & 0.00 & 0.863 & 0.00 & 1.150 \\
\hline 1.25 & 0.273 & 1.50 & 0.497 & 1.25 & 0.709 & 1.50 & 0.319 & 1.25 & 0.900 \\
\hline 3.25 & 0.233 & 2.50 & 0.437 & 2.25 & 0.591 & 2.50 & 0.215 & 2.00 & 0.760 \\
\hline 7.25 & 0.175 & 5.00 & 0.330 & 3.75 & 0.469 & 4.00 & 0.145 & 3.25 & 0.610 \\
\hline 10.25 & 0.147 & 6.50 & 0.290 & 6.75 & 0.323 & 6.00 & 0.102 & 5.25 & 0.460 \\
\hline 14.25 & 0.118 & 10.50 & 0.216 & 9.75 & 0.242 & 8.00 & 0.080 & 7.25 & 0.370 \\
\hline \multirow[t]{3}{*}{17.25} & 0.100 & 15.00 & 0.165 & 14.25 & 0.171 & 10.00 & 0.065 & 10.25 & 0.281 \\
\hline & & 20.00 & 0.128 & 18.00 & 0.135 & 12.00 & 0.055 & 13.25 & 0.225 \\
\hline & & & & & & & & 17.00 & 0.180 \\
\hline$I_{\min }:^{1}$ & 0.367 & & 0.305 & & 0.298 & & 1.429 & & 0.271 \\
\hline$x$ & 30 & & 33.2 & & 32.0 & & 25.0 & & 29.5 \\
\hline
\end{tabular}


TABLE XXV

RATE OF DECREASE OF OPTICAL DENSITY AT $305 \mathrm{~m} \mu$ WITH DIFFERENT

INITIAL CONCENTRATIONS OF THIOGLYCOLIC ACID

Extinction Coefficient at $305 \mathrm{~m} \mu 2600$ 1.M. -1

Conc. Sulphuric Acid $0.10 \mathrm{M} / \mathrm{l}$

Initial Conc. Ferric Ion $5.55 \times 10^{-5} \mathrm{M} / \mathrm{I}$

\begin{tabular}{|c|c|c|c|c|c|c|c|c|c|c|}
\hline \multicolumn{11}{|c|}{ Initial Conc. Thloglycolic Acid - M/l } \\
\hline $\begin{array}{c}0.00488 \\
(\operatorname{Exp} .78)\end{array}$ & \multicolumn{2}{|c|}{$\begin{array}{c}0.00488 \\
\text { (Fxp. 79) } \\
\end{array}$} & \multicolumn{2}{|c|}{$\begin{array}{c}0.00732 \\
(\text { Exp. 80) } \\
\end{array}$} & \multicolumn{2}{|c|}{$\begin{array}{r}0.00976 \\
(\text { Exp. } 81) \\
\end{array}$} & \multicolumn{2}{|c|}{$\begin{array}{c}0.01220 \\
(\operatorname{Exp} .82)\end{array}$} & \multicolumn{2}{|c|}{$\begin{array}{c}0.02440 \\
(\operatorname{Exp} .83) \\
\end{array}$} \\
\hline $\begin{array}{c}\text { Time } \\
\text { (min.) Denical } \\
\\
D_{305}\end{array}$ & $\begin{array}{l}\text { Time } \\
(\min .)\end{array}$ & $\begin{array}{l}\text { Optical } \\
\text { Density } \\
D_{305}\end{array}$ & $\begin{array}{c}\text { Time } \\
(\min .)\end{array}$ & $\begin{array}{l}\text { Optical } \\
\text { Density } \\
D_{305}\end{array}$ & $\begin{array}{c}\text { Time } \\
(\min .)\end{array}$ & $\begin{array}{l}\text { Optical } \\
\text { Density } \\
D_{305}\end{array}$ & $\begin{array}{c}\text { Time } \\
(\min .)\end{array}$ & $\begin{array}{l}\text { Optical } \\
\text { Density } \\
D_{305}\end{array}$ & $\begin{array}{c}\text { Time } \\
(\min .)\end{array}$ & $\begin{array}{l}\text { Optical } \\
\text { Density } \\
\text { D }_{305}\end{array}$ \\
\hline 1.035 & 1.50 & 1.050 & 1.25 & 0.825 & 1.50 & 0.523 & 1.50 & 0.402 & 1.00 & 0.176 \\
\hline 0.909 & 2.00 & 0.929 & 1.75 & 0.674 & 2.00 & 0.416 & 2.00 & 0.318 & 1.50 & 0.123 \\
\hline 0.811 & 3.00 & 0.760 & 2.25 & 0.582 & 3.00 & 0.296 & 3.00 & 0.228 & 2.00 & 0.092 \\
\hline 0.678 & 5.00 & 0.570 & 3.25 & 0.440 & 5.00 & 0.189 & 4.50 & 0.160 & 2.50 & 0.077 \\
\hline 0.540 & 8.00 & 0.420 & 5.25 & 0.303 & 7.50 & 0.129 & 6.00 & 0.126 & 3.00 & 0.062 \\
\hline 0.386 & 12.00 & 0.305 & 9.25 & 0.186 & 10.00 & 0.097 & 7.50 & 0.103 & 3.50 & 0.054 \\
\hline 10.00 & 17.00 & 0.215 & 14.25 & 0.123 & 12.00 & 0.081 & 9.50 & 0.084 & 4.00 & 0.049 \\
\hline 12.00 & & & 18.00 & 0.100 & 14.00 & 0.70 & 12.00 & 0.069 & 5.00 & 0.040 \\
\hline & & & & & 17.00 & 0.59 & & & 8.00 & 0.029 \\
\hline 0.243 & & 0.232 & & 0.520 & & 0.960 & & 1.205 & & 5.04 \\
\hline $\begin{array}{l}1=2 \min 0^{-1} \\
\left(10^{-6}\right)\end{array}$ & & 25.1 & & 25.2 & & 25.2 & & 21.1 & & 21.8 \\
\hline
\end{tabular}




\section{TABLE XXVI}

RATE OF DECREASE OF OPTICAL DENSITY WITH DIFFERFNT

CONCENTRATIONS OF SULPHURIC ACID

Extinction Coefficient at $305 \mathrm{~m} \mu 2600$ I.M. - I

Extinction Coefficient at $325 \mathrm{~m} \mu 2000$ 1.M. -1

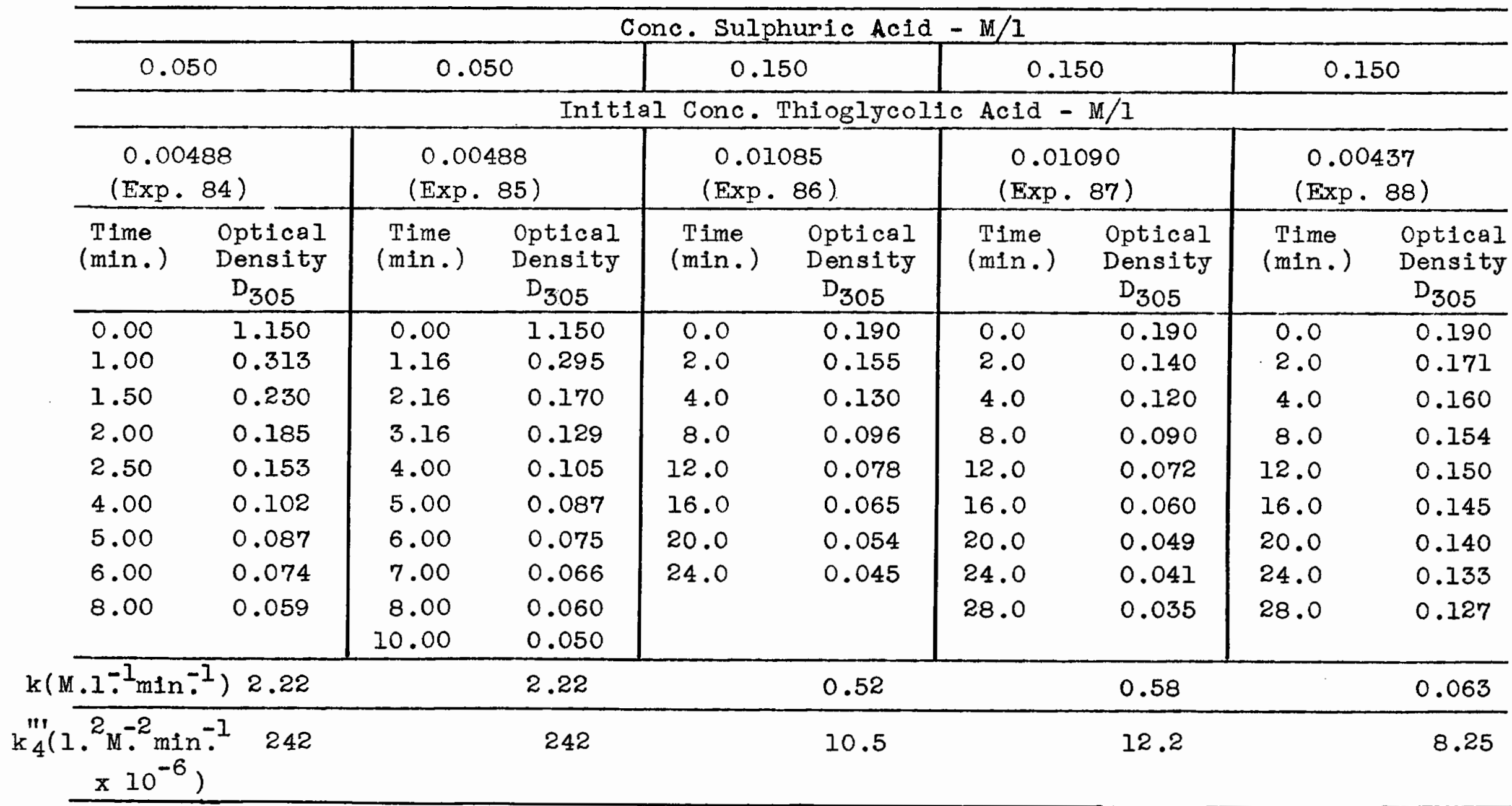


FIGURE 14

EFFECT OF DIFFERENT INITIAL CONCENTRATIONS OF

THIOGLYCOLIC ACID ON THE RATE OF REACTION OF FERRIC ION WITH THIOGLYCOLIC ACID

Conc. $\mathrm{H}_{2} \mathrm{SO}_{4} \quad 0.100 \mathrm{M} / \mathrm{I}$

O Exp. 74

$\square \quad 76$

$\triangle \quad 1 \quad 77$ 


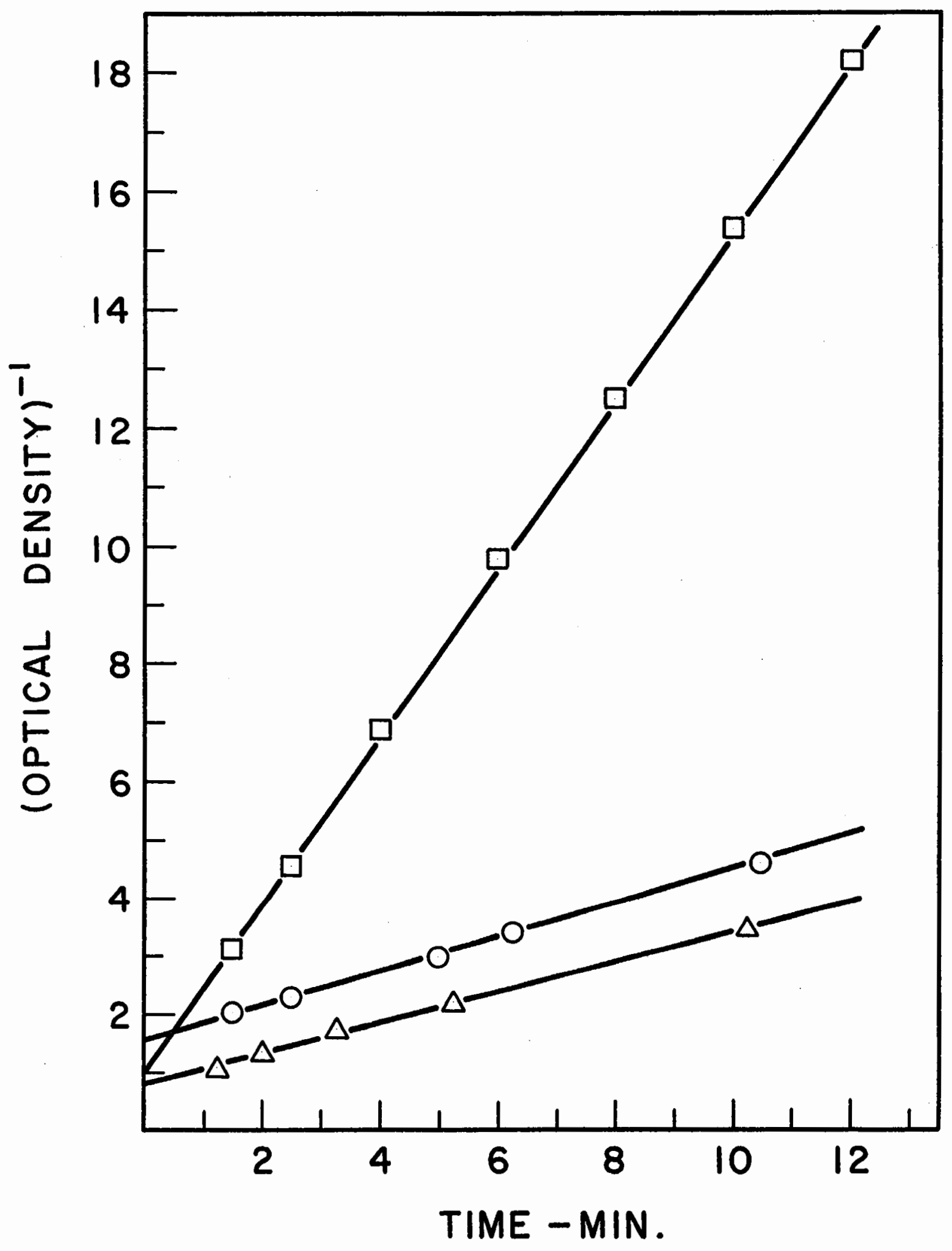




$$
-\frac{d(D)}{d t}=k(D)^{2}
$$

with rate constant, $k$, proportional to the square of the mercaptan concentration. Variation of the sulphuric acid concentration had a marked effect upon this rate constant (Table XXVII). It is suggested that the rate of disappearance of ferric ion is given by the following expression

$$
-\frac{d[\text { ferric }]}{d t}=k_{4}^{\prime \prime \prime}[\text { ferric }]^{2}[\mathrm{TSH}]^{2}
$$

and that

$$
\mathrm{k}_{4}^{\prime \prime \prime}=\frac{\epsilon \mathrm{k}}{[\mathrm{TSH}]^{2}}
$$

where $\epsilon$ represents the extinction coefficient of the ferric ion at $305 \mathrm{~m} \mu$ under these conditions.

A blue complex was observed to exist for brief periods in some of the above reaction mixtures, provided the concentrations of ferric ion and thloglycolic acid were sufficiently large. However, extrapolation of the measured optical densities at $305 \mathrm{~m} \mu$ to zero time indicated that the optical density of ferric ions was not influenced in any way by thioglycolic acid, and hence that the complexes between ferric ion and thioglycolic acid were highly dissoclated. Furthermore, this blue complex was also observed when persulphate was added to mixtures of ferrous and thioglycolic 
TABLE XXVII

VARIATION OF $k_{4}^{\prime \prime \prime}$, THE FOURTH ORDER RATE CONSTANT FOR THE FERRIC ION - THIOGLYCOLIC ACID REACTION, WITH THE CONCENTRATION OF SULPHURIC ACID

\begin{tabular}{c|c|c}
\hline Exp. Nos. & $\begin{array}{c}{\left[\mathrm{H}_{2} \mathrm{SO}_{4}\right]} \\
\mathrm{M} / 1\end{array}$ & $\begin{array}{c}\mathrm{k}_{4}^{\prime \prime \prime} \text { (average) } \\
\left(1^{2} \mathrm{M}^{-2} \mathrm{~min}^{-1}\right) \\
\mathrm{x} 0^{-6}\end{array}$ \\
\hline 84,85 & 0.050 & 242 \\
$73-83$ & 0.100 & 27.6 \\
\hline $86-88$ & 0.150 & 10.3 \\
\hline
\end{tabular}


acid in $0.10 \mathrm{M}$ sulphuric acid, provided the concentration of ferrous ion was greater than $5 \times 10^{-3} \mathrm{M}$.

The reaction of ferrous ion with persulphate was also investigated very briefly with the intention of comparing the measured values of the rate constant with those shown in Figure 9. The reaction was followed by measuring the optical density at $305 \mathrm{~m} \mu$ as a function of time in the same manner as that used for the ferric ion - thioglycolic acid reaction. The second order rate for the persulphate - ferrous ion reaction was determined from plots corresponding to the following equation (Figure 15),

$$
\log \frac{D_{\infty}-D}{D_{m}-D}=\frac{2 a-b}{2.3} k_{1} t+\log \frac{2 a}{b}
$$

where $\mathrm{D}=$ the measured optical density at time $t$

$D_{\infty}=$ the optical density when the reaction was complete $D_{m}=$ the optical density the solution would have if all the dissolved iron were ferric

$a$ = initial persulphate concentration

b = initial ferrous ion concentration.

The results are shown in Tables XXVIII and XXIX. To eliminate any effect of slight temperature fluctuations in the spectrophotometer cell for which there was no temperature control, the reactions in $0.15 \mathrm{M}$ sulphuric acid were followed by periodically removing aliquots from the reaction mixtures in the constant-temperature bath and examining these optically, 


\section{TABLE XXVIII}

RATE OF REACTION OF POTASSIUM PERSULPHATE WITH

FERROUS ION

$$
\underline{D_{m}=0.240}
$$

Initial Conc. Potassium Persulphate $7.88 \times 10^{-5} \mathrm{M} / 1$

\begin{tabular}{|c|c|c|c|}
\hline \multicolumn{4}{|c|}{ Conc. Potassium Sulphate $-M / I$} \\
\hline \multicolumn{2}{|c|}{0.000} & \multicolumn{2}{|c|}{0.100} \\
\hline \multicolumn{4}{|c|}{ Conc. Sulphuric Acid - M/I } \\
\hline \multicolumn{2}{|c|}{$\begin{array}{l}0.098 \\
(\text { Exp. 89) }\end{array}$} & \multicolumn{2}{|c|}{$\begin{array}{c}0.0098 \\
(\operatorname{Exp} .90)\end{array}$} \\
\hline $\begin{array}{l}\text { Time } \\
(\min .)\end{array}$ & $\begin{array}{c}\text { Optical } \\
\text { Density } \\
D_{305}\end{array}$ & $\begin{array}{c}\text { Time } \\
(\min .)\end{array}$ & $\begin{array}{c}\text { Optical } \\
\text { Density } \\
D_{305}\end{array}$ \\
\hline 1.25 & 0.227 & 1.00 & 0.166 \\
\hline 2.25 & 0.290 & 1.50 & 0.211 \\
\hline 4.25 & 0.334 & 2.00 & 0.250 \\
\hline \multirow[t]{6}{*}{7.25} & 0.344 & 3.00 & 0.305 \\
\hline & 0.349 & 4.00 & 0.372 \\
\hline & & 5.00 & 0.415 \\
\hline & & 8.00 & 0.430 \\
\hline & & 11.00 & 0.431 \\
\hline & & & 0.438 \\
\hline - & 782 & & \\
\hline
\end{tabular}




\section{TABLE XXIX}

RATE OF REACTION OF POTASS IUM PERSULPHATE

WITH FERROUS ION

Conc. Sulphuric Acid $0.150 \mathrm{M} / 1$

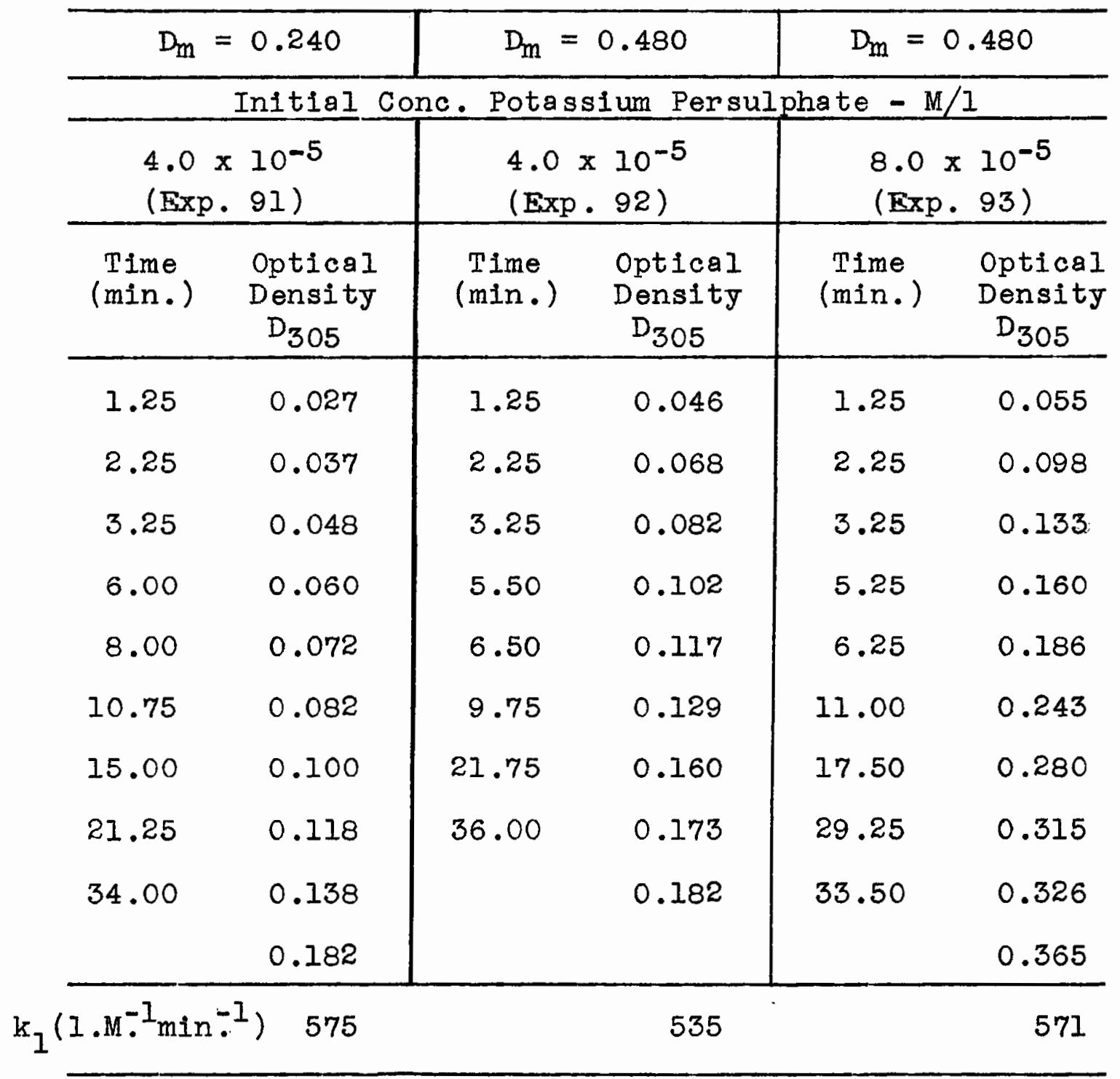


FIGURE 15

EFFECT OF DIFFERENT INITIAL CONCENTRATIONS OF PERSULPHATE

AND OF FERROUS ION ON THE RATE OF REACTION OF

PERSULPHATE WITH FERROUS ION

Conc. $\mathrm{H}_{2} \mathrm{SO}_{4} \quad 0.15 \mathrm{M} / \mathrm{I}$

- Exp.91

口 " $\quad 92$

- $\quad$ n 93 


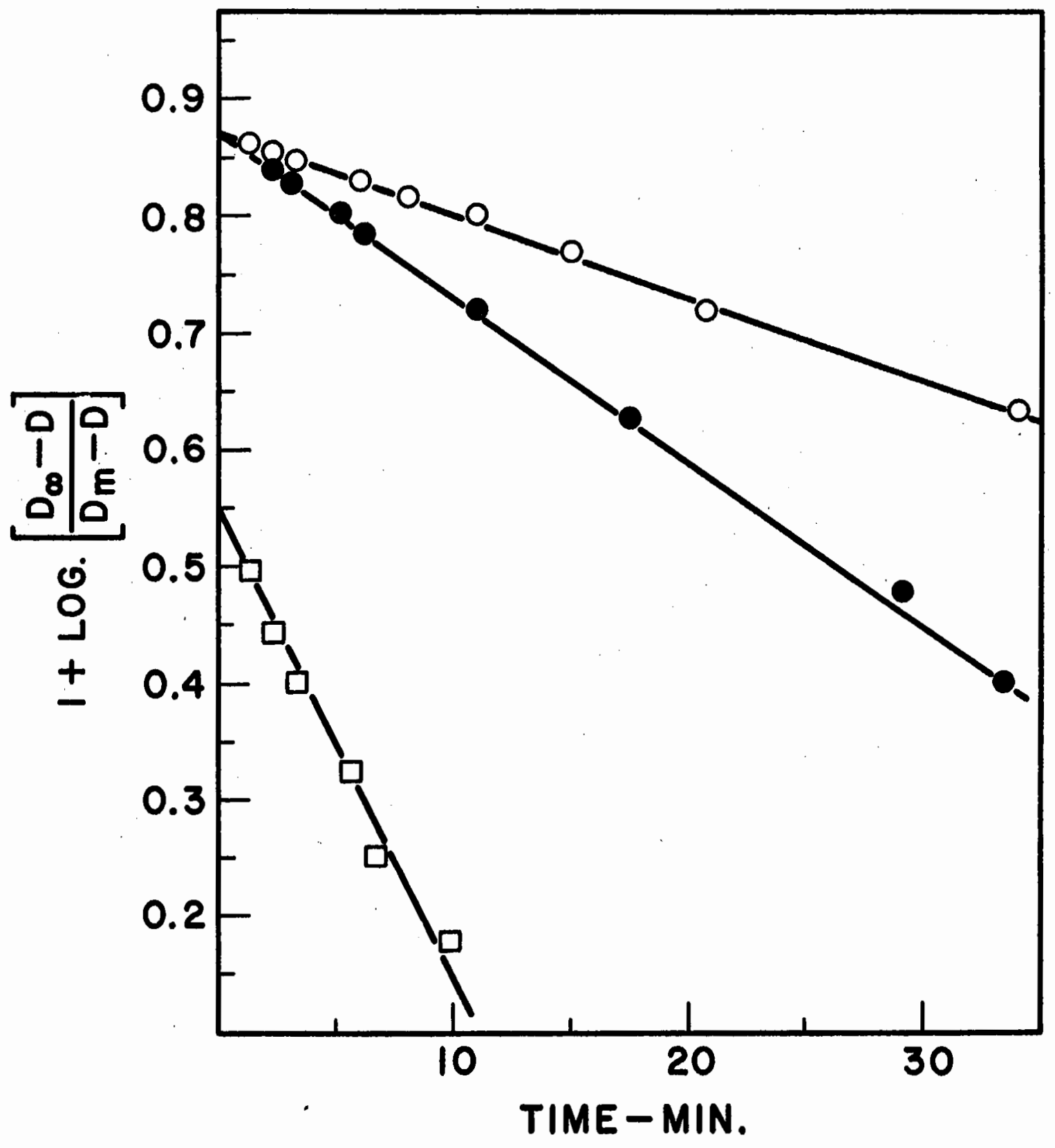


rather than by placing a sample of the reaction mixture in the spectrophotometer and leaving it there for the duration of the experiment.

In Table XXX the measured rate constants for the ferrous Ion - persulphate reaction are compared with values of $k_{1}$ (Figure 9) for the iron catalyzed reaction of persulphate with thioglycolic acid under similar conditions, and the agreement appears to be very good. Hence, support is given to the assumption that in all the reaction mixtures of the latter type, except those in which the sulphuric acid concentration was $0.10 \mathrm{M}$, the rate controlling step was reaction of persulphate with ferrous ion.

The results for the persulphate - mercaptan reactions in $0.10 \mathrm{M}$ sulphuric acid proved to be very thought provoking for the following reason. The rate of reaction of $5 \times 10^{-3} \mathrm{M}$ persulphate with $2 \times 10^{-5} \mathrm{M}$ ferrous ion is given by

$$
\text { Rate }=k_{1}\left[\mathrm{~S}_{2} \mathrm{O}_{8}=\right]\left[\mathrm{Fe}^{++}\right]=5.13 \times 10^{-5} \mathrm{M} .1 .^{-1} \mathrm{~min} .^{-1}
$$

and the rate of reaction of $5 \times 10^{-3} \mathrm{M}$ thioglycolic acid with $2 \times 10^{-5} \mathrm{M}$ ferric ion is

$$
\text { Rate }=k_{4}^{\prime \prime \prime}[\mathrm{TSH}]^{2}[\text { Ferric }]^{2}=2.00 \times 10^{-7} \mathrm{M} .17^{-1} \mathrm{~min}^{-1}
$$

Since the latter rate under these conditions was calculated to be very much less than the former, the rates of the persulphate - thioglycolic acid reactions in $0.10 \mathrm{M}$ sulphuric acid would have been expected to be in the neighbourhood of 


\section{TABLF XXX}

COMPARISON OF RATE CONSTANTS FOR THE FERROUS ION -

PERSULPHATE REACTION WITH THOSE INTERPOLATED FROM

FIGURE 9

\begin{tabular}{c|c|c|c}
\hline Exp. Nos. & $\begin{array}{c}\text { Ionic } \\
\text { Strength } \\
(\mu)\end{array}$ & $\begin{array}{c}\mathrm{k}_{I} \\
\left(1 . \mathrm{M}^{-1}{ }_{\min }^{-1}\right)\end{array}$ & $\begin{array}{c}\mathrm{k}_{1}^{*} \\
\left(1 . \mathrm{M}^{\left.-I_{\min }^{-1}\right)}\right.\end{array}$ \\
\hline 90 & .272 & 452 & 448 \\
$91-93$ & .259 & 782 & 730 \\
\hline
\end{tabular}

* See Figure 9. 
$10^{-7}$ moles/liter/minute rather than $10^{-5}$ moles $/ 1$ iter/minute as observed.

In the light of this observation it seemed that more information pertaining to the catalyst cycle could be acquired if, besides measuring the progress of reaction, the concentration of ferrous ion or of ferric ion were determined as a function of time. For example, it could then be shown whether the stationary state concept could be applied to the ferrous and ferric ion concentrations in the persulphate mercaptan reaction mixtures.

The concentration of ferric ion could be determined, presumably without disturbing the progress of the reaction, from its absorption of ultraviolet light in the presence of sulphuric acid. By knowing the total concentration of dissolved Iron, the concentration of ferrous ion could then be calculated.

However, not only the ferric sulphate complexes but also thioglycolic acid, the disulphide and persulphate were all observed to absorb ultraviolet light. The extinction coefficient of each component was therefore determined as a function of wavelength over the wavelength range of 400 to $210 \mathrm{~m} \mu$, using a Beckmann DK recording spectrophotometer. All the solutions were in $0.15 \mathrm{M}$ sulphuric acid and were adjusted to a temperature of $24.8^{\circ} \mathrm{C}$ in the thermostat prior to the spectrophotometric examination. Twelve concentrations each of persulphate, thioglycolic acid, and the disulphide, 
and six concentrations of ferric ion were used. Beer's Iaw was obeyed in all instances, as indicated by the results in Tables XXXI, XXXII, XXXIII and XXXIV. Two solutions of the disulphide were prepared by adding a known amount of ferric ion to a known amount of thioglycolic acid solution (70), and both gave identical results. When solutions of ferrous ion in $0.15 \mathrm{M}$ sulphuric acid were examined spectrophotometrically, the extinction coefficient was found to be negligible. In Figure 16, the logarithms of the extinction coefficients for the various components present in the persulphate - mercaptan reaction mixtures are plotted against the wavelength.

Various mixtures of the above substances were also prepared and examined spectrophotometrically. The optical densities of the mixtures were observed to be equal to the sum of the optical densities of the individual constituents $(T a b l e X X X V)$. In other words, the extinction coefficient of any one substance was not altered by the presence of the others. Hence, it may be inferred that no appreciable complex formation occurred between any of the components present in the reaction mixture. This observation in turn indicated that it should be possible to follow the progress of the iron catalyzed persulphate - thioglycolic acid reaction spectrophotometrically.

The rates of several reactions, for given initial conditions, were then measured by both iodimetric titration of aliquots 


\section{TABLE XXXI}

VARIATION OF THE OPTICAL DENSITY OF AQUEOUS PERSULPHATE SOLUTIONS WITH THE

CONCENTRATION OF POTASSIUM PERSULPHATE AND THE WAVELENGTH

Conc. Sulphuric Acid $0.15 \mathrm{M} / 1$

\begin{tabular}{|c|c|c|c|c|c|c|c|c|c|c|}
\hline \multirow{2}{*}{$\begin{array}{c}{\left[\mathrm{S}_{2} \mathrm{O}_{8}{ }{ }^{2}\right]} \\
\mathrm{M} / 1\end{array}$} & \multicolumn{10}{|c|}{ Optical Density } \\
\hline & $D_{300}$ & $\mathrm{D}_{280}$ & $D_{260}$ & $\mathrm{D}_{250}$ & $\mathrm{D}_{240}$ & $\mathrm{D}_{230}$ & $\mathrm{D}_{225}$ & $\mathrm{D}_{220}$ & $D_{215}$ & $\mathrm{D}_{210}$ \\
\hline 0.0241 & 0.050 & 0.130 & 0.380 & 0.700 & & & & & & \\
\hline 0.0160 & 0.040 & 0.095 & 0.260 & 0.470 & & & & & & \\
\hline 0.0112 & & 0.070 & 0.190 & 0.340 & 0.620 & & & & & \\
\hline 0.00802 & & 0.051 & 0.130 & 0.230 & 0.440 & & & & & \\
\hline 0.00481 & & 0.040 & 0.090 & 0.150 & 0.275 & 0.570 & & & & \\
\hline 0.00321 & & 0.030 & & & 0.175 & 0.365 & & & & \\
\hline 0.00225 & & & 0.049 & 0.075 & & 0.258 & 0.380 & 0.560 & 0.825 & \\
\hline 0.00160 & & & & & & 0.190 & 0.275 & 0.395 & 0.570 & 0.850 \\
\hline 0.000962 & & & & & 0.068 & 0.123 & 0.175 & 0.250 & 0.355 & 0.530 \\
\hline 0.000642 & & & & & & & 0.110 & 0.160 & 0.230 & 0.340 \\
\hline 0.000449 & & & & & & & 0.092 & 0.100 & 0.179 & 0.255 \\
\hline 0.000321 & & & & & & & 0.070 & & 0.137 & 0.200 \\
\hline$\epsilon\left(I \cdot M^{-1}\right)$ & 1.6 & 5.3 & 15.7 & 28.5 & 55.3 & 110 & 158 & 232 & 335 & 498 \\
\hline
\end{tabular}


TABLE XXXII

VARIATION OF THE OPTICAL DENSITY OF AQUEOUS THIOGLYCOLIC ACID SOLUTIONS WITH THE CONCENTRATION OF THIOGLYCOLIC ACID AND THE WAVELENGTH

Conc. Sulphuric Acid $0.15 \mathrm{M} / \mathrm{l}$

\begin{tabular}{|c|c|c|c|c|c|c|c|c|c|c|c|c|}
\hline \multirow{2}{*}{$\begin{array}{c}\text { [TSH] } \\
M / 1\end{array}$} & \multicolumn{12}{|c|}{ Optical Density } \\
\hline & $D_{300}$ & $\mathrm{D}_{280}$ & $\mathrm{D}_{270}$ & $\mathrm{D}_{260}$ & $\mathrm{D}_{250}$ & $\mathrm{D}_{245}$ & $\mathrm{D}_{240}$ & $\mathrm{D}_{235}$ & $\mathrm{D}_{230}$ & $\mathrm{D}_{225}$ & $\mathrm{D}_{220}$ & $\mathrm{D}_{210}$ \\
\hline 0.0238 & 0.040 & 0.100 & 0.210 & 0.670 & & & & & & & & \\
\hline 0.0119 & 0.022 & 0.052 & 0.105 & 0.330 & & & & & & & & \\
\hline 0.00595 & & 0.026 & 0.500 & 0.160 & 0.540 & 0.900 & & & & & & \\
\hline 0.00357 & & & & 0.100 & 0.329 & 0.520 & 0.710 & & & & & \\
\hline 0.00298 & & & & & & 0.420 & 0.575 & & & & & \\
\hline 0.00238 & & & & & 0.230 & 0.350 & 0.470 & 0.575 & 0.660 & 0.765 & & \\
\hline 0.00179 & & & 0.250 & 0.055 & 0.170 & 0.255 & 0.340 & 0.418 & 0.480 & 0.554 & 0.720 & \\
\hline 0.00119 & & & & & & & 0.235 & 0.290 & 0.330 & 0.388 & 0.495 & \\
\hline 0.000951 & & & & & & & & 0.225 & 0.260 & 0.300 & 0.380 & 0.790 \\
\hline 0.000713 & & & & & & 0.110 & 0.145 & 0.172 & 0.200 & 0.230 & 0.290 & 0.585 \\
\hline 0.000476 & & & & & & & & 0.120 & 0.140 & 0.165 & 0.208 & 0.400 \\
\hline 0.000238 & & & & & & & 0.048 & 0.065 & 0.080 & 0.100 & 0.124 & 0.196 \\
\hline$\epsilon\left(1 . M^{-1}\right)$ & 1.0 & 3.6 & 8.1 & 27 & 90 & 145 & 190 & 230 & 266 & 309 & 394 & 560 \\
\hline
\end{tabular}


TABLE XXXIII

VARIATION OF THE OPTICAL DENSITY OF AQUEOUS

DITHIODIGLYCOLIC ACID SOLUTIONS WITH THE CONCENTRATION

OF DITHIODIGLYCOLIC ACID AND THE WAVELENGTH

Conc. Sulphuric Acid $0.15 \mathrm{M} / 1$

(A) Dithiodiglycolic Acid Solution (Sample No. 1)

\begin{tabular}{|c|c|c|c|c|c|c|c|}
\hline \multirow{2}{*}{$\begin{array}{c}\text { [TSST] } \\
\mathrm{K} / \mathrm{I}\end{array}$} & \multicolumn{7}{|c|}{ Optical Density } \\
\hline & $D_{290}$ & $D_{280}$ & $\mathrm{D}_{270}$ & $\mathrm{D}_{260}$ & $\mathrm{D}_{250}$ & $\mathrm{D}_{240}$ & $D_{220}$ \\
\hline 0.000645 & 0.024 & 0.062 & 0.143 & 0.281 & 0.495 & 0.761 & \\
\hline 0.000430 & 0.022 & 0.046 & 0.098 & 0.190 & 0.323 & 0.472 & 0.737 \\
\hline 0.000215 & 0.010 & 0.023 & 0.046 & 0.092 & 0.154 & 0.221 & 0.334 \\
\hline 0.000086 & & 0.008 & 0.016 & 0.031 & 0.054 & 0.071 & 0.116 \\
\hline$\epsilon\left(1 . M^{-1}\right)$ & 40 & 104 & 220 & 434 & 756 & 1082 & 1542 \\
\hline
\end{tabular}

(B) Dithiodiglycolic Acld Solution (Sample No. 2)

\begin{tabular}{l|c|c|c|c}
\hline \multirow{2}{*}{$\begin{array}{c}\text { [TSST] } \\
M / 1\end{array}$} & $D_{294}$ & $D_{272}$ & $D_{270}$ & $D_{266}$ \\
\cline { 2 - 5 } & 0.125 & 0.648 & 0.718 & 1.010 \\
\hline 0.00300 & 0.090 & 0.435 & 0.503 & 0.646 \\
0.00200 & 0.055 & 0.221 & 0.255 & 0.321 \\
0.00100 & & 0.141 & 0.163 & 0.200 \\
0.00060 & & 0.110 & 0.126 & 0.151 \\
0.00040 & & & 0.075 & 0.089 \\
0.00020 & 0.030 & 210 & 240 & 312 \\
\hline$\epsilon\left(1 . \mathrm{M}^{-1}\right)$ & 35 &
\end{tabular}




\section{TABLE XXXIV}

VARIATION OF THE OPTICAL DENSITY OF FERRIC ION SOLUTIONS WITH THE

\section{CONCENTRATION OF FERRIC ION AND THE WAVELENGTH}

\section{Conc. Sulphuric Acid $0.15 \mathrm{M} / \mathrm{l}$}

\begin{tabular}{|c|c|c|c|c|c|c|c|c|c|c|c|c|c|}
\hline \multirow{2}{*}{$\begin{array}{c}{\left[\mathrm{Fe}^{+++}\right]} \\
\mathrm{M} / 1 \\
\times 10^{4}\end{array}$} & \multicolumn{13}{|c|}{ Optical Density } \\
\hline & $\mathrm{D}_{380}$ & $\mathrm{D}_{360}$ & $D_{340}$ & $\mathrm{D}_{330}$ & $\mathrm{D}_{320}$ & $\mathrm{D}_{305}$ & $\mathrm{D}_{280}$ & $\mathrm{D}_{272}$ & $\mathrm{D}_{256}$ & $\mathrm{D}_{250}$ & $D_{246}$ & $\mathrm{D}_{240}$ & $\mathrm{D}_{220}$ \\
\hline 3.33 & 0.035 & 0.150 & 0.428 & 0.620 & 0.820 & & 0.760 & 0.739 & & & & & \\
\hline 2.64 & & 0.120 & 0.335 & 0.485 & 0.650 & 0.778 & 0.618 & 0.595 & 0.865 & & & & \\
\hline 2.22 & 0.023 & 0.100 & 0.277 & 0.400 & 0.525 & 0.620 & 0.500 & 0.480 & 0.700 & 0.860 & 0.965 & & \\
\hline 1.55 & & 0.700 & 0.195 & 0.280 & 0.370 & 0.438 & 0.350 & 0.340 & 0.488 & 0.590 & 0.660 & 0.775 & 0.940 \\
\hline 1.11 & 0.010 & 0.500 & 0.142 & 0.205 & 0.270 & 0.318 & 0.260 & 0.248 & 0.357 & 0.429 & 0.480 & 0.560 & 0.660 \\
\hline 0.45 & 0.050 & 0.200 & 0.054 & 0.080 & 0.125 & 0.125 & 0.102 & 0.105 & 0.140 & 0.170 & 0.192 & 0.220 & 0.259 \\
\hline$\epsilon\left(1 . M^{-1}\right)$ & 100 & 450 & 1270 & 1840 & 2420 & 2780 & 2300 & 2210 & 3170 & 3850 & 4325 & 5000 & 5950 \\
\hline
\end{tabular}




\title{
FIGURE 16
}

\section{VARIATION OF THE EXTINCTION COEFFICIENT, , OF AQUEOUS SOLUTIONS OF PERSULPHATE, OF THIOGLYCOLIC ACID, OF DITHIODIGLYCOLIC ACID AND OF FERRIC ION WITH THE \\ WAVELENGTH}

\author{
Conc. $\mathrm{H}_{2} \mathrm{SO}_{4} \quad 0.15 \mathrm{M} / \mathrm{I}$ \\ - $\mathrm{s}_{2} \mathrm{O}_{8}=$ \\ 口 TSH
}

$\Delta \quad$ TSST

- $F e^{+++}$ 


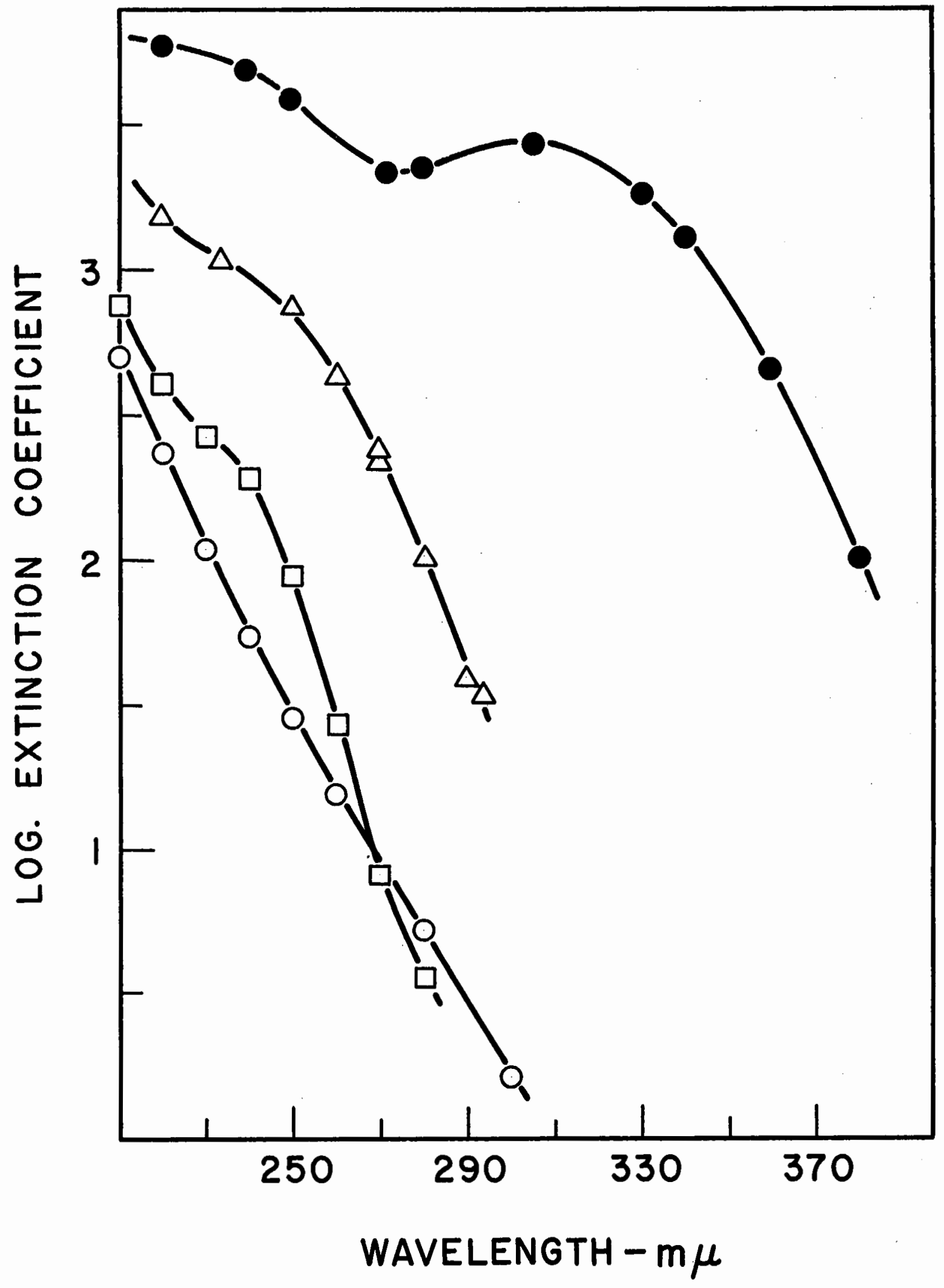


TABLE XXXV

OPTICAL DENSITY OF AQUEOUS SOLUTIONS OF THE COMPONENTS AND OF VARIOUS MIXPURES OF THE COMPONENTS PRESENT IN THE IRON CATALYZED PERSULPHATE - THIOGLYCOLIC ACID REACTION MIXTURES

Conc. Sulphuric Acid $0.15 \mathrm{M} / \mathrm{I}$

(A) Pure Components

\begin{tabular}{|c|c|c|c|c|c|c|c|}
\hline \multirow[b]{2}{*}{ Composition of Solution } & \multicolumn{7}{|c|}{ Optical Density } \\
\hline & $D_{330}$ & $\mathrm{D}_{310}$ & $\mathrm{D}_{290}$ & $\mathrm{D}_{270}$ & $\mathrm{D}_{250}$ & $\mathrm{D}_{230}$ & $\mathrm{D}_{210}$ \\
\hline $8.02 \times 10^{-4} \mathrm{MS}_{2} \mathrm{O}_{8}=$ & & & & 0.005 & 0.026 & 0.089 & 0.367 \\
\hline $0.955 \times 10^{-3} \mathrm{M}$ TSH & & & & 0.005 & 0.088 & 0.250 & 0.722 \\
\hline $1.00 \times 10^{-3} \mathrm{M} \mathrm{TSH}$ & & & & 0.005 & 0.075 & 0.240 & 0.783 \\
\hline $1.91 \times 10^{-3} \mathrm{M} \mathrm{TSH}$ & & & & 0.012 & 0.162 & 0.479 & \\
\hline $1.00 \times 10^{-4} \mathrm{M}$ TSST & & & & 0.024 & 0.098 & 0.189 & 0.331 \\
\hline $4.00 \times 10^{-4} \mathrm{M} \mathrm{Fe}^{++}$ & & & & & 0.010 & 0.018 & 0.020 \\
\hline $4.45 \times 10^{-5} \mathrm{M} \mathrm{Fe}^{+++}$ & 0.069 & 0.110 & 0.102 & 0.087 & 0.157 & 0.235 & 0.230 \\
\hline $8.00 \times 10^{-5} \mathrm{M} \mathrm{Fe}^{+++}$ & 0.134 & 0.199 & 0.185 & 0.160 & 0.276 & 0.408 & 0.415 \\
\hline
\end{tabular}

(B) Mixtures of Components

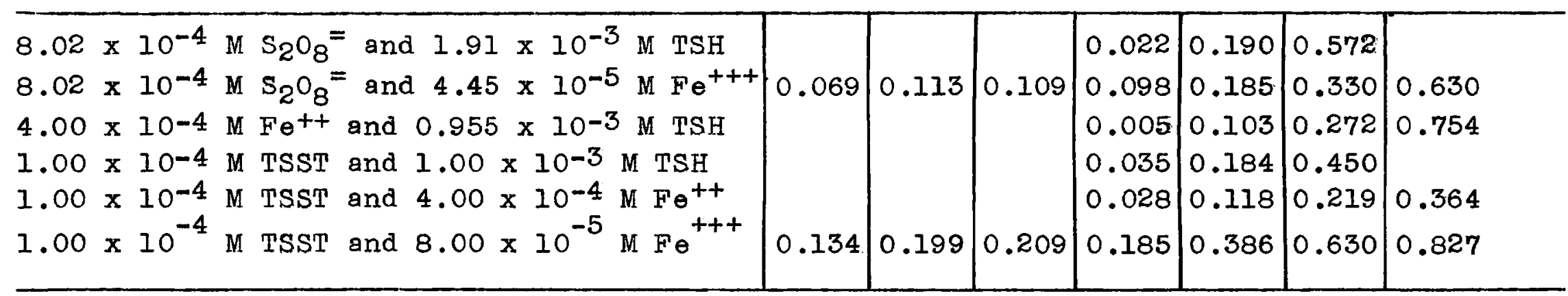


and by the spectrophotometric method. When the latter method was used, samples of the reaction mixture were periodically removed and the ultraviolet spectrum was recorded with the Beckmann DK spectrophotometer for wavelengths up to $400 \mathrm{~m} \mu$. The time was noted at the commencement of each recording, and the chart speed was known. Under the conditions of these experiments, only ferric ion absorbed in the wavelength range of $400 \mathrm{~m} \mu$ to $320 \mathrm{~m} \mu$ and its concentration could be readily determined. The optical densities at lower wavelengths were then corrected for the contribution by ferric ion, and, by using this corrected value, the concentrations of the remaining components in the reaction mixture at any time $t$ were calculated in the following manner.

The stolchiometric equation for the reaction was,

$$
\mathrm{S}_{2} \mathrm{O}_{8}=+2 \mathrm{TSH} \rightarrow \mathrm{TSST}+2 \mathrm{HSO}_{4}^{-}
$$

$\begin{array}{cccccc}\text { Time } & 0 & a & b & 0 & 0 \\ \text { Time } & t & a-x & b-2 x & x & 2 x\end{array}$

The optical density at any wavelength, after correction for the ferric ion absorption, is

$$
\begin{aligned}
\mathrm{D} & =\mathrm{D}_{\mathrm{TSH}}+\mathrm{D}_{\mathrm{S}_{2} \mathrm{O}_{8}}=+\mathrm{D}_{\mathrm{TSST}} \\
& =\epsilon_{\mathrm{TSH}}(\mathrm{b}-2 \mathrm{x})+\epsilon_{\mathrm{S}_{2} \mathrm{O}_{8}}=(\mathrm{a}-\mathrm{x})+\epsilon_{\mathrm{TSST}}(\mathrm{x}) \\
\mathrm{x} & =[\mathrm{TSST}]=\frac{\mathrm{D}-\epsilon_{\mathrm{TSH}} \mathrm{b}-\epsilon_{\mathrm{S}_{2} \mathrm{O}_{8}}=a}{\epsilon_{\mathrm{TSST}}-2 \epsilon_{\mathrm{TSH}}-\epsilon_{\mathrm{S}_{2} \mathrm{O}_{8}}=}
\end{aligned}
$$

The two analytical techniques gave identical, reproducible results, as shown in Tables XXXVI and XXXVII and in Figure 17 . 


\section{TABLE XXXVI}

RATE OF DISAPPEARANCE OF PERSULPHATE MEASURED BOTH IODIMETRICALLY AND

\section{SPECTROPHOTOMETR ICALLY}

Initial Conc. Ferrous Ion $1.00 \times 10^{-4} \mathrm{M} / 1$

Conc. Sulphuric Acid $0.15 \mathrm{M} / \mathrm{I}$

Initial Conc. Potassium Persulphate $0.00400 \mathrm{M} / \mathrm{l}$

Initial Conc. Thioglycolic Acid $0.01085 \mathrm{M} / 1$

\begin{tabular}{|c|c|c|c|c|c|c|c|c|c|c|c|}
\hline \multicolumn{12}{|c|}{ Analytical Method } \\
\hline \multicolumn{6}{|c|}{ Iodimetric } & \multirow{2}{*}{\multicolumn{6}{|c|}{$\frac{\text { Spectrophotometric }}{(\operatorname{Exp} \cdot 96)}$}} \\
\hline \multicolumn{3}{|c|}{ (Exp.94) } & \multicolumn{3}{|c|}{ (Exp. 95) } & & & & & & \\
\hline $\begin{array}{l}\text { Time } \\
(\min .)\end{array}$ & $\begin{array}{c}\text { [TSH] } \\
\mathrm{M} / 1 \\
\times 10^{3}\end{array}$ & $\begin{array}{c}{\left[\mathrm{S}_{2} \mathrm{O}_{8}=\right]} \\
\mathrm{M} / 1 \\
\times 10^{3}\end{array}$ & $\begin{array}{c}\text { Time } \\
(\min .)\end{array}$ & $\begin{array}{c}{[\mathrm{TSH}]} \\
\mathrm{M} / 1 \\
\times 10^{3}\end{array}$ & $\begin{array}{c}{\left[\mathrm{S}_{2} \mathrm{O}_{8}=\right]} \\
\mathrm{M} / 1 \\
\times 10^{3}\end{array}$ & $\begin{array}{c}\text { Time } \\
(\min .)\end{array}$ & $\begin{array}{l}\text { Optical } \\
\text { Density } \\
\text { D325 }\end{array}$ & $\begin{array}{l}\text { Optical } \\
\text { Density } \\
\text { D272 }\end{array}$ & $\begin{array}{c}{\left[\mathrm{S}_{2} \mathrm{O}_{8}=\right]} \\
\mathrm{M} / 1 \\
\times 10^{3}\end{array}$ & $\begin{array}{l}\text { Optical } \\
\text { Density } \\
\text { D266 }\end{array}$ & $\begin{array}{c}{\left[\mathrm{S}_{2} \mathrm{O}_{8}=\right]} \\
\mathrm{M} / 1 \\
\times 10^{3}\end{array}$ \\
\hline 2.75 & 10.20 & 3.67 & 2.00 & 10.34 & 3.74 & 4.00 & 0.090 & 0.302 & 3.49 & 0.418 & 3.51 \\
\hline 6.00 & 9.14 & 3.14 & 5.50 & 9.37 & 3.26 & 8.00 & 0.090 & 0.395 & 2.99 & 0.556 & 3.01 \\
\hline 9.50 & 8.49 & 2.82 & 9.00 & 8.59 & 2.87 & 12.00 & 0.090 & 0.467 & 2.60 & 0.665 & 2.61 \\
\hline 13.50 & 7.83 & 2.49 & 13.50 & 7.65 & 2.40 & 16.00 & 0.090 & 0.530 & 2.26 & 0.763 & 2.25 \\
\hline 17.75 & 7.09 & 2.12 & 18.00 & 6.96 & 2.05 & 20.00 & 0.090 & 0.590 & 1.94 & 0.842 & 1.96 \\
\hline 19.50 & 6.60 & 1.87 & 24.25 & 6.35 & 1.75 & 24.00 & 0.090 & 0.638 & 1.68 & 0.903 & 1.73 \\
\hline & & & 29.25 & 5.73 & 1.44 & & & & & & \\
\hline
\end{tabular}




\section{TABIE XXXVII}

RATE OF DISA PPEARANCE OF PERSULPHATE MEASURED BOTH IODIMETRICALIY AND

SPECTROPHOTOMETR ICALLY

Initial Conc. Ferric Ion $1.00 \times 10^{-4} \mathrm{M} / 1$

Conc. Sulphuric Ac1d $0.15 \mathrm{M} / 1$

Initial Conc. Potassium Persulphate $0.00400 \mathrm{M} / \mathrm{I}$

Inttial Conc. Thioglycolic Acid $0.01085 \mathrm{M} / \mathrm{l}$

\begin{tabular}{|c|c|c|c|c|c|c|c|c|}
\hline \multicolumn{9}{|c|}{ Analytical Method } \\
\hline \multicolumn{3}{|c|}{ Iodimetric } & \multicolumn{6}{|c|}{ Spectrophotometric } \\
\hline \multicolumn{3}{|c|}{ (Exp. 97) } & \multicolumn{6}{|c|}{ (Exp.98) } \\
\hline $\begin{array}{c}\text { Time } \\
(\min .)\end{array}$ & $\begin{array}{c}{[\mathrm{TSH}]} \\
\mathrm{M} / 1 \\
\times 10^{3}\end{array}$ & $\begin{array}{c}{\left[\mathrm{S}_{2} \mathrm{O}_{8}=\right]} \\
\mathrm{M} / 1 \\
\times 10^{3} \\
\end{array}$ & $\begin{array}{c}\text { TIme } \\
(\min .)\end{array}$ & $\begin{array}{c}\text { Optical } \\
\text { Density } \\
D_{325} \\
\end{array}$ & $\begin{array}{c}\text { Optical } \\
\text { Density } \\
\mathrm{D}_{272}\end{array}$ & $\begin{array}{c}{\left[\mathrm{S}_{2} \mathrm{O}_{8}=\right]} \\
\mathrm{M} / 1 \\
\times 10^{3} \\
\end{array}$ & $\begin{array}{c}\text { Optical } \\
\text { Density } \\
D_{266}\end{array}$ & $\begin{array}{c}{\left[\mathrm{S}_{2} \mathrm{O}_{8}=\right]} \\
\mathrm{M} / 1 \\
\times 10^{3} \\
\end{array}$ \\
\hline 2.25 & 10.85 & 4.00 & 2.00 & 0.160 & & & & \\
\hline 5.50 & 10.40 & 3.77 & 4.00 & 0.135 & 0.285 & 3.82 & 0.378 & 3.83 \\
\hline 9.00 & 9.77 & 3.56 & 8.00 & 0.110 & 0.333 & 3.43 & 0.460 & 3.43 \\
\hline 13.25 & 8.67 & 2.91 & 12.00 & 0.105 & 0.400 & 3.04 & 0.558 & 3.05 \\
\hline 18.00 & 7.88 & 2.51 & 16.00 & 0.105 & 0.468 & 2.68 & 0.664 & 2.66 \\
\hline 21.25 & 7.37 & 2.26 & 20.00 & 0.105 & 0.535 & 2.32 & 0.765 & 2.29 \\
\hline \multirow[t]{4}{*}{25.50} & 6.89 & 2.02 & 24.00 & 0.105 & 0.590 & 2.02 & 0.856 & 1.96 \\
\hline & & & 28.00 & 0.105 & 0.640 & 1.76 & 0.930 & 1.68 \\
\hline & & & 32.00 & 0.105 & 0.688 & 1.50 & & \\
\hline & & & 36.00 & 0.105 & 0.730 & 1.27 & & \\
\hline
\end{tabular}




\section{FIGURE 17}

RATE OF DISAPPEARANCE OF PERSULPHATE MEASURED

BOTH IODIMETRICALLY AND SPECTROPHOTOMETRICALLY

Initial Conc. $\mathrm{S}_{2} \mathrm{O}_{8}=0.00400 \mathrm{M} / 1$

Initial Conc. TSH $0.01085 \mathrm{M} / \mathrm{I}$

Conc. $\mathrm{H}_{2} \mathrm{SO}_{4} \quad 0.15 \mathrm{M} / \mathrm{I}$

- Exp. 95, $\left[\mathrm{S}_{2} \mathrm{O}_{8}=\right]$ measured iodimetrically

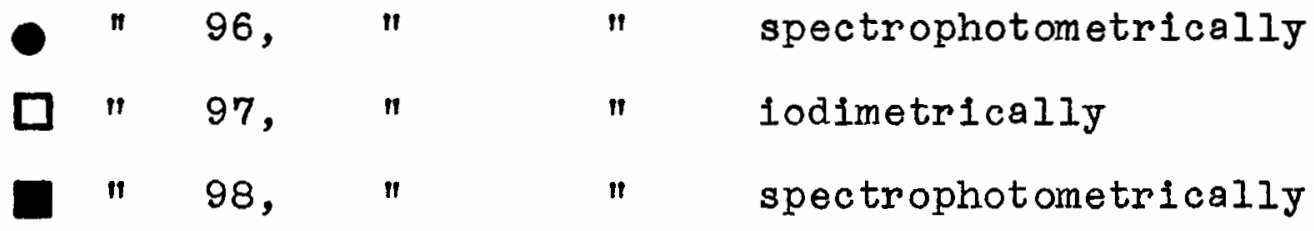




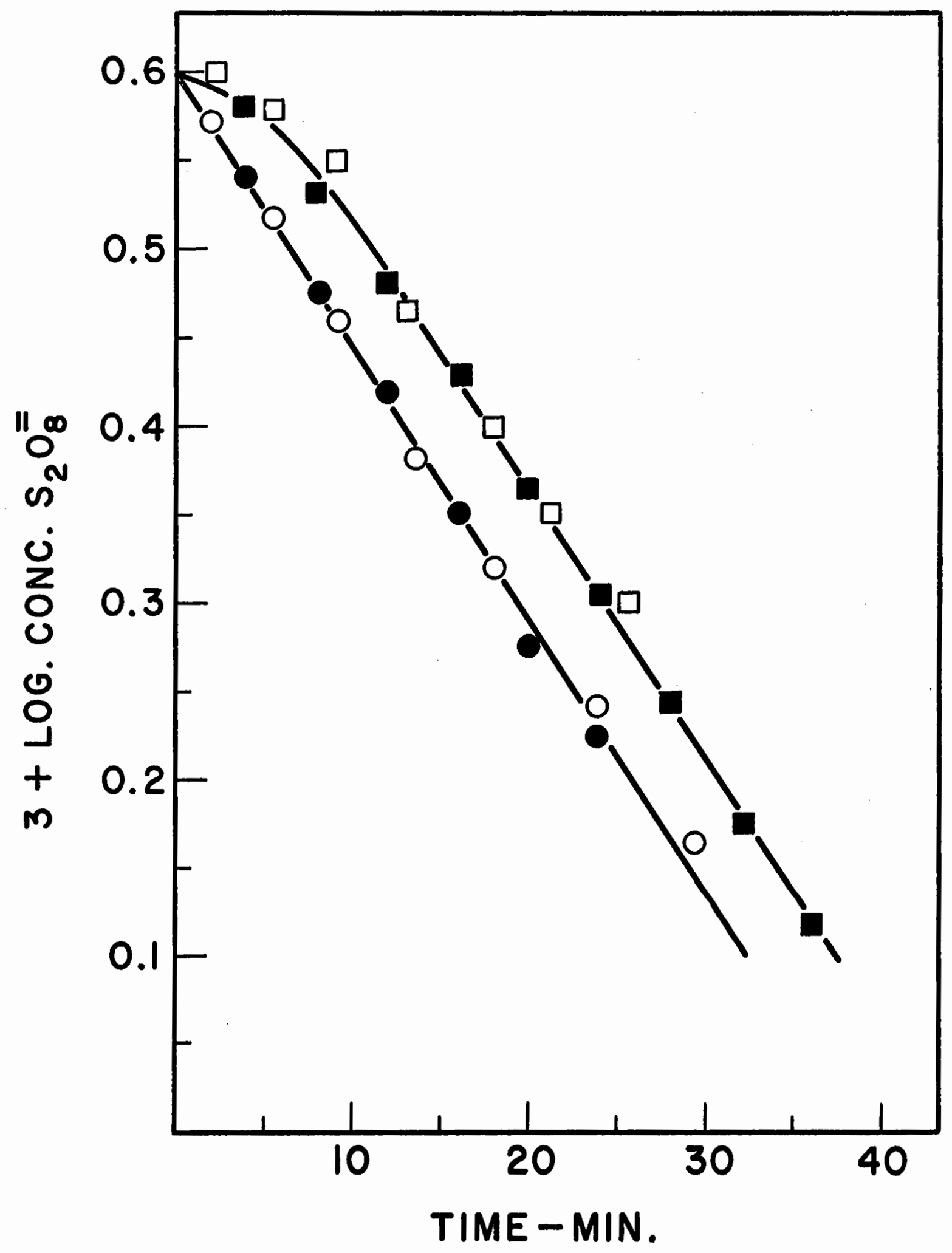


For reactions which were followed spectrophotometrically, the disulphide concentrations were calculated using optical densities measured at two wavelengths (272 and $266 \mathrm{~m} \mu$ ) and were found to be independent of the wavelength at which the optical density was measured. These results confirmed the belief that the net reaction involved the oxidation of two moles of thioglycolic acid by one mole of persulphate to form one mole of disulphide, and that reactions involving persulphate and the disulphide were unimportant during the earlier stages. Furthermore, these experiments showed that negligible concentrations of complexes (other than those between ferric ion and sulphate) were formed between any of the substances present in the reaction mixtures.

In agreement with an earlier observation from experiments made in $0.10 \mathrm{M}$ sulphuric acid, when the dissolved iron was initially in the ferric state, the reaction was preceded by an induction period (Figure 17 ), and the reaction rate at zero time was given approximately by the expression $k_{4}^{\prime \prime \prime}[\text { ferric }]^{2}[\mathrm{TSH}]^{2}$. However, owing to the rather brief existence of the induction period, this initial rate could not be measured accurately. The rate of disappearance of the ferric ion (Figure 18) during the greater part of the induction period was not influenced by the presence of persulphate, but the rate of production of disulphide at any instant, except at zero time, was greater in the presence of persulphate than was predicted by the expression $k_{4}^{\prime \prime}[\text { ferric }]^{2}[\mathrm{TSH}]^{2}$. 
FIGURE 18

THE VARIATION OF OPTICAL DENSITY AT $325 \mathrm{m \mu}$ WITH TIME

\author{
Initial Conc. TSH $0.01085 \mathrm{M} / 1$ \\ Initial Conc. $\mathrm{Fe}^{+++} 10.0 \times 10^{-4} \mathrm{M} / \mathrm{I}$ \\ Conc. $\mathrm{H}_{2} \mathrm{SO}_{4} \quad 0.15 \mathrm{M} / \mathrm{I}$ \\ - Exp. 98, Initial Conc. $\mathrm{S}_{2} \mathrm{O}_{8}=0.00400 \mathrm{M} / 1$

- "86, " " $" 0.00000 \mathrm{M} / \mathrm{l}$




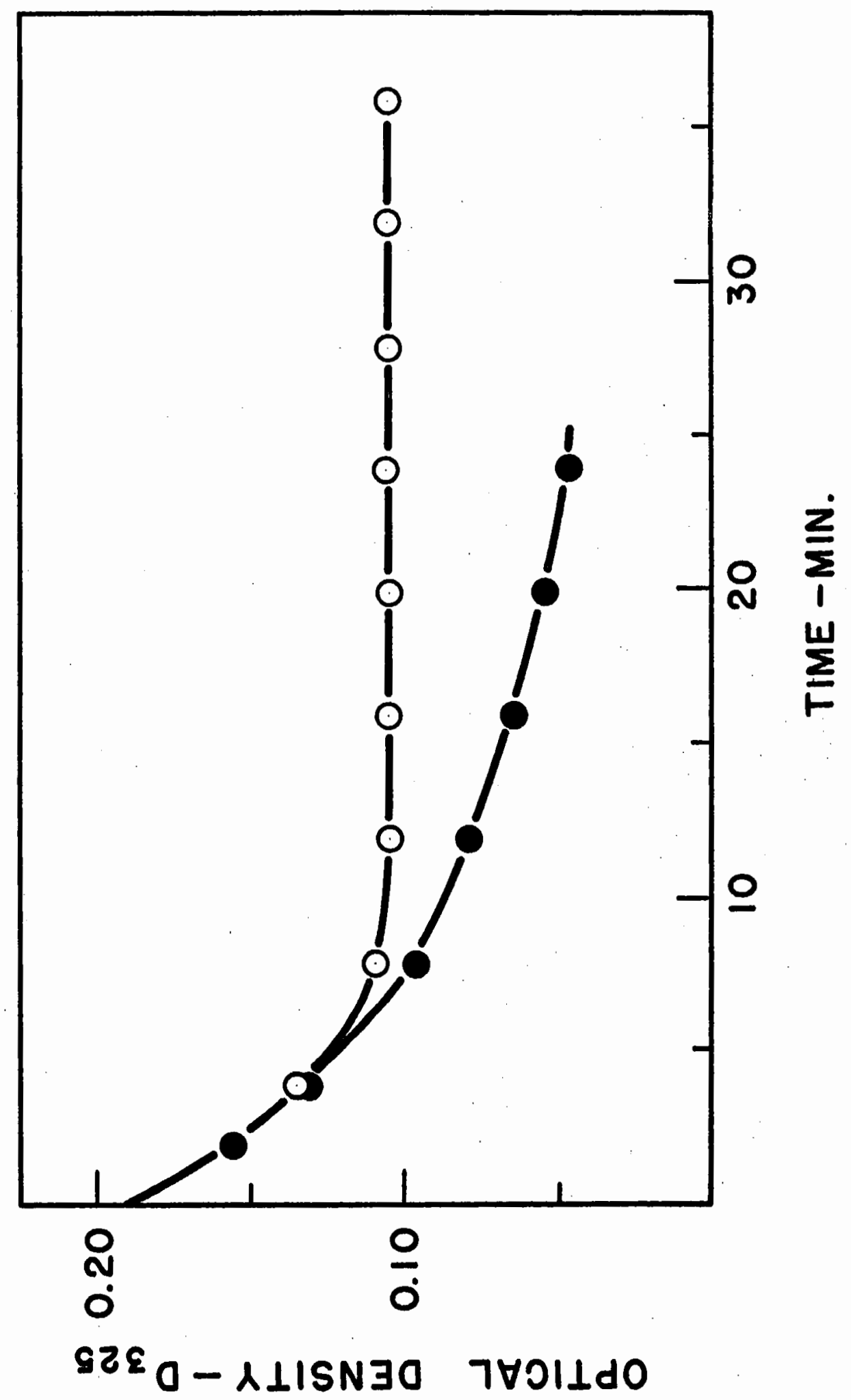


When the dissolved iron was initially in the ferrous state no induction period was observed. However, regardless of whether the iron was inftially ferrous or ferric, it seemed apparent that after a few minutes the concentrations of ferrous and ferric ions achieved stationary state values which were independent of the initial oxidation state of the Iron.

The preceding experiments showed that the spectrophotometric method yielded reliable measurements of both reaction rate and change of ferric ion concentration with time. The relations between these quantities and the initial concentrations of persulphate and thioglycolic acid were therefore studied with the technique as outlined above. Unless otherwise stated, the reaction mixtures were $0.15 \mathrm{M}$ in sulphuric acid and the dissolved iron was initially ferrous at a concentration of $10^{-4} \mathrm{M}$.

The effect of initial persulphate concentration was investigated at two levels of thioglycolfc acid (Tables XXXVIII and XXXIX). The first order rate constants for persulphate disappearance were observed to decrease with increase in the Initial persulphate concentration. Using the initial rates of reaction ( $\mathrm{Table} X I$ ) the order of the reaction in respect of the persulphate concentration was calculated to be approximately 0.80 .

Plots of the optical densities of the reaction mixtures against time, for a wavelength of $325 \mathrm{~m} \mu$, indicated that the 
TABLE XXXVIII

OPTICAL DENSITY AT $325 \mathrm{~m} \mu$ AND RATE OF DISAPPEARANCE OF PERSULPHATE WITH DIFFERENT

INIT IAL CONCENTRATIONS OF POTASSIUM PERSULPHATE

Initial Conc. Ferrous Ion $1.00 \times 10^{-4} \mathrm{M} / 1$

Conc. Sulphuric Acid $0.15 \mathrm{M} / \mathrm{l}$

Initial Conc. Thioglycolic Acid $0.01095 \mathrm{M} / 1$

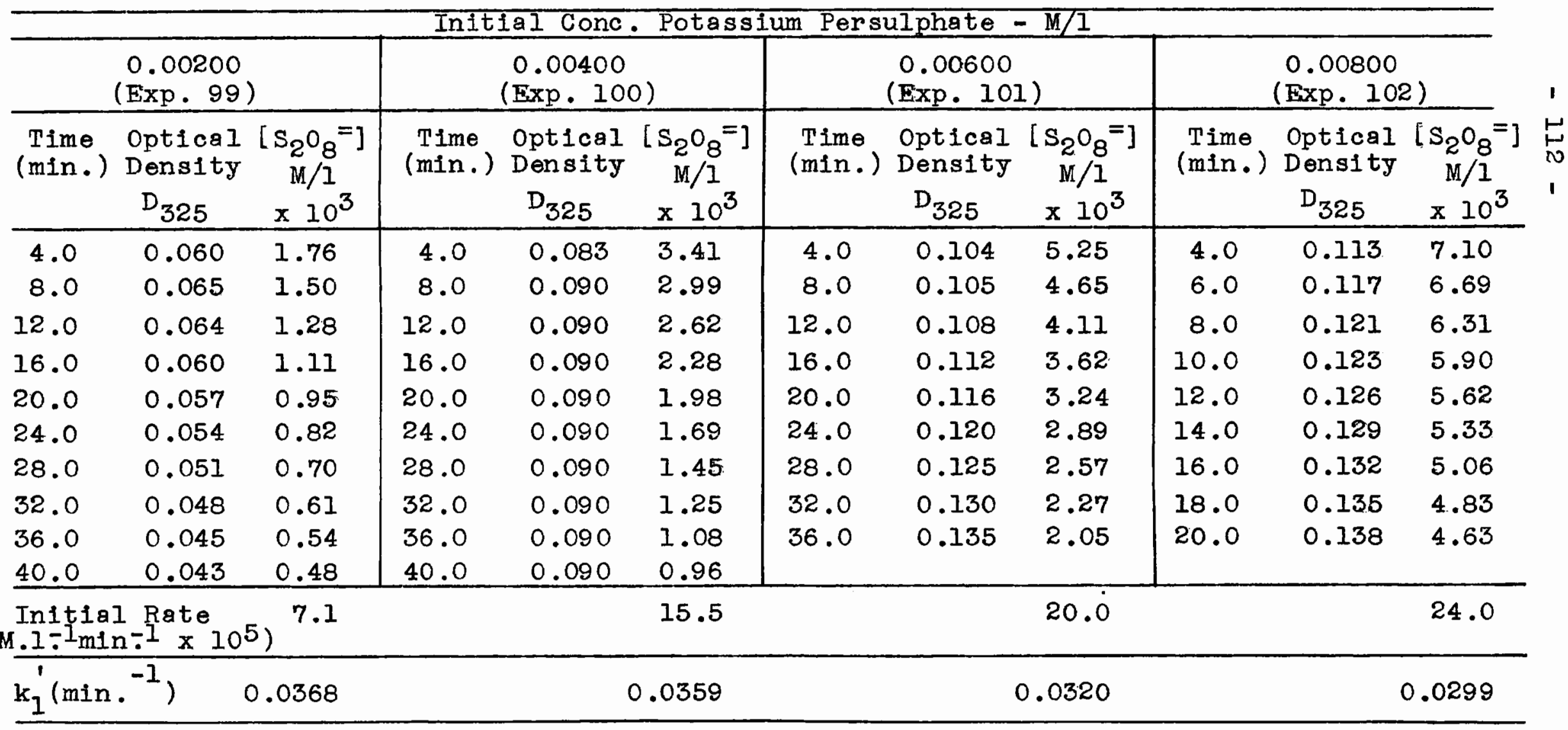




\section{TABLE XXXIX}

OPTICAL DENSITY AT 325 m $\mu$ AND RATE OF DISAPPEARANCE OF PERSULPHATE WITH DIFFERENT INITIAL CONCENTRATIONS OF POTASSIUM PERSULPHATE

Initial Conc. Ferrous Ion $1.00 \times 10^{-4} \mathrm{M} / 1$

Conc. Sulphuric Acid $0.15 \mathrm{M} / 1$

Initial Conc. Thioglycolic Acid $0.00438 \mathrm{M} / \mathrm{I}$

\begin{tabular}{|c|c|c|c|c|c|c|c|c|}
\hline \multicolumn{3}{|c|}{$\begin{array}{c}0.00200 \\
(\text { Exp. } 103) \\
\end{array}$} & \multicolumn{3}{|c|}{$\begin{array}{c}0.00400 \\
(\operatorname{Exp} .104) \\
\end{array}$} & \multicolumn{3}{|c|}{$\begin{array}{c}0.00800 \\
(\operatorname{Exp} .105)\end{array}$} \\
\hline $\begin{array}{l}\text { Time } \\
(\min .)\end{array}$ & $\begin{array}{c}\text { Optical } \\
\text { Density } \\
D_{325} \\
\end{array}$ & $\begin{array}{c}{\left[\mathrm{S}_{2} \mathrm{O}_{8}=\right]} \\
\mathrm{M} / 1 \\
\times 10^{3} \\
\end{array}$ & $\begin{array}{l}\text { Time } \\
(\min .)\end{array}$ & $\begin{array}{c}\text { Optical } \\
\text { Density } \\
D_{325} \\
\end{array}$ & $\begin{array}{c}{\left[\mathrm{S}_{2} \mathrm{O}_{8}=\right]} \\
\mathrm{M} / 1 \\
\times 10^{3} \\
\end{array}$ & $\begin{array}{l}\text { Time } \\
(\min .)\end{array}$ & $\begin{array}{c}\text { Optical } \\
\text { Density } \\
\text { D }_{325} \\
\end{array}$ & $\begin{array}{c}{\left[\mathrm{S}_{2} \mathrm{O}_{8}=\right]} \\
\mathrm{M} / 1 \\
\times 10^{3} \\
\end{array}$ \\
\hline 4.0 & 0.085 & 1.71 & 4.0 & 0.111 & 3.52 & 4.0 & 0.149 & 7.30 \\
\hline 8.0 & 0.097 & 1.49 & 8.0 & 0.117 & 3.14 & 8.0 & 0.152 & 6.72 \\
\hline 12.0 & 0.098 & 1.30 & 12.0 & 0.123 & 2.89 & 12.0 & 0.161 & 6.35 \\
\hline 16.0 & 0.099 & 1.14 & 16.0 & 0.129 & 2.67 & 16.0 & 0.170 & 6.13 \\
\hline 20.0 & 0.100 & 1.01 & 20.0 & 0.135 & 2.50 & 20.0 & 0.175 & 5.98 \\
\hline 24.0 & 0.101 & 0.88 & 24.0 & 0.141 & 2.34 & 24.0 & 0.177 & 5.85 \\
\hline 28.0 & 0.101 & 0.77 & 28.0 & 0.146 & 2.22 & 28.0 & 0.180 & 5.76 \\
\hline 32.0 & 0.102 & 0.68 & 32.0 & 0.150 & 2.11 & 32.0 & 0.182 & 5.69 \\
\hline 36.0 & 0.103 & 0.60 & 36.0 & 0.155 & 2.04 & 36.0 & 0.184 & 5.64 \\
\hline 40.0 & 0.104 & 0.55 & 40.0 & 0.160 & 1.99 & 40.0 & 0.186 & 5.61 \\
\hline $\begin{array}{l}\text { Initjal } \\
\text { (M.I. } I_{\text {min }}\end{array}$ & Rate $\left.\times 10^{5}\right)$ & 7.0 & & & 12.7 & & & 20.0 \\
\hline$k_{1}^{\prime}\left(\min .^{-1}\right.$ & & 0347 & & & 304 & & & 0253 \\
\hline
\end{tabular}


TABLE XI

VARIATION OF THE INITIAL REACTION RATE,

$-\frac{\mathrm{d}\left[\mathrm{S}_{2} \mathrm{O}_{8}=\right]}{\mathrm{dt}}$, AND OF THE CALCULATED FIRST ORDER RATE

CONSTANT, $k_{1}^{\prime}$, WITH THE INITIAL CONCENTRATION OF

POTASSIUM PERSULPHATE

\begin{tabular}{c|c|c|c|c}
\hline Exp. No. & $\begin{array}{c}\text { Initial } \\
{\left[\mathrm{S}_{2}{ }^{=}\right]} \\
\mathrm{M} / 1 \\
\times 10^{3}\end{array}$ & $\begin{array}{c}\text { Initial } \\
{[\mathrm{TSH}]} \\
\mathrm{M} / 1 \\
\times 10^{3}\end{array}$ & $\begin{array}{c}\text { Initial Rate } \\
\left(\mathrm{M.1} \mathrm{I}_{\mathrm{min}}^{-1}\right) \\
\times 10^{5}\end{array}$ & $\begin{array}{c}\mathrm{k}_{1}^{\prime} \\
\left.(\mathrm{min})^{-1}\right)\end{array}$ \\
\hline 99 & 2.00 & 10.95 & 7.1 & 0.0368 \\
100 & 4.00 & 10.95 & 15.5 & 0.0359 \\
101 & 6.00 & 10.95 & 20.0 & 0.0320 \\
102 & 8.00 & 10.95 & 24.0 & 0.0299 \\
103 & 2.00 & 4.38 & 7.0 & 0.0347 \\
104 & 4.00 & 4.38 & 12.7 & 0.0304 \\
105 & 8.00 & 4.38 & 20.0 & 0.0253 \\
\hline
\end{tabular}


stationary state concentration of ferric ion increased with increasing inftial persulphate concentration (Figures 19 and 20).

When the initial mercaptan concentration in the reaction mixture was varied at constant initial persulphate concentration the first order rate constant for persulphate disappearance increased with increase in the initial concentration of thioglycolic acid (Tables XII and XIII). The inftial rates of reaction indicated that the reaction was $=0.10$ order in thioglycolic acid concentration. In Figure 21, the optical densities of the reaction mixtures are plotted against the time, for a wavelength of $325 \mathrm{~m} \mu$, to show that the stationary state concentration of ferric ion decreased with increasing initial mercaptan concentration.

The results of all these experiments seemed to indicate that the concept of the stationary state could be applied to the concentrations of ferrous and ferric ions in the reaction mixtures. However, several minutes seemed to berequired before this stationary state was established. The reason for this is not readily apparent since under similar experimental conditions, but in the absence of mercaptan, persulphate was observed to oxidize ferrous ion to ferric ion almost instantaneously.

The rates of the reactions, after ferric ion concentration had reached a steady state, were estimated from slopes of 


\section{TABLE XLI}

OPTICAL DENSITY AT $325 \mathrm{~m} \mu$ AND RATE OF DISAPPEARANCE OF PERSULPHATE WITH DIFFERENT INITIAL CONCENTRATIONS OF THIOGLYCOLIC ACID

Initiel Conc. Ferrous Ion $1.00 \times 10^{-4} \mathrm{M} / 1$

Conc. Sulphuric Acid $0.15 \mathrm{M} / \mathrm{I}$

Initial Conc. Potassium Persulphate $0.00400 \mathrm{M} / 1$

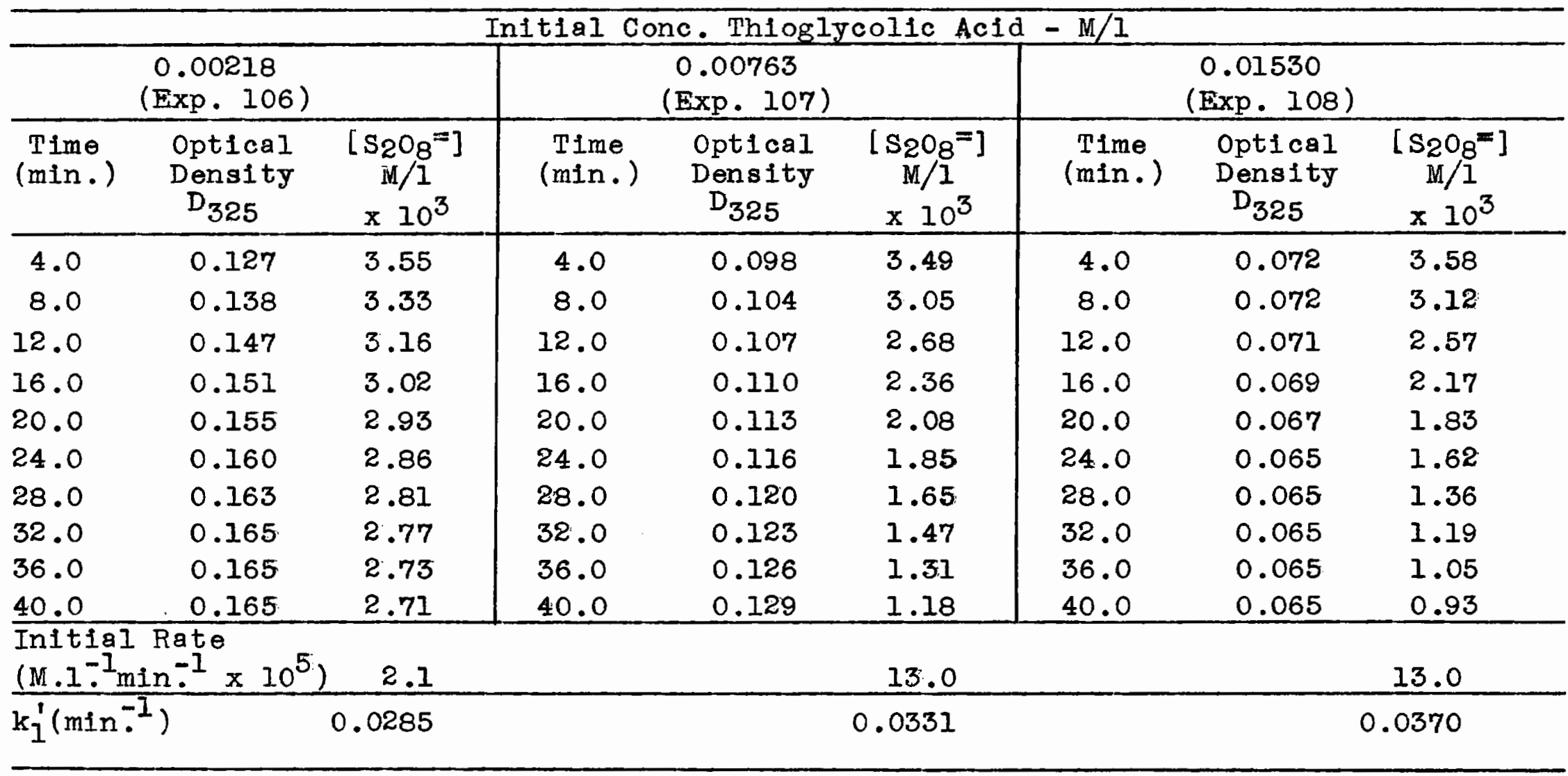




\section{TABLE XLII}

VARIATION OF THE INITIAL REACTION RATE,

$-\frac{\mathrm{d}\left[\mathrm{S}_{2} \mathrm{O}_{8}{ }{ }^{2}\right]}{\mathrm{dt}}$, AND OF THE CALCULATED FIRST ORDER RATE

CONSTANT, $k i$, WITH THE INITIAL CONCENTRATION OF

THIOGLYCOLIC ACID

Initial Conc. Potassium Persulphate $0.00400 \mathrm{M} / 1$

\begin{tabular}{l|c|c|c}
\hline Exp. No. & $\begin{array}{c}\text { Initial } \\
{[\mathrm{TSH}]} \\
\mathrm{M} / 1 \times 10^{3}\end{array}$ & $\begin{array}{c}\text { Initial Rate } \\
\left(\mathrm{M} .1 \mathbf{I}_{\mathrm{min}}^{-1}\right) \\
\mathrm{x} 10^{5}\end{array}$ & $\begin{array}{c}\mathrm{k}_{1}^{\prime} \\
(\mathrm{min}-1)\end{array}$ \\
\hline 106 & 2.18 & 12.1 & 0.0285 \\
107 & 7.63 & 13.0 & 0.0331 \\
108 & 15.30 & 13.0 & 0.0370 \\
\hline
\end{tabular}


FIGURES $19,20,21$

EFFECT OF DIFFERENT INITIAL CONCENTRATIONS OF PERSULPHATE AND OF THIOGLYCOLIC ACID ON THE OPTICAL DENSITY AT $325 \mathrm{m \mu}$

$$
\begin{gathered}
\text { Inftial Conc. } \mathrm{Fe}^{++} 10.0 \times 10^{-4} \mathrm{M} / \mathrm{I} \\
\text { Conc. } \mathrm{H}_{2} \mathrm{SO}_{4} 0.15 \mathrm{M} / \mathrm{I}
\end{gathered}
$$

\section{Figure 19}

\begin{tabular}{|c|c|c|c|c|c|}
\hline Exp & . 99 & Initial & Conc. & $\mathrm{S}_{2} \mathrm{O}_{8}=$ & $0.00200 \mathrm{M} / 1$ \\
\hline$"$ & 100 & $n$ & $"$ & $n$ & $0.00400 \mathrm{M} / \mathrm{I}$ \\
\hline$"$ & 101 & $"$ & $\pi$ & $n$ & $0.00600 \mathrm{M}$ \\
\hline$"$ & 102 & $"$ & $"$ & $"$ & 0.00800 \\
\hline
\end{tabular}

Initial Cone. TSH $0.01095 \mathrm{M} / \mathrm{I}$

\section{F1gure 20}

Initial Conc. TSH $0.00438 \mathrm{M} / \mathrm{I}$
0 Exp.103 Initial Conc. $\mathrm{S}_{2} \mathrm{O}_{8}=0.00200 \mathrm{M} / 1$
口 " 104 " " $" 0.00400 \mathrm{M} / \mathrm{I}$
$\Delta " 105 \quad " \quad " \quad 0.00800 \mathrm{M} / \mathrm{l}$

\section{Figure 21}

$$
\text { Initial Conc. } \mathrm{S}_{2} \mathrm{O}_{8}=0.00400 \mathrm{~m} / \mathrm{l}
$$

- Exp.106 Initial Conc. TSH $0.00218 \mathrm{M} / 1$
口 " 107
$"$
"
" $0.00763 \mathrm{M} / \mathrm{I}$
$\Delta \quad 108$
$"$
$"$
" $0.01530 \mathrm{M} / 1$ 


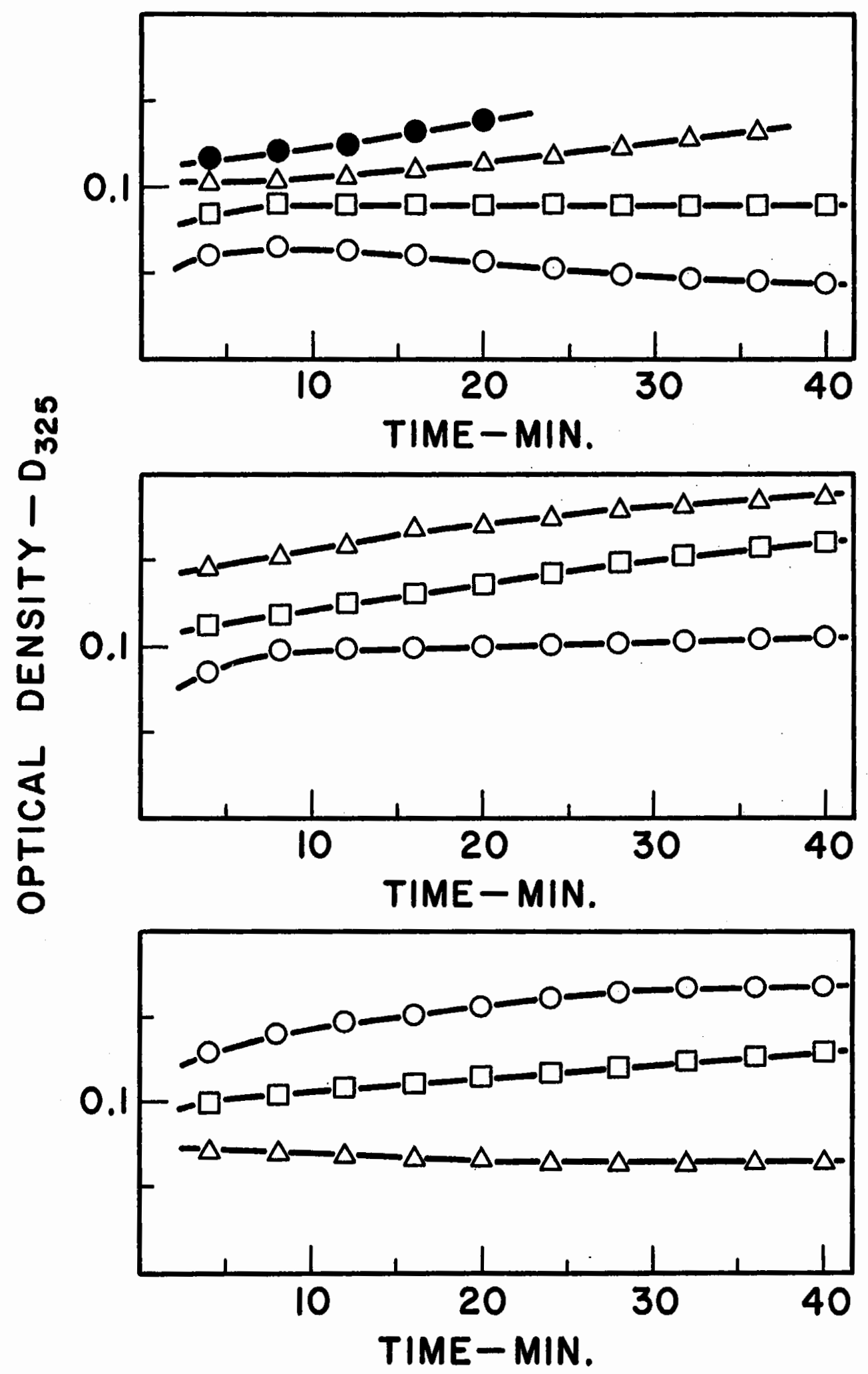


tangents to the curves relating persulphate concentration to time (Table XIIII). Division of the reaction rate by the product of the persulphate and ferrous ion concentrations at the corresponding time yielded a value which was independent of the particular reaction mixture. Also, this constant was in good agreement with the rate constant measured previously (Table XXX) for the reaction of ferrous ion with persulphate. However, division of the reaction rate by the product of the square of the thioglycolic acid concentration and the square of the ferric ion concentration yielded a value, which for different initial mercaptan concentrations, varied from one reaction mixture to another, and which was considerably greater than the rate constant for the reduction of ferric fon by thioglycolic acid for similar experimental conditions in the absence of persulphate.

These results suggest that persulphate reacted only with ferrous ion in the presence of thioglycolic acid, and that the rate of the reaction was not altered by the presence of the mercaptan. However, the reduction of ferric ion by thioglycolic acid appeared to be markedly accelerated by the presence of persulphate.

Experiments were also made in which the concentration of iron in the reaction mixture was varied under otherwise constant conditions, and the initial rate of reaction was observed to be directly proportional to the concentration of 


\section{TABIE XIIII}

VALUES OF THE RATE CONSTANTS $k_{1}$ AND $k_{4}^{\prime \prime \prime}$

CALC ULATED FROM THE MEASURED REACTION RATES

\begin{tabular}{|c|c|c|c|c|c|c|}
\hline $\begin{array}{r}\operatorname{Exp} . \\
\text { No. }\end{array}$ & {$\left[\begin{array}{c}\left.\mathrm{S}_{2} \mathrm{O}_{8}=\right] \\
\mathrm{M} / 1 \\
\times 10^{3}\end{array}\right.$} & $\begin{array}{l}{[\mathrm{TSH}]} \\
\mathrm{M} / 1 \\
\times 10^{3}\end{array}$ & $\begin{array}{l}\text { Optical } \\
\text { Density } \\
\text { D } 325\end{array}$ & $\begin{array}{c}\text { Reaction Rate } \\
\left(\mathrm{M} .1{ }^{-1} \min ^{-1}\right) \\
\times 10^{5}\end{array}$ & $\begin{array}{c}\mathrm{k}_{1} \\
\left(1 \cdot \mathrm{M}^{-1}\right. \\
\left.\min ^{-1}\right)\end{array}$ & $\begin{array}{c}k_{4}^{\prime \prime \prime} \\
\left(1 M^{2}\right. \\
\left.\min { }^{-1}\right) \\
x 10^{-9}\end{array}$ \\
\hline 99 & 1.00 & 8.90 & 0.058 & 4.0 & 576 & 1.09 \\
\hline 100 & 3.00 & 8.90 & 0.090 & 10.5 & 665 & 1.19 \\
\hline 101 & 5.00 & 8.90 & 0.105 & 15.5 & 692 & 1.29 \\
\hline 102 & 7.00 & 8.90 & 0.115 & 18.0 & 650 & 1.25 \\
\hline 104 & 3.00 & 2.36 & 0.120 & 6.5 & 590 & 6.00 \\
\hline 107 & 3.00 & 5.63 & 0.105 & 10.0 & 745 & 2.08 \\
\hline 108 & 3.00 & 13.30 & 0.073 & 11.8 & 638 & 0.91 \\
\hline \multicolumn{5}{|c|}{ Average $k_{1}$} & \multicolumn{2}{|l|}{651} \\
\hline \multicolumn{7}{|c|}{$k_{1}$ in the absence of } \\
\hline $\mathrm{k}_{4}^{\prime \prime \prime}$ & the & & $p$ & $\begin{array}{l}\text { hate } \\
\text { Table XXVII) }\end{array}$ & & $3 \times 10^{7}$ \\
\hline
\end{tabular}


iron present (Table XLIV and Figure 22).

It was also shown experimentally (Table XIV) that variation of either the initial persulphate concentration or the initial thioglycolic acid concentration in no way altered the induction period or the attainment of a steady state that were previously observed when the iron was initially in the ferric state.

It became apparent after studying these results that a better understanding of the reduction of ferric ion by thioglycolic acid in the absence of persulphate should be acquired. It will be recalled that the rate of the reaction was markedly retarded by sulphuric acid. This could have been due to inhibition by hydrogen ions or to decreased reactivity of ferric ions by their complex formation with sulphate ions, or perhaps to both causes. However, the results cannot be assessed quantitatively because the ionic strength was not controlled in these experiments.

To simplify the system, the rate of the ferric ion thioglycolic acid reaction was studied in the presence of perchloric rather than sulphuric acid, and the ionic strength was adjusted to unity with standard sodium perchlorate solution, the concentration of which was determined from density measurements (120). The thioglycolic acid concentration was in sufficient excess that it could be considered independent of time. The progress of the reaction was followed 
TABLE XLIV .

OPTICAL DFNS ITY AT $325 \mathrm{~m} \mu$ AND RATE OF DISAPPEARANCE

OF PERSULPHATE WITH DIFFERENT INITIAL CONCENTRATIONS OF

FERROUS ION

Conc. Sulphuric Acid $0.15 \mathrm{M} / \mathrm{I}$

Initial Conc. Potassium Persulphate $0.00400 \mathrm{M} / \mathrm{I}$

Initial Conc. Thioglycolic Acid $0.01095 \mathrm{M} / \mathrm{I}$

\begin{tabular}{|c|c|c|c|c|c|}
\hline \multicolumn{6}{|c|}{ Initial Conc. Ferrous Ion - $M / I$} \\
\hline \multicolumn{3}{|c|}{$\begin{array}{l}0.50 \times 10^{-4} \\
(\operatorname{Exp} .109)\end{array}$} & \multicolumn{3}{|c|}{$\begin{array}{l}1.50 \times 10^{-4} \\
(\operatorname{Exp} .110)\end{array}$} \\
\hline $\begin{array}{l}\text { Time } \\
(\min .)\end{array}$ & $\begin{array}{c}\text { Optical } \\
\text { Density } \\
D_{325}\end{array}$ & $\begin{array}{c}{\left[\mathrm{S}_{2} \mathrm{O}_{8}=\right]} \\
\mathrm{M} / 1 \\
\times \quad 10^{3} \\
\end{array}$ & $\begin{array}{l}\operatorname{Tim}{ }^{\prime} \\
(\min .)\end{array}$ & $\begin{array}{l}\text { Optical } \\
\text { Density } \\
D_{325}\end{array}$ & $\begin{array}{c}{\left[\mathrm{S}_{2} \mathrm{O}_{8}=\right]} \\
\mathrm{M} / 1 \\
\times 10^{3} \\
\end{array}$ \\
\hline 4.0 & 0.050 & 3.82 & 4.0 & 0.130 & 3.13 \\
\hline 8.0 & 0.050 & 3.56 & 8.0 & 0.130 & 2.46 \\
\hline 12.0 & 0.050 & 3.33 & 12.0 & 0.130 & 1.95 \\
\hline 16.0 & 0.050 & 3.13 & 16.0 & 0.130 & 1.60 \\
\hline 20.0 & 0.050 & 2.95 & 20.0 & 0.130 & 1.29 \\
\hline 24.0 & 0.050 & 2.78 & 24.0 & 0.130 & 1.03 \\
\hline 28.0 & 0.050 & 2.60 & 28.0 & 0.130 & 0.79 \\
\hline 32.0 & 0.050 & 2.43 & 32.0 & 0.130 & 0.65 \\
\hline 36.0 & 0.050 & 2.25 & 36.0 & 0.130 & 0.56 \\
\hline 40.0 & 0.050 & 2.05 & & & \\
\hline $\begin{array}{l}\text { Initia } \\
\text { M.1.1 }\end{array}$ & $\begin{array}{l}\text { te } \\
1 \\
\times 10^{5}\end{array}$ & 7.5 & & & 22.0 \\
\hline
\end{tabular}


$\underline{\text { TABLE XLV }}$

OPTICAL DENSITY AT $325 \mathrm{~m} \mu$ AND RATE OF DISAPPEARANCE

OF PERSULPHATE WITH DIFFERENT INITIAL CONCENTRATIONS OF

\section{THIOGLYCOLIC ACID}

Initial Conc. Ferric Ion $1.00 \times 10^{-4} \mathrm{M} / \mathrm{l}$

Conc. Sulphuric Acid $0.15 \mathrm{M} / 1$

Init1al Conc. Potassium Persulphate $0.00800 \mathrm{M} / \mathrm{I}$

\begin{tabular}{|c|c|c|c|c|c|}
\hline \multicolumn{3}{|c|}{$\begin{array}{c}0.01095 \\
(\text { Exp. 111) }\end{array}$} & \multicolumn{3}{|c|}{$\begin{array}{c}0.00436 \\
(\operatorname{Bxp} .112) \\
\end{array}$} \\
\hline $\begin{array}{l}\text { Time } \\
(\min .)\end{array}$ & $\begin{array}{c}\text { Optical } \\
\text { Density } \\
D_{325}\end{array}$ & $\begin{array}{c}{\left[\mathrm{S}_{2} \mathrm{O}_{8}=\right]} \\
\mathrm{M} / 1 \\
\times 10^{3} \\
\end{array}$ & $\begin{array}{c}\text { Time } \\
\text { (min.) }\end{array}$ & $\begin{array}{c}\text { Optical } \\
\text { Density } \\
D_{325}\end{array}$ & $\begin{array}{c}{\left[\mathrm{S}_{2} \mathrm{O}_{8}=\right]} \\
\mathrm{M} / 1 \\
\times 10^{3} \\
\end{array}$ \\
\hline 2.5 & 0.140 & 7.97 & 2.5 & 0.150 & 7.97 \\
\hline 4.0 & 0.130 & 7.70 & 4.0 & 0.145 & 7.81 \\
\hline 8.0 & 0.115 & 7.02 & 8.0 & 0.140 & 7.33 \\
\hline 12.0 & 0.115 & 6.27 & 12.0 & 0.144 & 6.83 \\
\hline 16.0 & 0.123 & 5.65 & 16.0 & 0.157 & 6.48 \\
\hline 20.0 & 0.132 & 5.07 & 20.0 & 0.165 & 6.25 \\
\hline 24.0 & 0.140 & 4.59 & 24.0 & 0.171 & 6.08 \\
\hline \multirow[t]{4}{*}{26.0} & 0.144 & 4.36 & 28.0 & 0.176 & 5.94 \\
\hline & & & 32.0 & 0.181 & 5.82 \\
\hline & & & 36.0 & 0.186 & 5.73 \\
\hline & & & 40.0 & 0.190 & 5.69 \\
\hline
\end{tabular}


FIGURE 22

EFFECT OF DIFFERENT INITIAL CONCENTRATIONS OF

FERROUS ION ON THE INITIAL RATE OF DISAPPEARANCE

OF PERSULPHATE IN $0.15 \mathrm{M}$ SULPHURIC ACID

Initial Conc. $\mathrm{S}_{2} \mathrm{O}_{8}=0.00400 \mathrm{M} / 1$

Initial Conc. TSH $0.01095 \mathrm{M} / 1$ 


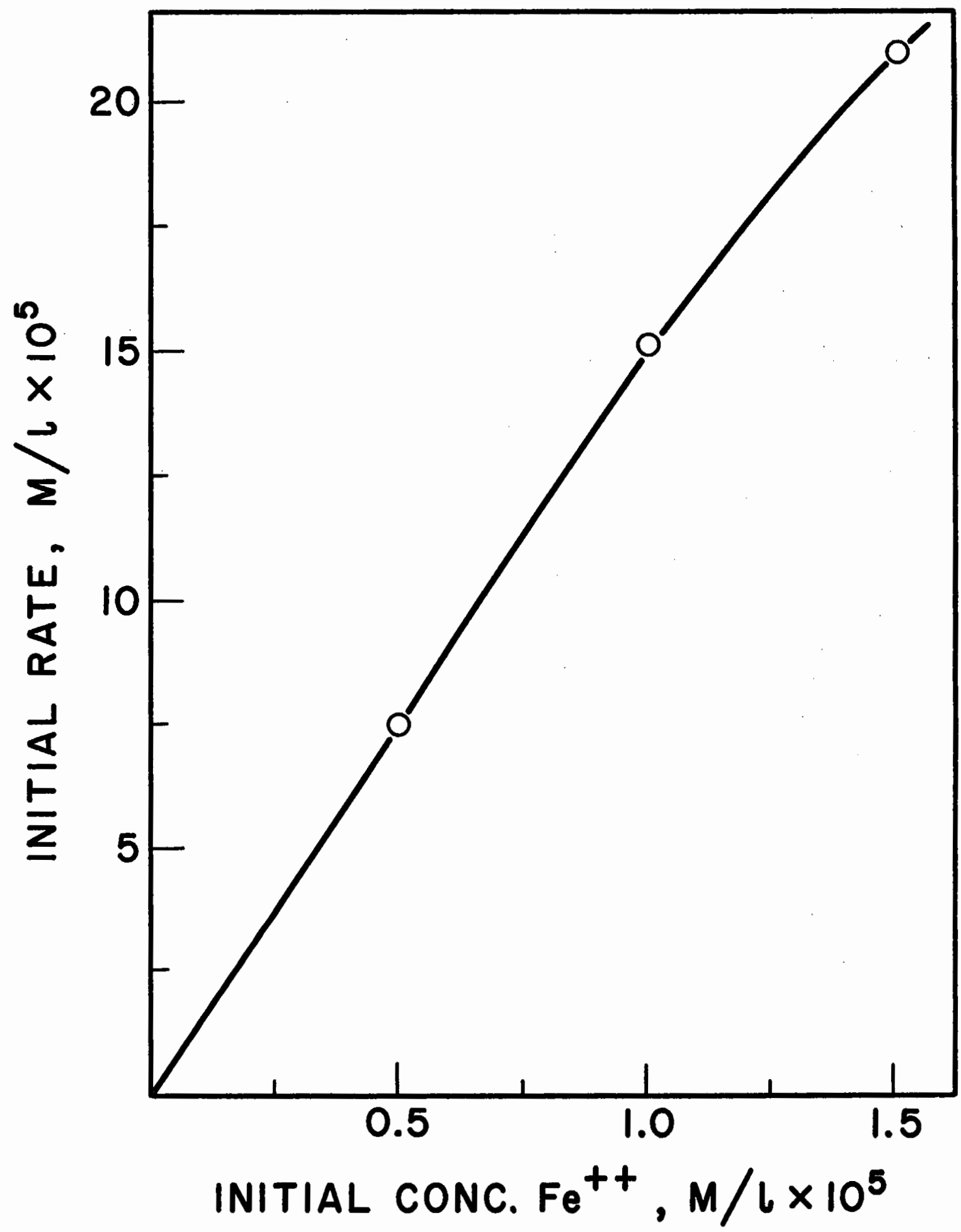


by periodically adding $10 \mathrm{ml}$. aliquots to mixtures of $5 \mathrm{ml}$. of $2 \mathrm{M}$ potassium thiocyanate solution and $2 \mathrm{ml}$. of $2 \mathrm{M}$ hydrochloric acid solution in $25 \mathrm{ml}$. volumetric flasks which were then fllled to the mark with water. The optical densities of the resulting red complex were then measured at a wavelength of $480 \mathrm{~m} \mu$ with a Beckmann DK spectrophotometer. The measurements are shown in Table XLVI.

The reciprocal optical densities for three representative experiments plotted against time (Figure 23) yield straight Iines corresponding to

$$
-\frac{d(D)}{d t}=k D^{2}
$$

The value of $k$ is directly proportional to the square of the mercaptan concentration. The fourth order rate constant is

$$
\mathbf{k}_{4}^{\prime}=\frac{k}{(\mathrm{TSH})^{2}} \quad \frac{\epsilon}{2.5}
$$

where $\epsilon$ represents the extinction coefficient of the ferric Ion - thiocyanate complex at $480 \mathrm{~m} \mu$ (Table XLVII). The logarithm of the fourth order rate constant plotted against the logarithm of the hydrogen ion concentration yielded a straight line of slope -3.7 (Figure 24). The rate constant may therefore be taken as inversely proportional to approximately the fourth power of the hydrogen ion concentration. Experiments were also made in which relatively small concentrations of sulphuric acid were added, and a marked 


\section{TABLE XIVI}

RATE OF DECREASE OF OPTICAL DENSITY (FERRIC ION CONCFNTRATION) WITH

DIFFERENT INITIAL CONCENTRATIONS OF FFRRIC ION AND THIOGLYCOLIC ACID

Extinction Coefficient $-1.10 \times 10^{4} 1 . M^{-1}$

Ionic Strength 1.00

\begin{tabular}{|c|c|c|c|c|c|c|c|}
\hline \multicolumn{8}{|c|}{ Conc. Perchloric Acid - M/I } \\
\hline \multicolumn{2}{|c|}{0.101} & \multicolumn{3}{|c|}{0.202} & 0.303 & \multicolumn{2}{|c|}{0.404} \\
\hline \multicolumn{8}{|c|}{ Initial Conc. Thioglycolic Acid $-\mathrm{M} / \mathrm{I}$} \\
\hline $\begin{array}{c}0.00075 \\
(\operatorname{Exp} .113) \\
\end{array}$ & $\begin{array}{c}0.00188 \\
(\operatorname{Exp} .114) \\
\end{array}$ & $\begin{array}{c}0.00375 \\
(\operatorname{Exp} .115) \\
\end{array}$ & $\begin{array}{c}0.00563 \\
(\operatorname{Exp} .116) \\
\end{array}$ & $\begin{array}{c}0.00375 \\
(\operatorname{Exp} .117) \\
\end{array}$ & $\begin{array}{c}0.00563 \\
(\operatorname{Exp} .118) \\
\end{array}$ & $\begin{array}{r}0.0 \\
(E \times F \\
\end{array}$ & $\begin{array}{l}00563 \\
p .119) \\
\end{array}$ \\
\hline $\begin{array}{c}\text { Time Optical } \\
\text { (min.)Density } \\
\text { D }\end{array}$ & $\begin{array}{c}\text { Time Optica] } \\
\text { (min.) Densit } \\
\text { D }\end{array}$ & $\begin{array}{l}\text { Time Optical } \\
\text { (min.) Density } \\
\text { D }\end{array}$ & $\begin{array}{l}\text { Time Optical } \\
\text { (min.) Density }\end{array}$ & $\begin{array}{c}\text { Time Optical } \\
\text { (min.) Density } \\
\text { D }\end{array}$ & $\begin{array}{c}\text { Time Optical } \\
\text { (min.) Density } \\
\text { D }\end{array}$ & $\begin{array}{l}\text { Time } \\
\text { (min.) }\end{array}$ & $\begin{array}{l}\text { Optical } \\
\text { Density } \\
\text { D }\end{array}$ \\
\hline $0.00 \quad 0.526$ & $0.00 \quad 0.526$ & $0.00 \quad 0.370$ & $0.00 \quad 0.370$ & $0.00 \quad 0.526$ & $0.00 \quad 0.526$ & 0.00 & 0.370 \\
\hline $2.25 \quad 0.392$ & $2.00 \quad 0.223$ & $2.00 \quad 0.263$ & $2.25 \quad 0.203$ & $2.00 \quad 0.363$ & 0.415 & 2.00 & 0.340 \\
\hline $5.50 \quad 0.301$ & 5.250 .110 & $5.75 \quad 0.178$ & 0.114 & $5.75 \quad 0.227$ & 0.310 & 9.00 & 0.283 \\
\hline $9.25 \quad 0.240$ & 8.750 .068 & 0.135 & 0.081 & 0.164 & 0.250 & 25.50 & 0.209 \\
\hline $13.25 \quad 0.199$ & & 0.100 & 0.057 & $13.00 \quad 0.129$ & 12.75 & 43.25 & 0.162 \\
\hline $17.00 \quad 0.166$ & & $17.75 \quad 0.078$ & $17.50 \quad 0.049$ & $16.50 \quad 0.108$ & $16.25 \quad 0.175$ & 70.00 & 0.125 \\
\hline $20.75 \quad 0.148$ & & $23.00 \quad 0.062$ & & $20.25 \quad 0.089$ & $19.75 \quad 0.153$ & & \\
\hline $\begin{array}{r}\left.1^{-1} \min { }^{-1}\right) \\
0.240\end{array}$ & 1.444 & 0.515 & 1.010 & 0.464 & 0.235 & & 0.0788 \\
\hline $\begin{array}{r}-2 \min ^{-1} \times 10^{-} \\
188\end{array}$ & 164 & 16.2 & 14.0 & 14.6 & 3.27 & & 1.10 \\
\hline
\end{tabular}




\section{FIGURE 23}

\section{EFFECT OF DIFFERENT INITIAL CONCENTRATIONS OF FERRIC ION, OF THIOGLYCOLIC ACID AND OF PERCHLORIC ACID ON THE RATE OF REACTION OF FERRIC ION WITH THIOGLYCOLIC ACID}

Ionic Strength 1.00
O Exp. 113
口 " 115
$\Delta \quad " 116$
- $\quad 117$ 


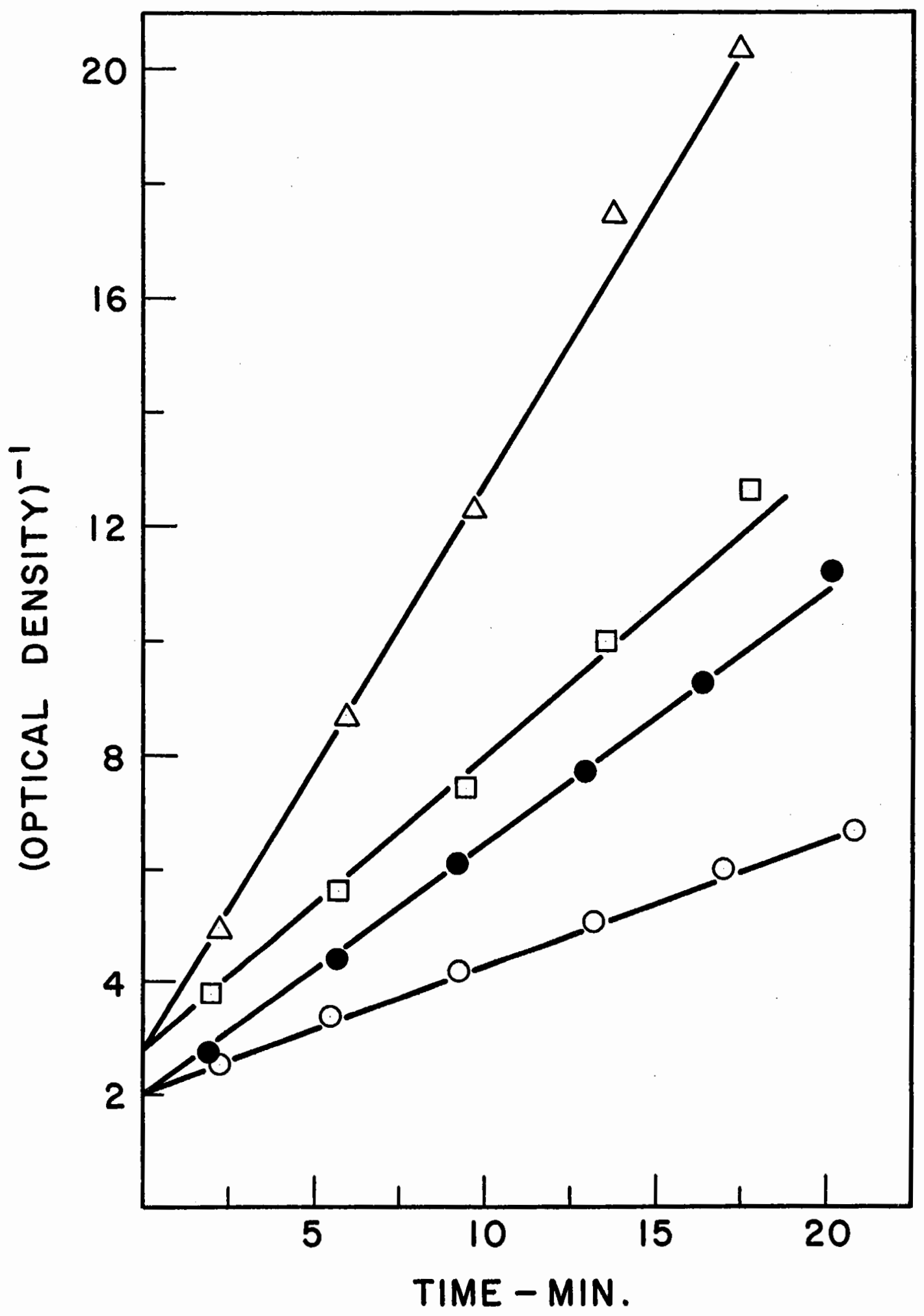


TABIE XLVII

EFFECT OF PERCHLORIC ACID CONCENTRATION ON THE FOURTH ORDER RATE CONSTANT $\mathrm{k}_{4}^{\prime}$

Ionic Strength 1.00

\begin{tabular}{c|c|c}
\hline Exp. No. & $\begin{array}{c}{\left[\mathrm{HClO}_{4}\right]} \\
\mathrm{M} / 1\end{array}$ & $\begin{array}{c}\mathrm{k}_{4}^{\prime} \\
\left(12 \mathrm{M}-2_{\mathrm{min}}^{-1}\right) \\
\mathrm{x} 10^{7}\end{array}$ \\
\hline 113 & 0.101 & 188 \\
114 & 0.101 & 164 \\
115 & 0.202 & 16.2 \\
116 & 0.202 & 14.0 \\
117 & 0.202 & 14.6 \\
118 & 0.303 & 3.27 \\
119 & 0.404 & 1.10 \\
\hline
\end{tabular}


$-129-$

FIGURE 24

EFFECT OF DIFFERENT CONCENTRATIONS OF PERCHLORIC ACID ON $k_{4}^{\prime}$, THE FOURTH ORDER RATE

CONSTANT FOR THE FERRIC ION - THIOGLYCOLIC ACID REACTION

Ionic Strength 1.00 


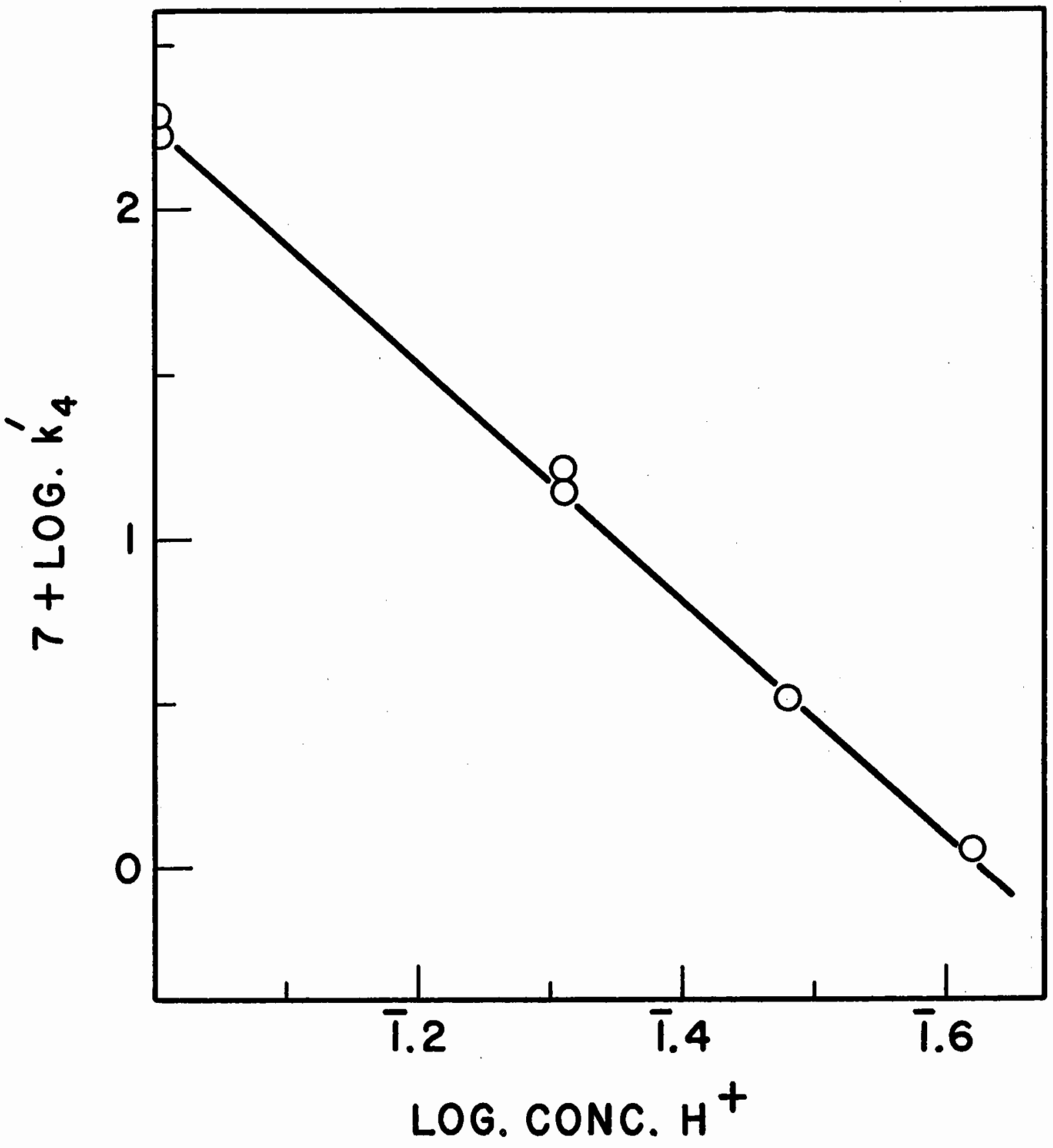


decrease in the reaction rate and in the fourth order rate constant resulted (Tables XIVIII and XIIX). This decrease was greater than could be explained by the small increase in hydrogen ion concentration resulting from the sulphuric acid adition to the system, and hence, it would seem apparent that sulphate ions were also retarding the reaction. Since under the conditions of these experiments $\mathrm{HSO}_{4}$ - ions were not completely dissociated, the dissociation constant (117) of this ion was employed in the determination of the sulphate ion concentration in the reaction mixture. From the above experiments, it may be concluded that the rate of reaction of ferric ions with thioglycolic acid in acidic solution ( $\mathrm{pH}<2$ ) was markedly retarded by both hydrogen and sulphate ions. 


\section{TABLE XLVIII}

RATE OF DECREASE OF OPTICAL DENSITY WITH DIFFERENT

CONCENTRATIONS OF SULPHURIC ACID

Ionic Strength 1.00

Conc. Perchloric Acid $0.101 \mathrm{M} / \mathrm{l}$

\begin{tabular}{c|c}
\hline \multicolumn{2}{c}{ Conc. Sulphuric Acid - M/I } \\
\hline 0.0098 & 0.0245 \\
\hline
\end{tabular}

Initial Conc. Thioglycolic Acid - M/I

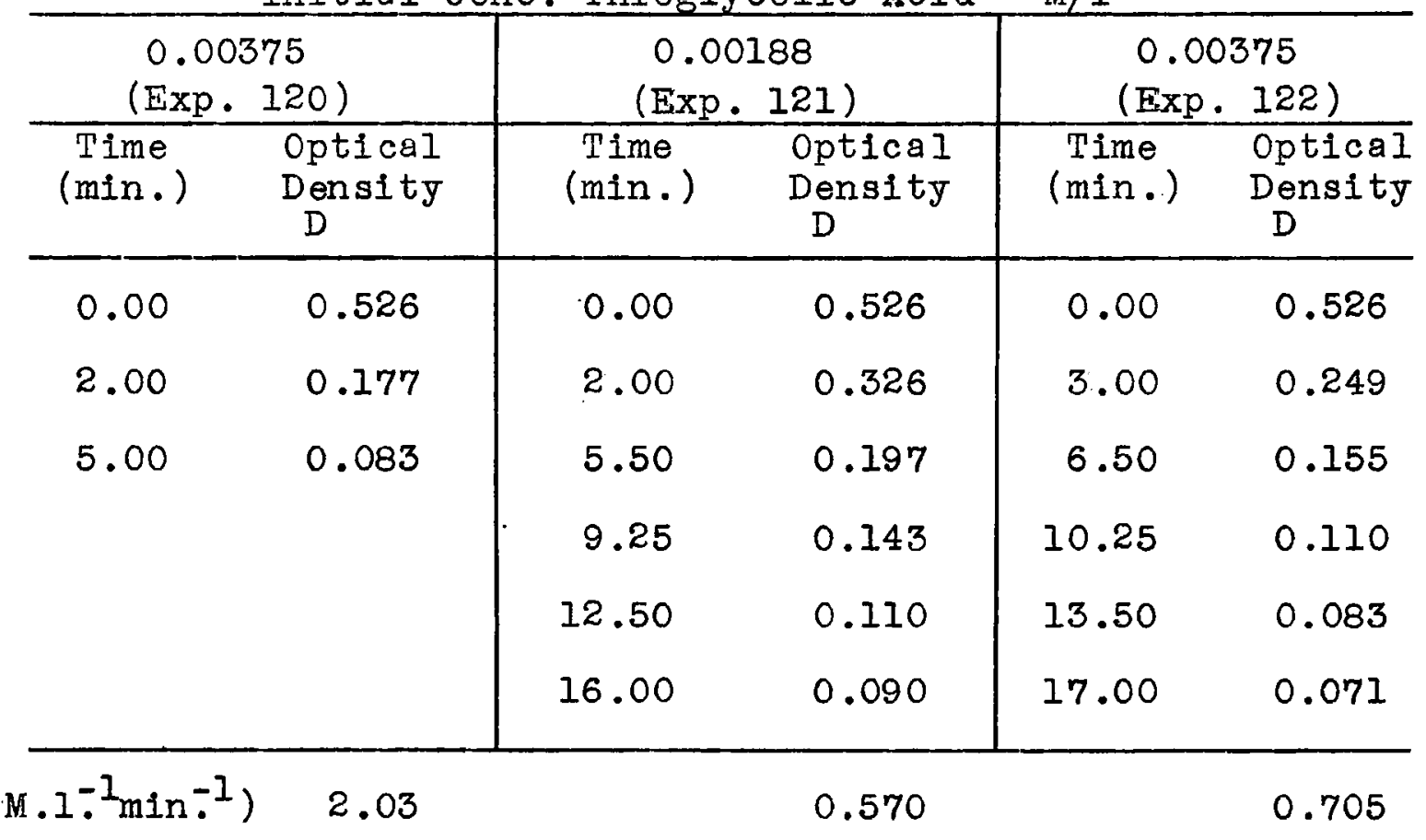

$k_{4}^{\prime \prime}\left(1{ }^{2}{ }^{2} 2^{2} \min ^{-1} \times 10^{-7}\right) 63.8$

71.4

22.1 
TABLE XLIX

EFFECT OF SULPHURIC ACID CONCENTRATION ON THE FOURTH

ORDER RATE CONSTANT $\mathrm{k}_{4}^{\prime \prime}$

Ionic Strength 1.00

\begin{tabular}{|c|c|c|c|c|c|}
\hline $\begin{array}{l}\text { Exp. } \\
\text { No. }\end{array}$ & $\begin{array}{c}{\left[\mathrm{H}_{2} \mathrm{SO}_{4}\right]} \\
\mathrm{M} / 1\end{array}$ & $\begin{array}{c}{\left[\mathrm{SO}_{4}=\right]} \\
\mathrm{M} / 1\end{array}$ & $\begin{array}{l}{\left[\mathrm{H}^{+}\right]} \\
M / 1\end{array}$ & $\left(\begin{array}{c}\left.\mathrm{k}_{4}^{\prime \prime} \mathrm{M}^{-2_{\min }^{-1}}{ }^{-1}\right) \\
\times 10^{-7}\end{array}\right.$ & $\begin{array}{c}k_{4}^{k_{4}^{\prime}} \\
\left(1_{\mathrm{M}}^{-2}{ }_{\min }^{-1}\right) \\
\times 10^{-7}\end{array}$ \\
\hline 120 & 0.0098 & 0.0070 & 0.118 & 63.8 & 110 \\
\hline 121 & 0.0098 & 0.0070 & 0.118 & 71.4 & 110 \\
\hline 122 & 0.0245 & 0.0170 & 0.143 & 22.1 & 52.5 \\
\hline
\end{tabular}

Note: Values of $k_{4}^{\prime}$ were interpolated from Figure 22. 


\section{DISCUSSION}

The results of the experiments which were made in the presence of added iron demonstrated that cations of this metal were capable of catalyzing very markedly the reaction of persulphate with thioglycolic acid to yield dithiodiglycolic acid. The reaction rate was observed to decrease with decrease in the concentration of dissolved iron, and to extrapolate to zero when the concentration of iron approached zero (Figuresio and 22). In the light of this observation it is concluded that, in the presence of measurable concentrations of dissolved iron, the disappearance of persulphate by either homolytic dissociation or by direct reaction with thioglycolic acid was negligible under the conditions of these experiments.

The rate of the iron catalyzed reaction, except when the reaction mixtures were $0.10 \mathrm{M}$ and $0.15 \mathrm{M}$ in sulphuric acid, was independent of the mercaptan concentration and was first order in the concentration of persulphate. Division of the first order rate constant for persulphate disappearance by the total concentration of iron present yielded a value which was independent of the iron concentration, and which was equal to the rate constant for the reaction of persulphate with ferrous ion measured under similar conditions, but in the absence of mercaptan. In addition, the above mentioned quotient was influenced by ionic strength in exactly the same way as the rate constant for the ferrous ion - persulphate reaction (32). 
Hence, under the conditions of these experiments the form of the catalyst cycle appears to be quite clear. The observations suggest that ferrous ion was slowly oxidized by persulphate to ferric ion, and that this step was followed by the very rapid reduction of the ferric ion by thioglycolic acid. The results of previous investigations (32, 33, 42) have indicated that when persulphate reacts with ferrous ion, a ferric ion and a sulphate ion radical are produced. The sulphate ion radical may in turn react with a second ferrous ion or with an organic compound provided one is present. For the reaction which is being considered here, the following tentative scheme is suggested.

and/or

$$
\begin{aligned}
& \mathrm{S}_{2} \mathrm{O}_{8}=+\mathrm{Fe}^{++} \stackrel{(\mathrm{slow}}{\longrightarrow} \mathrm{Fe}^{+++}+\mathrm{SO}_{4}=+\mathrm{SO}_{4} \dot{-} \\
& \mathrm{SO}_{4} \dot{-}+\mathrm{Fe}^{++} \stackrel{\text { (fast) }}{\longrightarrow} \mathrm{Fe}^{+++}+\mathrm{SO}_{4}= \\
& \mathrm{SO}_{4} \dot{-}+\mathrm{TSH} \stackrel{\text { (fast) }}{\rightarrow} \mathrm{TS} \cdot+\mathrm{HSO}_{4}^{-} \\
& 2 \mathrm{Fe}^{+++}+2 \mathrm{TSH} \stackrel{\text { (fast) }}{\longrightarrow} \mathrm{TSST}+2 \mathrm{Fe}^{++}+2 \mathrm{H}^{+} \\
& \text {2TS } \stackrel{\text { (frst) }}{\rightarrow} \text { TSST }
\end{aligned}
$$

These steps predict that the reaction rate will be given by the following expression

$$
\begin{aligned}
-\frac{d\left[\mathrm{~S}_{2} \mathrm{O}_{8}=\right]}{\mathrm{dt}} & =\mathrm{k}_{1}\left[\mathrm{~S}_{2} \mathrm{O}_{8}=\right]\left[\mathrm{Fe}^{++}\right] \\
& =\mathrm{k}_{1}\left[\mathrm{~S}_{2} \mathrm{O}_{8}=\right][\mathrm{Fe}]
\end{aligned}
$$


where [Fe] represents the total concentration of iron in the system.

It was possible to determine from the spectrophotometric measurements both the persulphate and ferrous ion concentrations as functions of time in the reaction mixtures which were $0.15 \mathrm{M}$ in sulphuric acid, and these results also indicated that the rate of disappearance of persulphate was given by the above expression, namely

$$
-\frac{d\left[\mathrm{~S}_{2} \mathrm{O}_{8}=\right]}{d t}=k_{1}\left[\mathrm{~S}_{2} \mathrm{O}_{8}=\right]\left[\mathrm{Fe}^{++}\right]
$$

Hence, the avallable evidence establishes beyond reasonable doubt that persulphate was destroyed only by reaction with ferrous ion and by no other process, and that neither thioglycolic acid nor any substances derlved from thioglycolic acid had any influence upon this reaction.

Second order rate constants for the persulphate - ferrous Ion reaction have been measured by Williams and his co-workers $(32,33)$ at several temperatures. In their reaction mixtures the $\mathrm{pH}$ was adjusted to four. The second order rate constants measured in the present series of experiments were approximately $50 \%$ of the values obtained by Williams et al. The difference might result from the much larger hydrogen ion concentration (100 to 1000 fold) in the present experiments. However, until more experiments have been made the reason for the discrepancy will remain uncertain. 
When the persulphate - mercaptan mixtures were $0.10 \mathrm{M}$ and $0.15 \mathrm{M}$ in sulphuric acid, the rate of disappearance of persulphate was a function of both the initial concentration of thioglycolic acid and the initial persulphate concentration. This observation suggests that, at higher acid concentration, the reduction of ferric ion by thioglycolic acid no longer proceeded at a rate which was rapid relative to the rate of the persulphate - ferrous ion reaction. However, before considering the possible significance of these results it seems necessary to examine the data for the reaction between ferric ions and thioglycolic acid in the absence of persulphate.

The rate of reaction of ferric ion with thioglycolic acid was second order in both the concentration of ferric ion and the concentration of thioglycolic acid,

i.e. $\quad-\frac{d[f e r r i c]}{d t}=k_{4}[\text { ferric }]^{2}[\operatorname{thiog} 1 \text { jcolic acid }]^{2}$

This suggests that before reaction occurred, a complex containing two ferric ions and two thioglycolic acid molecules was formed. That complexes in the ferric ion - thioglycolic acid system do exist is indicated by the blue colour which was produced when the two reactants were mixed initially. This blue complex disappeared very rapidly, and partly for this reason no attempt was made to determine experimentally either its structure or its mode of decay. However, Lamfrom and Nielsen (105) have shown that the blue complex disappeared 
by a first order process at $-35^{\circ} \mathrm{C}$ in a solvent consisting of 6 parts by volume of ethanol to 10 parts water. It would appear, therefore, that the blue complex might well be formed of two ferric ions and two thioglycolic acid molecules. The fourth order rate constant for the reaction was observed to be inversely proportional to the fourth power of the concentration of perchloric acid. Hydrated ferric ion, $\mathrm{FeOH}^{+}$, would exist in very small quantities even in these acidic solutions $(\mathrm{pH} \cong 1.0)$ (121), and this substance rather than free ferric ion might have been the reactive species. Also, both the carboxyl group and the sulphydryl group of the thioglycolic acid are capable of ionizing according to the following scheme, though under the conditions of these experiments both these ionizations would have occurred to only a very low degree (7I, 72).

$$
\begin{aligned}
\mathrm{HSCH}_{2} \mathrm{COOH} & \Rightarrow \mathrm{HSCH}_{2} \mathrm{COO}^{-}+\mathrm{H}^{+} \\
\mathrm{H}^{+}+-\mathrm{SCH}_{2} \mathrm{COOH} & \rightleftarrows-\mathrm{SCH}_{2} \mathrm{COO}^{-}+2 \mathrm{H}^{+} \\
{\left[-\mathrm{SCH}_{2} \mathrm{COOH}\right] } & =\frac{\mathrm{K}^{\prime \prime}\left[\mathrm{HSCH}_{2} \mathrm{OOH}\right]}{\left[\mathrm{H}^{+}\right]} \\
\text {and } & =\frac{\mathrm{K}^{\prime} \mathrm{K}^{\prime \prime \prime} \mathrm{K}^{\prime \prime \prime}\left[\mathrm{HSCH} \mathrm{COOH}^{\prime \prime \prime}\right.}{\left[\mathrm{K}^{+}\right]} \\
{\left[-\mathrm{SCH}_{2} \mathrm{COO}\right] } & =\frac{\mathrm{K}^{\prime} \mathrm{K}^{\prime \prime \prime}\left[\mathrm{HSCH}_{2} \mathrm{COOH}\right]}{\left[\mathrm{H}^{+}\right]^{2}} \\
& =\frac{\mathrm{K}^{\prime} \mathrm{K}^{\prime \prime \prime}\left[\mathrm{HSCH}_{2} \mathrm{COOH}\right]}{\left[\mathrm{H}^{+}{ }^{2}\right.}
\end{aligned}
$$


It is conceivable that one of the ionized species of thloglycolic acid rather than the undissociated molecule was important in the reaction.

When low concentrations of sulphuric acid were added to the reaction mixtures in perchloric acid and sodium perchlorate, the fourth order rate constant was decreased markedly. Since the change in the hydrogen ion concentration brought about by the addition of the sulphuric acid was insufficlent to explain the large decrease in the rate constant, it appeared that the ferric sulphate complex must have been formed (119) and was incapable of reaction with the mercaptan.

These observations may be explained by postulating either hydrated ferric ion to be in equilibrium with the mercaptide ion or free ferric ion to be in equilibrium with the doubly ionized thioglycolic acid. It is suggested that the reaction rate was governed by the first order decomposition of the complex containing the two ferric ions and the two thioglycolic acid molecules to yield disulphide and ferrous ion. The following mechanism is proposed:

$$
\begin{aligned}
\mathrm{Fe}^{+++}+\mathrm{SO}_{4}= & \rightleftarrows \mathrm{FeSO}_{4}^{+} \\
\mathrm{FeSO}_{4}^{+}+\mathrm{SO}_{4}= & \rightleftharpoons \mathrm{Fe}\left(\mathrm{SO}_{4}\right)_{2}^{-} \\
\mathrm{Fe}^{+++}+\mathrm{ClO}_{4}^{-} & \rightleftharpoons \mathrm{FeClO} 4^{2+} \\
\mathrm{Fe}^{+++}+\mathrm{H}_{2} \mathrm{O} & \rightleftharpoons \mathrm{FeOH}{ }^{2+}+\mathrm{H}^{+} \\
\mathrm{TSH} & \rightleftharpoons \mathrm{TS}^{-}+\mathrm{H}^{+}
\end{aligned}
$$




$$
\begin{aligned}
& \mathrm{FeOH}^{2+}+\mathrm{TS}^{-} \rightleftharpoons \mathrm{FeOHTS}^{2+} \\
& 2 \mathrm{FeOHTS}^{2+} \rightleftharpoons \mathrm{Fe}_{2}(\mathrm{OH})_{2}(\mathrm{TS})_{2}{ }^{4+} \\
& \mathrm{Fe}_{2}(\mathrm{OH})_{2}(\mathrm{TS})_{2}^{4+} \rightarrow 2 \mathrm{Fe}^{++}+\mathrm{TSST}+2 \mathrm{H}_{2} \mathrm{O}
\end{aligned}
$$

Step (II) in the above scheme is assumed to be rate controlling, hence rate of disappearance of ferric ion to be given by

$$
\begin{aligned}
-\frac{\mathrm{d}[\mathrm{ferric}]^{2}}{\mathrm{dt}} & =k_{4}^{\prime}[\text { ferric }]^{2}[\text { thioglycolic acid }]^{2}= \\
& =\mathrm{k}_{11}\left[\mathrm{Fe} 2(\mathrm{OH})_{2}(\mathrm{TS})_{2}^{4+}\right]
\end{aligned}
$$

If the iron - mercaptan complexes are assumed to be highly dissociated, then (i) becomes

$$
\begin{aligned}
& \mathrm{k}_{4}^{1}[\text { ferric }]^{2}[\text { thioglycolic acid }]^{2}= \\
= & \frac{\mathrm{k}_{11} \mathrm{~K}_{10} \mathrm{~K}_{9}^{2} \mathrm{~K}_{\mathrm{B}}^{2} \mathrm{~K}_{7}^{2}}{\left[\mathrm{H}^{+}\right]^{4}}\left[\mathrm{Fe}^{+++}\right]^{2}[\mathrm{TSH}]^{2}
\end{aligned}
$$

where [ferric] and [thioglycolic acid] represent the total concentrations of ferric ion and thioglycolic acid in the reaction mixture respectively. In the absence of sulphate ion the following relations will hold:

$$
\begin{aligned}
{[\text { ferric }] } & =\left[\mathrm{Fe}^{+++}\right]\left\{1+\mathrm{K}_{6}\left[\mathrm{ClO}_{4}-\right]+\mathrm{K}_{7} /\left[\mathrm{H}^{+}\right]\right\} \\
& \cong\left[\mathrm{Fe}^{+++}\right]
\end{aligned}
$$

and $[$ thioglycolic acid $]=[\mathrm{TSH}]\left\{I+K_{8} /\left[\mathrm{H}^{+}\right]\right\}$

$$
\cong[\mathrm{TSH}]
$$


Since the hydrogen ion concentrations in the reaction mixtures were large, both $\mathrm{K}_{7} /\left[\mathrm{H}^{+}\right]$and $\mathrm{K}_{8} /\left[\mathrm{H}^{+}\right]$may be neglected. Evidence has been obtained by Sykes (55) that complex formation between ferric ions and perchlorate ions does occur to a small degree, but it will be assumed to be negligible in the present experiments. Hence,

$$
k_{4}^{\prime}=\frac{k_{11} K_{10} K_{9}^{2} K_{8}^{2} K_{7}^{2}}{\left[H^{+}\right]^{4}}
$$

In the presence of low concentrations of sulphuric acid, the reaction rate is postulated to be given by

$$
\begin{aligned}
& k_{4}^{\prime \prime}[\text { ferric }]^{2}[\text { thioglycolic acid }]^{2}= \\
& =\frac{\mathrm{K}_{11} \mathrm{~K}_{10} \mathrm{~K}_{9}^{2} \mathrm{~K}_{8}^{2} \mathrm{~K}_{7}^{2}}{\left[\mathrm{H}^{+}\right]^{4}}\left[\mathrm{Fe}^{+++}\right]^{2}[\mathrm{TSH}]^{2}
\end{aligned}
$$

and under these conditions

Hence

$$
[\text { ferric }]=\left[\mathrm{Fe}^{+++}\right] \quad\left\{1+\mathrm{K}_{4}\left[\mathrm{SO}_{4}=\right]\right\}
$$

$$
k_{4}^{n}=\frac{k_{11} K_{10} K_{9}^{2} K_{8}^{2} K_{7}^{2}}{\left[\mathrm{H}^{+}\right]^{2}\left\{1+K_{4}\left[\mathrm{sO}_{4}=\right]\right\}^{2}}
$$

The concentration of sulphate ion was sufficiently low that the concentration of $\mathrm{Fe}\left[\mathrm{SO}_{4}\right]_{2}^{-}$was negligible (II9). By combining equations (iii) and $(v)$ the following relation was obtained.

$$
\mathrm{K}_{4} \stackrel{\sqrt{\mathrm{x}_{4}^{\prime} / \mathrm{k}_{4}^{\prime \prime}-1}}{\left[\mathrm{SO}_{4}=\right]}
$$


Values of the association constant, $K_{4}$, of the ferric ion sulphate complex were calculated (Table L) using equation (vi), and were considerably less than the value of $95 \pm 5$ reported by Whitekar and Davidson (119). The uncertainty of \pm 15 in the present values arose from errors of $\pm 10 \%$ in the rate constants, which were very sensitive to hydrogen ion concentration. However, in spite of the difference between the present value and that determined by Whitekar and Davidson, support is given to the assumption that ferric ion sulphate complexes did not react appreciably with thioglycolic acid.

According to the proposed mechanism, the fourth order rate constant, $k_{4}^{\prime \prime \prime}$, measured in the earlier experiments when only sulphuric acid was present in appreciable amounts in the ferric ion - mercaptan reaction mixtures, would be given by the expression

$$
k_{4}^{\prime \prime \prime}=\frac{k_{11} K_{10} K_{9}^{2} K_{8}^{2} K_{\eta}^{2}}{\left[H^{+}\right]^{4}\left\{1+K_{4}\left[S_{4}=\right]+K_{4} K_{5}\left[S_{4}=\right]^{2}\right\}^{2}}
$$

However, when the concentration of sulphuric acid was varied, the ionic strength of the reaction mixtures was not kept constant and the above equation cannot be examined in detall. In the above discussion, it has been assumed that hydrated ferric ions were in equilibrium with mercaptide ion. As was mentioned earlier, however, the results could be explained equally well by assuming that free ferric ions were 
- $142-$

TABLE L

ASSOCIATION CONSTANT FOR THE COMPLEX BETWEEN

FERRIC AND SULPHATE IONS

\begin{tabular}{c|c}
\hline Exp. No. & $\begin{array}{c}\mathrm{K}_{4} \\
\left(1 . \mathrm{M}^{-1}\right)\end{array}$ \\
\hline 120 & $45 \pm 15$ \\
122 & $34 \pm 15$ \\
\hline
\end{tabular}


in equilibrium with doubly ionized thioglycolic acid. In mildly acidic solution and in alkaline solution $(\mathrm{pH}=4.6$ to 10$)$ it has been postulated that hydrated ferric ion rather than free ferric ion may complex with thioglycolic acid (101, 105, 107). Furthermore, the present experimental results may also be accounted for if the complexes $\mathrm{Fe}_{2}(\mathrm{OH})_{2} \mathrm{TS}^{3+}$ and $\mathrm{FeOH}(\mathrm{TS})_{2}$ (or $\mathrm{Fe}_{2} \mathrm{TS}^{4+}$ and $\mathrm{Fe}(\mathrm{TS})_{2}^{-}$) are also postulated to exist. Except for the uncertainty about the structure of the ferric ion - mercaptan complexes, the reaction of ferric ion with thioglycolic acid in acidic solution appears to be straightforward. Returning now to the problem of main interest, namely the iron catalyzed reaction of persulphate with thioglycotic acid, an attempt will be made to interpret the results of the experiments which were made in $0.10 \mathrm{M}$ and $0.15 \mathrm{M}$ sulphuric acid.

When the reaction mixtures were in sulphuric acid of these concentrations, it was observed that ferric ion was reduced by thioglycolic acid much more rapidly in the presence of persulphate than in its absence. This indicates that, In the presence of persulphate, ferric ion and thioglycolic acid disappeared by a reaction which did not occur in the absence of persulphate, and consequently would not be involved in the mechanism postulated for the ferric ion - thioglycolic acid reaction.

In experiments in which persulphate was added to mixtures of ferrous ion and thioglycolic acid in $0.10 \mathrm{M}$ sulphuric acid, 
the blue complex was observed to form and subsequently disappear provided the initial ferrous ion concentration was sufficiently large $\left(\geq 5 \times 10^{-3} \mathrm{M}\right)$. This indicated that besides the additional ferric ion - thioglycolic acld reaction, the reactions postulated in the mechanism for the ferric ion mercaptan reaction occurred to some extent in the presence of persulphate.

Hence, neglecting for the time being this rapid reaction of ferric ion with thioglycolic acid, which takes place in the presence of persulphate, it is assumed that the following reactions occurred in the persulphate - mercaptan mixtures.

$$
\begin{aligned}
& \mathrm{S}_{2} \mathrm{O}_{8}=+\mathrm{Fe}^{++} \rightarrow \mathrm{Fe}^{+++}+\mathrm{SO}_{4}=+\mathrm{SO}_{4} \dot{-} \\
& \mathrm{SO}_{4} \dot{-}+\mathrm{Fe}^{++} \rightarrow \mathrm{Fe}^{+++}+\mathrm{SO}_{4}= \\
& \mathrm{SO}_{4}-\dot{\mathrm{TSH}} \rightarrow \mathrm{TS} \cdot+\mathrm{HSO}_{4}^{-} \\
& \mathrm{Fe}^{+++}+\mathrm{SO}_{4}=\mathrm{FeSO}_{4}^{+} \\
& \mathrm{FeSO}_{4}{ }^{+}+\mathrm{SO}_{4}=\mathrm{Fe}\left(\mathrm{SO}_{4}\right)_{2}^{-} \\
& \mathrm{Fe}^{+++}+\mathrm{H}_{2} \mathrm{O} \rightleftharpoons \mathrm{FeOH}^{2+}+\mathrm{H}^{+} \\
& \mathrm{TSH}=\mathrm{TS}^{-}+\mathrm{H}^{+} \\
& \mathrm{FeOH}^{2+}+\mathrm{TS}^{-}=\mathrm{FeOHTS}^{+} \\
& 2 \mathrm{FeOHTS}^{+}=\mathrm{Fe}_{2}(\mathrm{OH})_{2}(\mathrm{TS})_{2} 2+ \\
& 2 \mathrm{Fe}_{2}(\mathrm{OH})_{2}(\mathrm{TS})_{2} \rightarrow 2 \mathrm{Fe} e^{++}+\mathrm{TSST}+2 \mathrm{H}_{2} \mathrm{O} \\
& \text { 2TS } \cdot \rightarrow \text { TSST }
\end{aligned}
$$

In all the experiments the thloglycolic acid concentrations exceeded the concentrations of iron by a factor of at least twenty, and assuming the rate constants of steps (2) and (3) 
to be of the same order of magnitude, reaction (2) may be neglected without introducing an appreciable error.

The results obtained when the reaction mixtures in $0.15 \mathrm{M}$ sulphuric acid were examined spectrophotometrically appear to justify application of the stationary state concept to the ferrous ion concentration. This yields the following expression.

$$
-\frac{\mathrm{d}\left[\mathrm{Fe}^{++}\right]}{\mathrm{dt}}=\mathrm{k}_{1}\left[\mathrm{~S}_{2} \mathrm{O}_{8}=\right]\left[\mathrm{Fe}^{++}\right]-\mathrm{k}_{11}\left[\mathrm{Fe} 2(\mathrm{OH})_{2}(\mathrm{TS})_{2}^{2+}\right]=0
$$

Hence,

$$
\begin{aligned}
\mathrm{k}_{1}\left[\mathrm{~S}_{2} \mathrm{O}_{8}=\right]\left[\mathrm{Fe}^{++}\right] & =\mathrm{k}_{11}\left[\mathrm{Fe} e_{2}(\mathrm{OH})_{2}(\mathrm{TS})_{2}^{2+}\right] \\
& =k_{4}^{\prime \prime \prime}[\mathrm{ferric}]^{2}[\text { thioglycolic acid }]^{2}
\end{aligned}
$$

This rearranges to

$$
\frac{D_{m}-D}{D^{2}}=\frac{k_{4}^{\prime \prime \prime}}{\epsilon k_{1}} \frac{[T S H]^{2}}{\left[S_{2}{ }^{\circ}=\right]}
$$

where

$$
D=\epsilon[\text { ierric }]
$$

and

$$
\left.D_{m}-D=\epsilon \text { [ferrous }\right]
$$

D represents the optical density of the system at $325 \mathrm{~m} \mu$, and $D_{m}$ represents the optical density if all the iron had been in the ferric state.

In Figures 25, 26 and 27 values of $\frac{D_{m}-D}{D^{2}}$, for reaction mixtures in which the iron was initially ferrous, were plotted against $[\mathrm{TSH}]^{2} /\left[\mathrm{S}_{2} \mathrm{O}_{8}=\right.$ ] to yield straight lines for constant initial mercaptan concentration. The slopes of these lines, multiplied by $\epsilon$, gave values which were much greater than the 
calculated values of $k_{4}^{\prime \prime \prime} / k_{1}$, and were approximately inversely proportional to the initial thioglycolic acid concentration (Table LIV) - the curved line of Figure 27 was probably due to the varying initial mercaptan concentrations in these particular experiments. On the other hand, they were not a function of the extent of reaction in a given system (Figure 25) which suggested that

$$
\frac{D_{m}-D}{D^{2}} \propto \frac{1}{[\mathrm{TSH}]_{0}} \frac{[\mathrm{TSH}]^{2}}{\left[\mathrm{~S}_{2} \mathrm{O}_{8}{ }^{\mathrm{x}}\right]}
$$

where $[\mathrm{TSH}]_{0}$ represents the initial thioglycolic acid concentration. For constant initial concentrations of persulphate and the mercaptan $\frac{D_{m}-D}{D^{2}}$ decreased with decrease in the concentration of iron in the system (Table LV). This suggested that, contrary to the earlier assumption, the reaction of sulphate ion radicals with ferrous ion was not negligible relative to that with thioglycolic acid.

In the light of these observations, it appears that the experimental results can be described by the following relation,

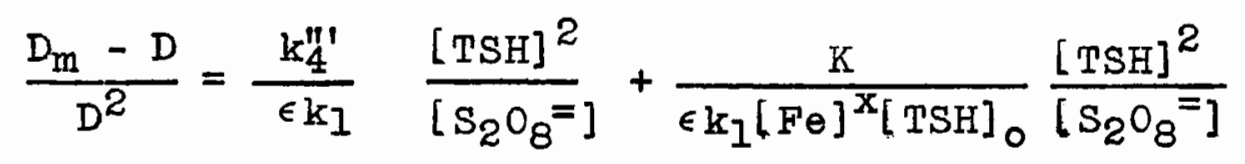

where $x$ need not be a constant, and it is postulated that the second term on the right represents the contribution by the relatively rapid reaction of ferric ion with thioglycolic acid in the presence of persulphate. The first term refers to 
TABLE LI

VARIATION OF $\frac{D_{m}-D}{D^{2}}$ WITH $\frac{[T S H]^{2}}{\left[\mathrm{~S}_{2} \mathrm{O}_{8}=\right]}$

Conc. Sulphuric Acid $0.15 \mathrm{M} / \mathrm{I}$

Initial Conc. Thioglycolic Acid $0.01095 \mathrm{M} / \mathrm{l}$

$\underline{D_{m}}=0.190$

\begin{tabular}{c|c|c|c|c|c}
\hline $\begin{array}{c}\text { Exp. } \\
\text { No. }\end{array}$ & $\begin{array}{c}\text { Optical } \\
\text { Density } \\
D_{325}\end{array}$ & $\frac{D_{m}-D}{D^{2}}$ & $\begin{array}{c}{\left[\mathrm{S}_{20}=\right]} \\
\mathrm{M} / 1 \\
\times 10^{3}\end{array}$ & $\begin{array}{c}{[\mathrm{TSH}]} \\
\mathrm{M} / 1 \\
\times 10^{3}\end{array}$ & $\begin{array}{c}\frac{[\mathrm{TSH}]^{2}}{\left[\mathrm{~S}_{2} \mathrm{O}_{8}\right]} \\
\mathrm{M} / 1 \times 10^{2}\end{array}$ \\
\hline 99 & 0.065 & 29.6 & 1.50 & 9.90 & 6.53 \\
99 & 0.058 & 39.4 & 1.00 & 8.90 & 7.90 \\
100 & 0.083 & 15.5 & 3.50 & 9.90 & 2.80 \\
100 & 0.090 & 12.3 & 3.00 & 8.90 & 2.63 \\
100 & 0.090 & 12.3 & 1.00 & 4.95 & 2.44 \\
101 & 0.100 & 9.0 & 5.50 & 9.90 & 1.78 \\
101 & 0.105 & 7.7 & 5.00 & 8.90 & 1.58 \\
101 & 0.119 & 5.0 & 3.00 & 4.95 & 0.81 \\
102 & 0.108 & 7.1 & 7.50 & 9.90 & 1.31 \\
102 & 0.115 & 5.7 & 7.00 & 8.90 & 1.13 \\
102 & 0.133 & 3.2 & 5.00 & 4.95 & 0.49 \\
\hline
\end{tabular}


TABLE LII

VARIATION OF $\frac{D_{m}-D}{D^{2}}$ WITH $\frac{\left[\mathrm{TSH}^{2}\right.}{\left[\mathrm{S}_{2} \mathrm{O}_{8}=\right]}$

Conc. Sulphuric Acid $0.15 \mathrm{~m} / 1$

Initial Conc. Thioglycolic Acid $0.00436 \mathrm{M} / \mathrm{l}$

$\underline{D_{m}}=0.190$

\begin{tabular}{l|c|c|c|c|c}
\hline Exp. No. & $\begin{array}{c}\text { Optica } \\
\text { Density } \\
D_{325}\end{array}$ & $\frac{D_{m}-\mathrm{D}}{\mathrm{D}^{2}}$ & $\begin{array}{c}{\left[\mathrm{S}_{2} \mathrm{O}_{8}=\right]} \\
\mathrm{M} / 1 \\
\mathrm{x} 10^{3}\end{array}$ & $\begin{array}{c}{[\mathrm{TSH}]} \\
\mathrm{M} / 1 \\
\times 10^{3}\end{array}$ & $\begin{array}{c}\frac{[\mathrm{TSH}]^{2}}{\left[\mathrm{~S}_{2} \mathrm{O}_{8}=\right.} \\
\mathrm{M} / 1 \\
\mathrm{x} 10^{2}\end{array}$ \\
\hline 103 & 0.098 & 9.60 & 1.50 & 3.36 & 0.747 \\
103 & 0.100 & 9.00 & 1.00 & 2.36 & 0.558 \\
104 & 0.114 & 5.85 & 3.50 & 3.36 & 0.323 \\
104 & 0.120 & 5.00 & 3.00 & 2.36 & 0.185 \\
105 & 0.142 & 2.38 & 7.50 & 3.36 & 0.150 \\
105 & 0.148 & 1.93 & 7.00 & 2.36 & 0.080 \\
\hline
\end{tabular}


TABLE LIII

VARIATION OF $\frac{D_{m}-D}{D^{2}}$ WITH $\frac{[T S H]^{2}}{\left[\mathrm{~S}_{2} \mathrm{O}_{8}=\right.}$

Conc. Sulphuric Acid $0.15 \mathrm{M} / \mathrm{I}$

Initial Conc. Potassium Persulphate $0.00400 \mathrm{M} / \mathrm{I}$

$D_{m}=0.190$

\begin{tabular}{c|c|c|c|c|c|c}
\hline $\begin{array}{c}\text { Exp. } \\
\text { No. }\end{array}$ & $\begin{array}{c}\text { In1tial } \\
{[\mathrm{TSH}]_{0}} \\
\mathrm{M} / 1 \\
\mathrm{x} 10^{3}\end{array}$ & $\begin{array}{c}\text { Optical } \\
\text { Density }\end{array}$ & $\frac{\mathrm{D}_{\mathrm{m}}-\mathrm{D}}{\mathrm{D}^{2}}$ & $\begin{array}{c}{\left[\mathrm{S}_{2} \mathrm{O}_{8}\right]} \\
\mathrm{M} / 1 \\
\times 10^{3}\end{array}$ & $\begin{array}{c}{[\mathrm{TSH}]} \\
\mathrm{M} / 1 \\
\times 10^{3}\end{array}$ & $\begin{array}{c}\frac{[\mathrm{TSH}]^{2}}{\left[\mathrm{~S}_{2} \mathrm{O}_{8}\right]^{2}} \\
\mathrm{M} / 1 \mathrm{x} 0^{2}\end{array}$ \\
\hline 106 & 2.18 & 0.131 & 3.45 & 3.50 & 1.18 & 0.04 \\
107 & 7.63 & 0.098 & 9.58 & 3.50 & 6.63 & 1.26 \\
107 & 7.63 & 0.105 & 7.73 & 3.00 & 5.63 & 1.02 \\
108 & 15.30 & 0.072 & 22.8 & 3.50 & 14.30 & 5.82 \\
108 & 15.30 & 0.073 & 22.0 & 3.00 & 13.30 & 5.87 \\
\hline
\end{tabular}




\section{TABLE LIV}

COMPARISON OF THE CALCULATED VALUE OF $\frac{k_{4}^{n \prime}}{k_{l}}$ WITH

THOSE DETERMINED FROM THE SLOPES IN FIGURES 25 AND 26

\begin{tabular}{l|l|c|c|c|c}
\hline Figure & Slope & $\begin{array}{c}\epsilon \times \text { Slope } \\
\times 10^{-4} \\
\left(=\frac{\mathrm{k}_{4}^{\prime \prime \prime}}{\mathrm{k}_{1}}\right)\end{array}$ & $\begin{array}{c}\frac{\mathrm{k}_{4}^{\prime \prime}}{\mathrm{k}_{1}} \\
\times 10^{-4}\end{array}$ & $\begin{array}{c}\text { In1t18] } \\
{[\mathrm{TSH}] \circ} \\
\mathrm{M} / 1\end{array}$ & $\begin{array}{c}\epsilon \times \text { Slope } \\
\times[\mathrm{TSH}]\end{array}$ \\
24 & 486 & 92.3 & 1.85 & 0.01095 & 1.01 \\
25 & 1750 & 333 & 1.85 & 0.00436 & 1.45 \\
\hline
\end{tabular}


FIGURES 25, 26

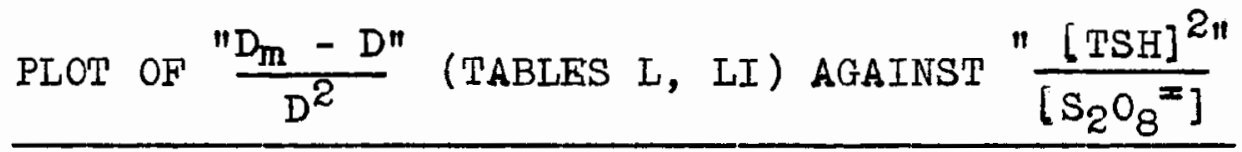

Conc. $\mathrm{H}_{2} \mathrm{SO}_{4} \quad 0.15 \mathrm{M} / \mathrm{I}$

$D_{m}=0.190$

Figure 25

Initial Cone. TSH $0.01095 \mathrm{M} / \mathrm{I}$

- Exp. 99 Initial Conc. $\mathrm{S}_{2} \mathrm{O}_{8} 0.00200 \mathrm{M} / 1$

口" " " " $1000.00400 \mathrm{M} / 1$

- "101 " $" 0.00600 \mathrm{~m} / \mathrm{I}$

$\Delta \quad " 202 "$ " $\quad$ " $0.00800 \mathrm{M} / 1$

\section{Figure 26}

Initial Conc. TSH $0.00436 \mathrm{M} / \mathrm{I}$

- Exp. 103 Initial Conc. $\mathrm{S}_{2} \mathrm{O}_{8}=0.00200 \mathrm{M} / \mathrm{l}$

口" " 204 " $0.00400 \mathrm{M} / \mathrm{I}$

$\Delta " 105 \quad " \quad " \quad 0.00800 \mathrm{M} / \mathrm{I}$ 

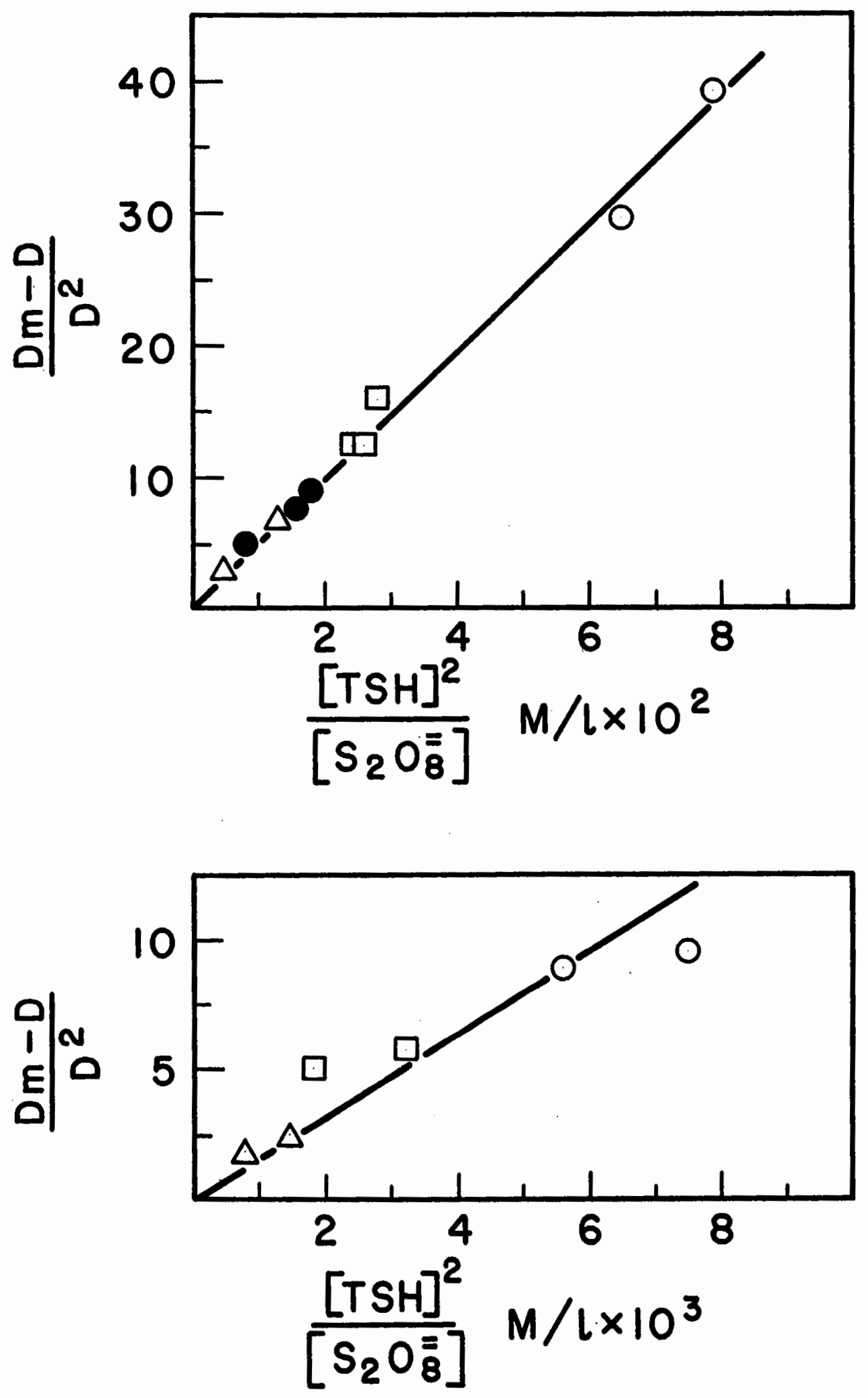
FIGURE 27

PLOT OF " $\frac{D_{m}-D^{\prime}}{D^{2}}$ (TABLE LII) AGAINST $\frac{\text { [TSH] }]^{2 "}}{\left[\mathrm{~S}_{2} \mathrm{O}_{8}=\right]}$

Conc. $\mathrm{H}_{2} \mathrm{SO}_{4} \quad 0.15 \mathrm{M} / \mathrm{I}$

$D_{m}=0.190$

Init1al Conc. $\mathrm{S}_{2} \mathrm{O}_{8}=0.00400 \mathrm{M} / 1$

- Exp. 106 Inftial Conc. TSH $0.00218 \mathrm{M} / \mathrm{I}$

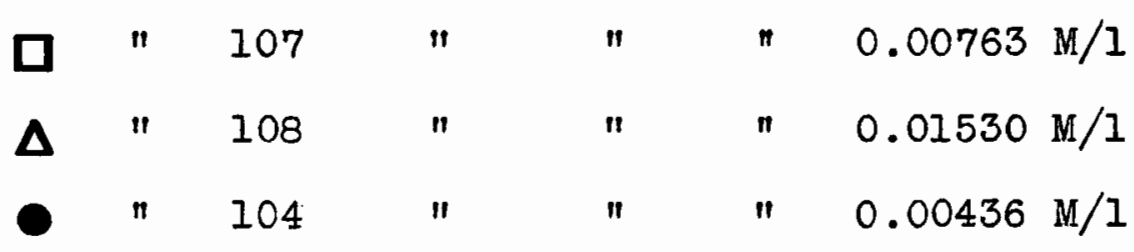




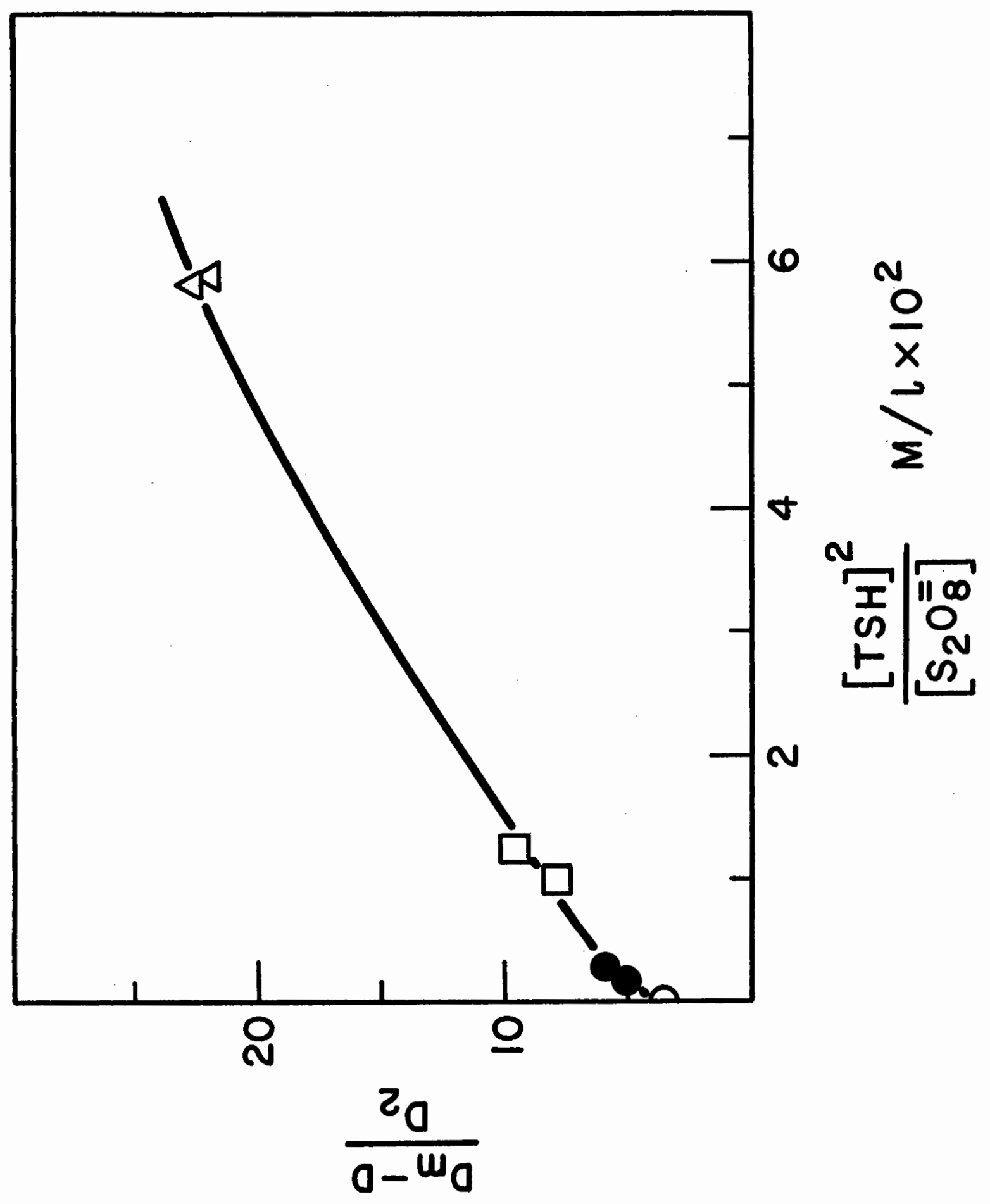


the reduction of the mercaptan according to the above series of reactions.

Hence, the rate of disappearance of ferric ion in the presence of persulphate is given by

$-\frac{d[\text { ferric }]}{d t}=k_{4}^{\prime \prime \prime}[\text { ferric }]^{2}[\mathrm{TSH}]^{2}+\frac{\mathrm{K}}{[\mathrm{Fe}]^{\mathrm{x}}[\mathrm{TSH}]_{0}}\left[\right.$ ferric $^{2}[\mathrm{TSH}]^{2}$

and since for these experiments $k_{4}^{\prime \prime} \ll \frac{K}{[\mathrm{Fe}]^{\mathrm{x}}[\mathrm{TSH}]_{0}}$

(Table LIV) this becomes

$-\frac{d[\text { ferric }]}{d t} \cong \frac{K}{[\mathrm{Fe}]^{\mathrm{X}}[\mathrm{TSH}]_{0}}[\text { ferric }]^{2}[\mathrm{TSH}]^{2}$.

Consequently under these conditions

$$
\frac{D_{m}-D}{D^{2}} \cong \frac{K}{\epsilon \mathrm{k}_{1}[\mathrm{Fe}]^{\mathrm{X}}[\mathrm{TSH}]_{0}} \cdot \frac{[\mathrm{TSH}]^{2}}{\left[\mathrm{~S}_{2} \mathrm{O}_{8}=\right]} \text {. }
$$

At very low conversions when $[\mathrm{TSH}]_{0}=[\mathrm{TSH}]$ this equation becomes,

$$
\frac{D_{m}-D}{D^{2}} \cong \frac{K}{\epsilon k_{1}\left[\mathrm{Fe}^{\mathrm{x}}\left[\mathrm{S}_{2} \mathrm{O}_{8}\right]\right.}
$$

When this equation was plotted for a series of reactions (Figure 28) a straight line was obtained, the slope of which ylelded a value of $K(K=\epsilon x$ slope $=9500)$ in good agreement with values of $K$ determined from the results in Figures 24 and 25. The values of the ordinate, $\frac{D_{m}-D}{D^{2}}$, were determined during the inftial stages of the reaction in order that the 
TABLE LV

VARIATION OF $\frac{D_{m}-D}{D^{2}}$ WITH INITIAL CONCENTRATION

OF FERROUS ION

Conc. Sulphuric Acid $0.15 \mathrm{M} / 1$

Initial Conc. Potassium Persulphate $0.00400 \mathrm{M} / \mathrm{l}$

Initial Conc. Thioglycolic Acid $0.01095 \mathrm{M} / \mathrm{l}$

\begin{tabular}{l|c|c|c|c}
\hline Exp. No. & $\begin{array}{c}\text { Initial } \\
{[\mathrm{Fe}++} \\
\mathrm{M} / 1 \times 10^{++}\end{array}$ & $\begin{array}{c}\text { Optical } \\
\text { Density } \\
\mathrm{D}_{325}\end{array}$ & $\mathrm{D}_{\mathrm{m}}$ & $\frac{\mathrm{D}_{\mathrm{m}}-\mathrm{D}}{\mathrm{D}^{2}}$ \\
\hline 109 & 0.50 & 0.050 & 0.095 & 18.0 \\
100 & 1.00 & 0.090 & 0.190 & 12.4 \\
110 & 1.50 & 0.130 & 0.285 & 9.2 \\
\hline
\end{tabular}




\section{TABLE LVI}

$$
\text { VARIATION OF } \frac{D_{m}-D}{D^{2}} \text { WITH } \frac{[\text { TSH }]}{\left[\mathrm{S}_{2} \mathrm{O}_{8}\right]}{ }^{-} \text {DURING }
$$

THE INIT IAL STAGES OF THE REACTION

Conc. Sulphuric Acid $0.15 \mathrm{M} / \mathrm{I}$

$$
\underline{D_{m}}=0.190
$$

\begin{tabular}{c|c|c|c|c}
\hline Exp. No. & $\frac{D_{m}-D}{D^{2}}$ & $\begin{array}{c}{[\mathrm{TSH}]} \\
\mathrm{M} / 1 \times 10^{3}\end{array}$ & $\begin{array}{c}{\left[\mathrm{S}_{2} \mathrm{O}_{8}=\right]} \\
\mathrm{M} / 1 \times 10^{3}\end{array}$ & $\left.\frac{[\mathrm{TSH}]}{\left[\mathrm{S}_{2} \mathrm{O}_{8}=\right.}\right]$ \\
\hline 99 & 29.6 & 9.90 & 1.50 & 6.38 \\
100 & 15.5 & 9.90 & 3.50 & 2.83 \\
101 & 9.0 & 9.90 & 5.50 & 1.80 \\
102 & 7.1 & 9.90 & 7.50 & 1.32 \\
103 & 9.6 & 3.36 & 1.50 & 2.24 \\
104 & 5.85 & 3.36 & 3.50 & 0.96 \\
105 & 2.38 & 3.36 & 7.50 & 0.45 \\
106 & 3.45 & 1.18 & 3.50 & 0.34 \\
107 & 7.73 & 6.63 & 3.50 & 1.60 \\
108 & 22.8 & 14.30 & 3.50 & 4.08 \\
& & & & \\
\hline
\end{tabular}


- 156 -

FIGURE 28

PLOT OF " $\frac{D_{m}-D^{\prime}}{D^{2}}$ (TABLE LV) AGAINST " $\frac{[T S H]}{\left[\mathrm{S}_{2} \mathrm{O}_{8}=\right]}$

Conc. $\mathrm{H}_{2} \mathrm{SO}_{4} \quad 0.15 \mathrm{M} / \mathrm{I}$

$\mathrm{D}_{\mathrm{m}}=0.190$ 


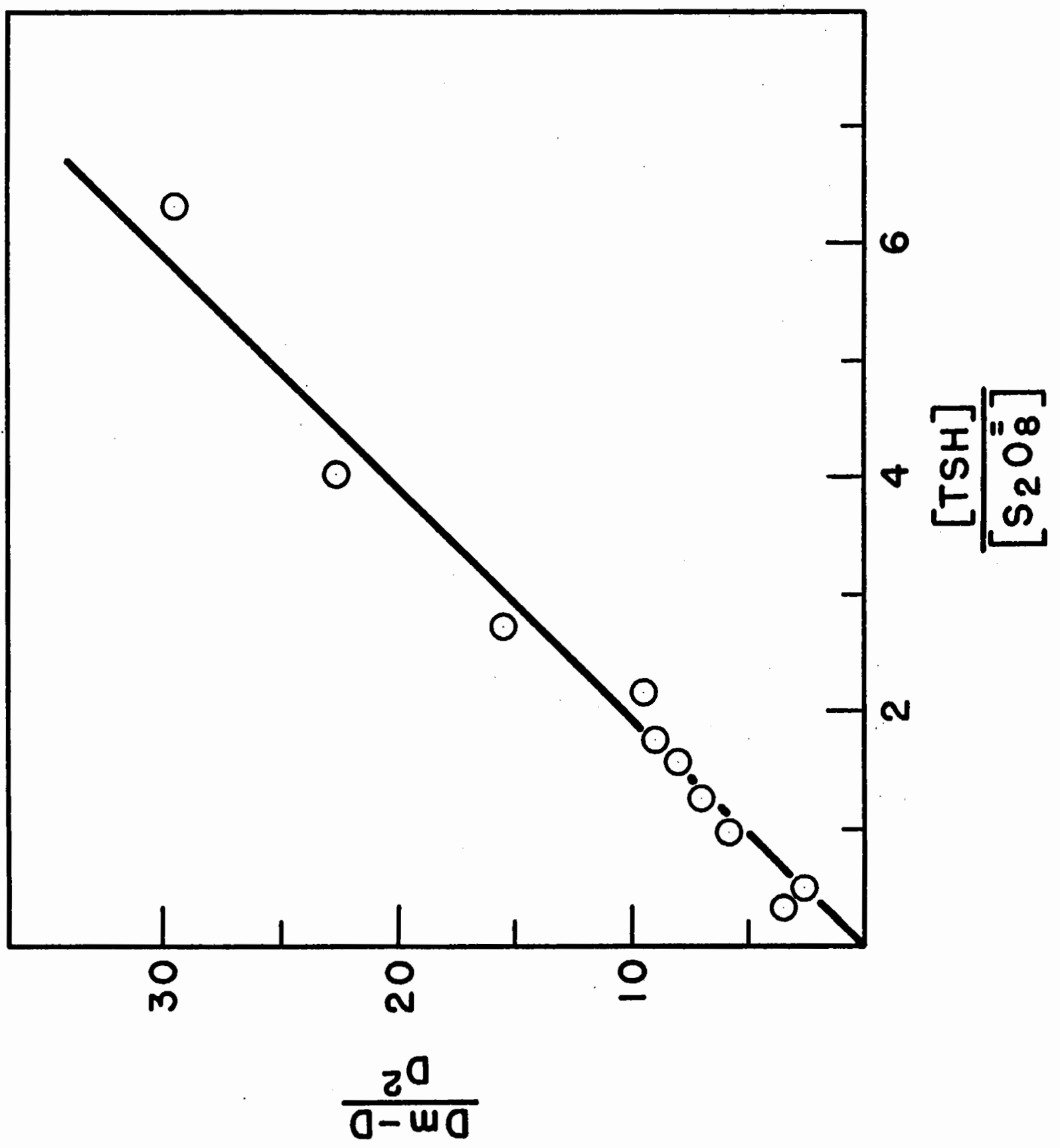


above approximation would be valid. Owing to difficulties in extrapolation, values of $D$ were not determined at zero time.

It can be seen from inspection of equation (ix) that by increasing the concentration of iron in the reaction mixture, the relative importance of the second term on the right to that of the first term would be diminished. Hence, it is not surprising that, when the concentration of iron was greater than $5 \times 10^{-3} \mathrm{M}$, the blue complex was observed when persulphate was added to mixtures of mercaptan and ferrous ion.

No attempt has been made up to this point to postulate by what means persulphate was able to accelerate so markedly the reaction of ferric ion with thioglycolic acid. In the rate expression for this reaction there was no term involving persulphate concentration, which suggests that persulphate was not directly concerned in the reaction. This supports an earlier conclusion that persulphate reacted only with ferrous ion, and that this reaction was not influenced in any way by thioglycolic acid. Hence, it would seem that some species derived from the persulphate - ferrous ion reaction, e.8. the sulphate ion radical or the thigl radical, was responsible for this acceleration, perhaps by reacting rapidly with a ferric ion - thioglycolic acid complex.

Further evidence for such a radical reaction rather than direct attack of persulphate on the complex was afforded by the observation that, when the iron in the reaction mixtures was inftially in the ferric state, the reaction was preceded by an induction period. In these experiments it was also 
observed that until the steady state was reached, the rate of disappearance of ferric ion was not influenced by persulphate. This may be accounted for by postulating the occurrence of the following reactions,

$$
\begin{aligned}
& \mathrm{Fe}_{2}(\mathrm{OH})_{2}(\mathrm{TS})_{2} \stackrel{(\mathrm{slow})}{\longrightarrow} 2 \mathrm{Fe}^{++}+2 \mathrm{H}_{2} \mathrm{O}+\mathrm{TSST} \\
& \mathrm{S}_{2} \mathrm{O}_{8}=+\mathrm{Fe}^{++} \stackrel{\text { (fast) }}{\rightarrow} \mathrm{Fe}^{+++}+\mathrm{SO}_{4}^{\dot{-}}+\mathrm{SO}_{4}= \\
& \text { (very fast) } \mathrm{Fe}^{++}+\text {TSST } \\
& \mathrm{X}+\mathrm{Fe}(\text { III) TSH-complex } \stackrel{\rightarrow}{\text { (very fast) }}
\end{aligned}
$$

where $X$ represents a radical derived from the persulphate ferrous ion reaction, e.g. the sulphate ion or the thiyl radical. Consequently, during the early stages of the reaction before the ferric ion had reached a stationary concentration, the rate of disappearance of ferric ion would not be influenced by the presence of persulphate as was observed provided the extent of reaction (14) was negligible. On the other hand if reaction (14) was not negligible during this early period, the rate of disappearance of ferric ion would have been less in the presence of persulphate than in 1ts absence. This in turn suggests that when ferrous and ferric ions had reached a steady state, some of the $X$ radicals did not react with the iron - mercaptan complexes, for otherwise the stationary concentration of ferric ion relative to that of ferrous ion would have been negligible. 
then quite evident that they particlpated in the following reactions.

$$
\begin{aligned}
\mathrm{SO}_{4} \dot{-}+\mathrm{Fe}^{++} & \rightarrow \mathrm{SO}_{4}=+\mathrm{Fe}^{+++} \\
\mathrm{SO}_{4} \dot{-}+\mathrm{TSH} & \rightarrow \mathrm{TS} \cdot+\mathrm{HSO}_{4}^{-} \\
\mathrm{SO}_{4} \dot{-}+\mathrm{Fe}(\mathrm{III}) \mathrm{TSH}-\mathrm{complex} & \rightarrow \mathrm{Fe}^{++}+\mathrm{TSST}^{+}+\mathrm{HSO}_{4}^{-}
\end{aligned}
$$

Increasing the concentrations of ferrous ion and thioglycolic acid would tend to eliminate the reaction of sulphate ion radicals with the complex, and hence decrease the relative importance of this reaction, provided the concentration of the complex was proportional to less than the first power of the mercaptan concentration. Because of the high degree of dissociation of these complexes, it must be postulated that $k_{15} \gg k_{2}$ and $k_{15} \gg k_{3}$. This seems improbable since both steps (2) and (3) are very fast.

It is also conceivable that thiyl radicals may react with a complex to give the observed results and the following two reactions might compete.

$$
\begin{aligned}
\mathrm{TS} \cdot+\mathrm{Fe}(\text { III }) \mathrm{TSH}-\mathrm{complex} & \rightarrow \mathrm{Fe}^{++}+\mathrm{TSST}+\mathrm{H}^{+} \\
2 \mathrm{TS} \cdot & \rightarrow \mathrm{TSST}
\end{aligned}
$$

A similar mechanism was postulated by Lamfrom and Nielsen (105) to account for their measurements of the rate of oxygen uptake by mixtures of ferric ion and thioglycolic acid in weakly acidic solution $(\mathrm{pH}=4.6-6.0)$. If this type of reaction occurred, it is difficult to understand why the rate of reaction of ferric ion with mercaptan in the presence of persulphate was inversely proportional to the inftial mercaptan concentration. However, assuming sulphate ion radicals to 
react with both ferrous ion and thioglycolic acid, an increase In concentration of thioglycolic acid would increase the stationary concentration of thiyl radicals. This in turn would bring about an increase in the relative amounts of disulphide produced by steps (12) and (16). But the rate of step (16) is more dependent than the rate of step (12) upon the thiyl radical concentration, and if the concentration of the complex changed less rapidly than the thiyl radical concentration with thioglycolic acid concentration, the relative importance of the fast reaction (step (16)) would decrease with Increase initial thioglycolic acid concentration as observed experimentally.

It seems that, regardless of whether the sulphate ion radical or the thiyl radical reacted with the complex, the influence of the total iron and initial thioglycolic acid concentrations on the rate of this fast reaction was brought about by competition between ferrous ion and mercaptan for sulphate ion radicals.

With the existing information it is extremely difficult to determine either the structure of the complex which entered into this rapid reaction, or the nature of the radical, whether sulphate ion or thiyl, which reacted with the complex. Since sulphate ion radicals may react with both ferrous ion and thioglycolic acid, the situation is even more complex, especially since the relative rates of these two reactions are unkmown. 
In spite of these questions which for the present must remain unanswered, the general nature of the catalyst cycle appears to be straightforward, namely that ferrous ion was oxidized by persulphate to ferric ion and the resulting ferric was reduced by the thioglycolic acid back to ferrous. It is very probable that other cations present in the reaction mixtures as impurities were also capable of catalyzing the reaction, but this matter was not investigated since sufficient iron was present to make these reactions negligible.

At the outset of this study, it was intended to determine whether thioglycolic acid exerted any influence upon the rate of decomposition of persulphate in aqueous solution. It is conceivable that if, in the absence of cationic impurities, the mercaptan neither reacted directly with persulphate nor Influenced its rate of homolytic dissociation, it would react with the sulphate ion radicals, resulting from this dissociation, to produce disulphide. Although this thesis sheds no light upon these questions, it does demonstrate under what conditions experiments would have to be made in order that the required information could be obtained.

The concentrations of those metallic ions in the reaction mixtures, which were capable of catalyzing the reaction, would have to be sufficiently low that the rate of the catalyzed reaction would be negligible relative to the rate of the thermal decomposition of persulphate in aqueous solution. To fulfill this condition, the concentration of iron in reaction 
mixtures at $25^{\circ} \mathrm{C}$ would have to be less than $10^{-11}$ moles/liter (10). It is apparent that following an extensive purification it would be very difficult to devise a means of determining whether catalysis was eliminated in a given series of experiments. It must be emphasized that reproducible results would not serve as a criterion that the effect of catalysis had been eliminated. 
SUMMARY AND CONTRIBUTIONS TO KNOWLEDGE

1. Volumetric methods were developed for following the reaction between potassium persulphate and thioglycolic acid by measuring the rates of disappearance of persulphate and thioglycolic acid and the rate of appearance of hydrogen ion. The reaction is best described by the following stoichiometric equation:

$$
\mathrm{S}_{2} \mathrm{O}_{8}=+\mathrm{TSH} \rightarrow \mathrm{TSST}+2 \mathrm{HSO}_{4}^{-}
$$

2. The reaction between potassium persulphate and thioglycolic acid was catalyzed markedly by soluble salts of iron. However, in the absence of added iron reproducible measurements of the reaction rate could not be made, and for this reason the iron catalyzed reaction was investigated.

3. A spectrophotometric method was developed which, in addition to following the progress of the iron catalyzed reaction between potassium persulphate and thioglycolic acid, measured the stationary concentration of ferric ion in the reaction mixture as a function of time. This method was employed only for experiments which were made in $0.15 \mathrm{M}$ sulphuric acid.

4. A spectrophotometric method was developed for following the reaction between ferrous ion and persulphate ion by measuring the rate of appearance of ferric ion. Both a spectrophotometric and a colourimetric method were 
developed for following the reaction between ferric ion and thioglycolic acid by measuring the rate of disappearance of ferric ion.

5. In solutions of sulphuric acid the reaction between ferrous ion and persulphate ion displayed second order kinetics in agreement with earlier investigations, but values of the second order rate constant, $k_{1}$, were approximately one half those determined by Williams et al $(32,33)$.

6 . In acid solution $(\mathrm{pH}<2)$ the reaction between ferric ion and thioglycolic acid was found to have the following characteristics:

(a) The reaction rate was second order in both the ferric ion concentration and in thioglycolic acid concentration.

(b) The reaction rate was inversely proportional to the hydrogen ion concentration raised to a power of 3.7 .

(c) The reaction was markedly Inhibited by sulphate ion.

(d) Upon inftial mixing of ferric ion with thioglycolic acid a blue complex was formed which disappeared rapidly.

7. The following mechanism for the reaction between ferric ion and thioglycolic acid was postulated to explain the experimental observations:

(a) Iron - mercaptan complexes in dynamic equilibrium with ferric ion and thioglycolic acld are formed.

(b) The rate controlling step for the reaction between ferric ion and thioglycolic acid is the first order decomposition of a complex containing either two free 
ferric ions and two doubly charged negative ions of thioglycolic acid or two ferric hydroxyl ions $\left(\mathrm{FeOH}^{++}\right.$) and two singly charged negative ions of thioglycolic acid.

(c) Sulphate Ions retarded the reaction by forming complexes with ferric ions which do not react with thioglycolic acid at an appreciable rate.

8. At a pH of approximately 2 the iron catalyzed reaction between potassium persulphate and thioglycolic acld was found to have the following characteristics:

(a) The reaction rate was directly proportional to the concentrations of persulphate ion and added iron but independent of the concentration of thioglycolic acid.

(b) Division of the first order rate constant for persulphate disappearance by the concentration of added iron yielded a second order rate constant, $k_{1}$, which was independent of the concentration of iron.

(c) The calculated second order rate constant, $k_{1}$, was equal to the rate constant for the reaction between ferrous ion and persulphate ion and varied with ionic strength in the same manner as did the rate constant for the ferrous ion - persulphate reaction.

9. In $0.15 \mathrm{M}$ sulphuric acid the iron catalyzed reaction between potassium persulphate and thioglycolic acid was found to have the following characteristics: (a) The reaction was 0.80 order in persulphate 
concentration and 0.10 order in thioglycolic acid concentration.

(b) The stationary state concentration of ferric ion increased with increased initial persulphate concentration and decreased with increased initial thioglycolic acid concentration.

(c) Values of the second order rate constant, $k_{1}$, calculated from the rate of disappearance of persulphate ion and the concentrations of persulphate and ferrous ions at a given instant of time, were approximately equal to the second order rate constant for the persulphate ferrous ion reaction in $0.15 \mathrm{M}$ sulphuric acid.

(d) The reduction of ferric ion by thioglycolic acid occurred much more rapidly in the presence of potassium persulphate than in its absence.

(e) When the added iron was initially in the ferric state, the reaction of potassium persulphate with thioglycolic acid was preceded by an induction period. However, following this induction period the reaction rate achieved the same value as when the added iron was initially in the ferrous state. Furthermore, the stationary state concentration of ferric ion was independent of whether the added iron was initially in the ferrous or ferric state.

(f) When the added iron was initially in the ferric state, the rate of disappearance of ferric ion, during the 
induction period before its concentration had reached a stationary state value, was not influenced by the presence of potassium persulphate.

(g) Solutions of potassium persulphate, thioglycolic acid, dithiodiglycolic acid and ferric ion in $0.15 \mathrm{M}$ sulphuric acid and various mixtures of these components in $0.15 \mathrm{M}$ sulphuric acid were examined spectrophotometrically in the wavelength range from 400 to $210 \mathrm{~m} \mu$. Evidence that measurable concentrations of complexes between these substances existed was not obtained.

10. The following mechanism for the iron catalyzed reaction of potassium persulphate with thioglycolic was postulated to explain the experimental observations:

(a) The persulphate ion oxidizes ferrous ion to produce ferric ion and a sulphate ion radical. Direct reaction between persulphate ion and thioglycolic acid in the presence of added iron is negligible.

(b) Sulphate ion radicals react with both ferrous ion and thioglycolic acid to produce ferric ion and thiyl radicals respectively.

(c) The catalytic cycle is completed by the reduction of ferric ion by thioglycolic to yield ferrous ion and dithiodiglycolic acid.

(d) Dithiodiglycolic acid is also produced by the recombination of thiyl radicals. 
(e) The relatively rapid reduction of ferric ion by thioglycolic, which occurred in the presence of potassium persulphate, is due to the reaction of either a sulphate ion radical or a thiyl radical with a ferric ion - thioglycolic acid complex. 


\section{BIBLIOGRAPHY}

1. R.G.R. Bacon, Trans. Far. Soc., 42 , 140 (1946).

2. L.B. Morgan, ibid., $\underline{42}, 169$ (1946).

3. R.G.R. Bacon, Quart. Revs., 9, 287 (1955).

4. R.I. Eagar and C.A. Winkler, Can. J. Research, 26B, $527(1948)$.

5. D.M. Yost and H. Russel, Jr., "Systematic Inorganic Chemistry", Prentice-Hall, New York (1944), p. 374.

6. A.V. Tobolsky and R.B. Mesrobian, "Organic Peroxides", Interscience Publishers, New York, 1954, p. 130.

7. M.G. Evans and J.H. Baxendale, Trans. Far. Soc., 42 , 195 (1946).

8. L. Green and 0. Masson, J. Chem. Soc., 97, 2083 (1910).

9. P.D. Bartlett and J.D. Cotman, J. Am. Chem. Soc. 7I, 1419 (1949).

10. I.M. Kolthoff and I.K. Miller, ibid., 73, 3055 (1951).

1I. P.D. Bartlett and K. Nozaki, J. Pol. Sci., 3, 46 (1948).

12. B.J.P. Whalley, H.G.V. Bvans and C.A. Winkler, Can. J. Chem., 34, 1154 (1956).

13. I.M. Kolthoff, E.J. Meehan and E.M. Carr, J.Am. Chem. Soc., 75, 1439 (1953).

14. E. Collis on and A.J. Swallow, Quart. Revs. 9, 311 (1955).

15. W.J. Skraba, J.C. Burr, Jr., and D.N. Hess, J. Chem. Phys., 21, 1296 (1953).

16. L.S. Levitt and E.R. Malinowski, J.Am. Chem. Soc. 77, $4519(1955)$.

17. L.S. Levitt and E.R. Malinowski, ibid., 78, 2018 (1956).

18. E.R. Malinowski and L.S. Levitt, Abstracts of Papers, 132nd Meeting, American Chemical Society, New York, 1957, p. 77P.

19. D.L. Ball, Dissert. Abs., 16, 2300 (1956). 
20. I.M. Kolthoff and E.J. Meehan, CR-1092 (1946).

21. I.M. Kolthoff and R.J. Stenberg, CR-643 (1945).

22. F.A. Bovey, I.M. Kolthoff, A.I. Medalla and E.J. Meehan, "High Polymers", Interscience Publishers, Inc., New York, 1955, Vol. IX, p. 21.

23. L.S. Levitt, Can. J. Chem., 31, 915 (1953).

24. R.L. Eager and K.J. McCallum, Can. J. Chem., 32, 692 (1954).

25. H. Elkeles and C. Brosset, Chem. Abs., 47, 6298d (1953).

26. P.C. Riesbos and A.H.W. Aten, J. Am. Chem. Soc., 74, 2440 (1952).

27. I.M. Kolthoff and I.K. Miller, ibid., 73, 5118 (1951).

28. " ", ibid., 74, 4419 (1952).

29. E. Howard, Jr., and L.S. Levitt, ibid., 75, 6170 (1953).

30. C.F.H. Bawn and D. Margerison, Trans. Far. Soc., 5l, 925 (1955).

31. A.V. Tobolsky and R.B. Mesrobian, "Organic Peroxides", Interscience Publishers, New York, 1954, p. 76.

32. J.W.L. Fordham and H.L. Williams, J. Am. Chem. Soc., 73, 4855 (1951).

33. R.J. Orr and H.L. Williams, ibld., 77, 3715 (1955).

34. " " , J. Phys. Chem., 57, 925 (1953).

35. J.H. Baxendale, "Advances in Catalysis", Academic Press, New York, 1954, Vol. IV, p. 46.

36. T.H. Hardwick, Can. J. Chem., 35, 428 (1957).

37. R.J. Orr and H.L. Williams, Can. J. Chem. 30, 985 (1952).

38. J.W.I. Fordham and H.L. Williams, J. Am. Chem. Soc., $\underline{73}, 1634$ (1951).

39. I.M. Kolthoff and W.I. Reynolds, Disc. Far. Soc., I7, 167 (1954).

40. A.E. Cahill and H. Taube, J. Am. Chem. Soc., 74, 2312 (1952). 
41. F. Haber and J. Weiss, Proc. Roy. Soc., Al47, 332 (1934). 42. I.M. Kolthoff, A.I. Medalia, H.P. Raaen, J. Am. Chem. Soc., 73, 1733 (1951).

43. J.H. Merz and W.A. Waters, J. Chem. Soc., SI5 (1949).

44. N. Ur1, Chem. Rev., 트, 375 (1952).

45. I.M. Kolthoff and A.I. Medalia, J. Am. Chem. Soc., 7I, 3777 (1949).

46. I.M. Kolthoff and A.I. MedaIia, ibid., Iㅡ, 3784 (1949).

47. " " $"$, ibid., 71, 3789 (1949).

48. D.M. Yost, ibid., 48, 152 (1926).

49. D.M. Yost and W.H. Claussen, ibid., 53, 3349 (1931).

50. A. Dekker, H.A. Levy and D.M. Yost, ibid., 59, 2129 (1937).

51. W.H. Cone, ibid., 67, 78 (1945).

52. D.M. Yost, ibid., 48, 375 (1926).

53. C.V. King, ibid., $\underline{49}, 2689$ (1927).

54. C.V. King and F.L. Grisswold, 1bid., 52, 1493 (1930).

55. K.W. Sykes, "The Kinetics and Mechanism of Inorganic Reactions in Solution", Spec. Publ. No. 1, The Chemical Society, London, 1954, p. 64.

56. K.W. Sykes, J. Chem. Soc., 1952, 124 .

57. J. Hudis and A.C. Wahl, J. Am. Chem. Soc., 75, 4153 (1953).

58. L.E. Orgel, Quart. Rev., 8, 422 (1954).

59. C.V. King, J. Am. Chem. Soc., 50, 2089 (1928).

60. T.L. Allen, ibid., 73, 3589 (1951).

61. C.V. King and 0. Steinbeck, ibid., 52, 4779 (1930).

62. C.H. Sorum and J.0. Edward, ib1d., 74, 1204 (1952).

63. A. Kiss and L. Zambory, Rec. trav. chim., 46, 225 (1927).

64. A. Kiss and I. Bossany1, ibid., 47 , 618 (1928). 
65. E. Jette and C.V. King, J. Am. Chem. Soc., 51, 1034 (1929).

66. F.A. Moelwyn-Hughes, "The Kinetics of Reactions in Solution", 2nd Ed., Oxford, 1947, p. 99.

67. J.H. Baxendale, "Advances in Catalysis", Academic Press, New York, 1954, Vol. IV, p. 36.

68. J.H. Baxendale, "The Kinetics and Mechanism of Inorganic Reactions in Solution", Spec. Publ. No. 1, The Chemical Society, London, 1954, p. 40.

69. M. Calvin, Chem. Abs., 48, 8628i (1954).

70. D.L. Leussing and I.M. Kolthoff, J. Electrochem. Soc., 100,334 (1953).

71. N.C. Li and R.A. Manning, J. Am. Chem. Soc., 77, 5225 (1955).

72. E. Larsson, Z. anorg. u. allgem. Chem., 172, 375 (1928).

73. H. Gilman, "Organic Chemistry", 2nd Ed., John Wiley and Sons, New York, 1943, Vol. I, p. 851, 861.

74. A. Schoberl and A. Wagner, Methoden der Organischen Chemie", (Houben-Weyl), Georg Thieme Verlag, Stuttgart, 1955, Vol. IX, p. 45.

75. I.M. Kolthoff and W. Stricks, J. Am. Chem. Soc., 73, 1728 (1951).

76. B.C.R. Sarkar and R. Sivaraman, The Analyst, 81, 668 (1956).

77. I.M. Kolthoff and W.E. Harris, Anal. Chem. 21, 963 (1949).

78. H. Gilman, "Organic Chemistry", 2nd Ed., John Wiley and Sons, New York, 1943, Vol. I, p. 888, 907.

79. A. Schoberl, Z. Physiol. Chem., 209, 231 (1932).

80. G.C. Stoner and G. Dougherty, J. Am. Chem. Soc., 63, 1291 (1941).

81. J.C. Ghosh and B.C. Kar, J. Ind. Chem. Soc., 11, 485 (1934).

82. J.C. Ghosh and B.C. Kar, ibid., 14, 249 (1937).

83. H. Gilman, "Organic Chemistry", 2nd Ed., John Wiley and Sons, New York, 1943, Vol. I, p. 889. 
84. A. Schoberl and A. Wagner, Methoden der Organischen Chemie", (Houben-Weyl), Georg Thieme Verlag, Stuttgart, 1955, Vol. IX, p. 81 .

85. S.W. Lee and G. Dougherty, J. Org. Chem., 5, 82 (1940). 86. S. Siggia and R.L. Fdsberg, Anal. Chem., 20, 938 (1948). 87. M. Onyszchuk and C. Sivertz, Can. J. Chem., 33, 1034 (1955).

88. V.A. Dinsburg and A.A. Vansheidt, J.Gen. Chem., U.S.S.R., 24, 839 (1954).

89. R.M. Pierson, A.J. Costanza and A.H. Welnstein, J. Pol. Sci., I7, 221 (1955).

90. I.M. Kolthoff, W. Stricks and R.C. Kapoor, J. Am. Chem. Soc., 77, 4733 (1955).

91. J.C. Ghosh and S.C. Ganguli, Biochem. J., 279, 296 (1935).

92. A. Fava, A. Iliceto and E. Camera, J. Am. Chem. Soc., $\underline{79}, 833(1957)$.

93. A. Schoberl and A. Wagner, "Methoden der Organishen Chemie", (Houben-Weyl), Georg Thieme Verlag, Stuttgart, 1955, Vol. IX, p. 75.

94. S. Tarbell and D.P. Harnish, Chem. Rev. 49, I (1951).

95. J.M. Swan, Nature, I79, 965 (1957).

96. W. Stricks and I.M. Kolthoff, J. Am. Chem. Soc., 73, 4569 (195I).

97. I.M. Kolthoff and W.E. Harris, Ind. Eng. Chem., AnaI. Ed., 18, 161 (1946).

98. W. Stricks, I.M. Kolthoff and A. Hyndrickx, J. Am. Chem. Soc., 76, 1515 (1954).

99. W. Stricks and I.M. Kolthoff, ib1d., 75, 5673 (1953).

100. W. Stricks and I.M. Kolthoff, ibid., 73, 1723 (1951).

101. D.L. Leussing and I.M. Kolthoff, ibid., 75, 3904 (1953).

102. N. Tanaka, I.M. Kolthoff and W. Stricks, ibid., 77, 1996 $(1955)$. 
103. B.K. Cannon and G.W. Richardson, Biochem. J., 23, $1242(1929)$.

104. F.M. Page, Trans. Far. Soc., 51, 919 (1955).

105. H. Lamfrom and S.O. Nielsen, J. Am. Chem. Soc., 79, 1966 (1957).

106. R.G. Neville, ibid., 79, 2456 (1957).

107. D.L. Leussing and L. Newman, ibid., 78, 552 (1956).

108. N. Tanaka, W. Stricks and I.M. Kolthoff, ibid., 77 , 2004 (1955).

109. I.M. Kolthoff and C. Barnum, ibid., 62, 3061 (1940).

110. " ", ibid., 63, 520 (1941).

1II. I.M. Kolthoff, W. Stricks and N. Tanaka, ibid., 77, 4739 (1955).

112. I.M. Kolthoff, W, Stricks and N. Tanaka, ibid., 77, 5215 (1955).

113. I.M. Kolthoff and E.M. Carr, Anal. Chem., 25, 298 (1953).

114. D.M. Yost and H. Russel, Jr., "Systematic Inorganic Chemistryn, Prentice-Hall, New York (1944), p. 378.

115. 0. Behagel and M. Roliman, Ber. 62, 2696 (1929).

116. I.M. Kolthoff, L.S. Guss, D.R. May and A.I. Medalia, J. Pol. Sci., I, 340 (1946).

117. M. Kerker, J. Am. Chem. Soc., 79, 3664 (1957).

118. I.L. Jenkins and C.B. Monk, ibid., 72, 2695 (1950).

119. R.A. Whiteker and N. Davidson, ibid., 75, 3081 (1953).

120. International Critical Tables, 3 , 80 (1929).

121. R.C. Turner and K.E. Miles, Can. J. Chem., 35, 1002 (1957). 